UNIVERSIDADE DE SÃO PAULO

INSTITUTO DE PSICOLOGIA

$$
\text { ÉRICA SILVA NAKAI }
$$

Fissão-fusão em Cebus nigritus:

flexibilidade social como estratégia de ocupação de

\author{
ambientes limitantes
}

São Paulo

2007 


\section{Fissão-fusão em Cebus nigritus:}

\section{flexibilidade social como estratégia de ocupação de}

\section{ambientes limitantes}

Dissertação apresentada ao Instituto de Psicologia

da Universidade de São Paulo, como parte dos requisitos pra obtenção do grau de Mestre em Psicologia.

Área de concentração: Psicologia Experimental Orientadora: Profa. Dra. Patrícia Izar

São Paulo 
Nakai, Érica Silva.

Fissão-fusão em Cebus nigritus: flexibilidade social como estratégia de ocupação de ambientes limitantes / Érica Silva Nakai; orientadora Patrícia Izar. -- São Paulo, 2007.

$97 \mathrm{p}$.

Dissertação (Mestrado - Programa de Pós-Graduação em Psicologia. Área de Concentração: Psicologia Experimental) Instituto de Psicologia da Universidade de São Paulo.

1. Macacos-prego 2. Etologia animal 3. Gregariedade (animal) 4. Ecologia 5. Tamanho do grupo 6. Primatas (não humanos) I. Título. 


\title{
FISSÃO-FUSÃO EM CEBUS NIGRITUS: FLEXIBILIDADE SOCIAL COMO ESTRATÉGIA DE OCUPAÇÃO EM AMBIENTES LIMITANTES
}

\author{
Érica Silva Nakai
}

Dissertação apresentada ao Instituto de Psicologia da Universidade de São Paulo, como parte dos requisitos pra obtenção do grau de Mestre em Psicologia

Área de concentração: Psicologia Experimental

Aprovado em:

Banca Examinadora

Prof. Dr.

Instituição:

Assinatura:

Prof. Dr.

Instituição:

Assinatura:

Prof. Dr.

Instituição:

Assinatura: 
Dedico esta dissertação à memória do meu avô Abel Teófilo da Silva, que sempre apoiou a realização dos meus sonhos e deixou saudades no coração de todos que o conheciam. 


\section{Agradecimentos}

A Deus, por permitir desenvolver meu trabalho e a realização de um sonho.

Aos meus pais por todo carinho, apoio, compreensão e respeito na minha pesquisa e sem os quais nunca teria chegado até aqui.

À Prof ${ }^{a} \operatorname{Dr}^{\mathrm{a}}$ Patrícia Izar pela orientação, paciência e ensino sobre pesquisa com primatas.

Ao Prof. Dr. Eduardo B. Ottoni por toda ajuda, apoio e atenção quando necessários, especialmente nas sugestões durante o exame de qualificação.

À $\operatorname{Prof}^{\mathrm{a}} \operatorname{Dr}^{\mathrm{a}}$ Emma Otta pelas críticas e sugestões apresentadas durante o exame de qualificação.

Ao diretor José Luis Camargo Maia do Parque Estadual Carlos Botelho - SP por permitir desenvolver a pesquisa.

Aos funcionários do PECB, principalmente João Maria, Elza, Glacy e Teresinha por toda ajuda, carinho e companhia durante a pesquisa no Parque.

Ao Eraldo Vieira pelo auxílio no campo e ajuda na coleta de dados.

À minha família Aluísio, Roberto, Tércio, Chubaca, Leia e Tobias pela compreensão das neuras e ausências em momentos especiais. 
Aos amigos de laboratório Juliana, Marcos, Olívia, Tiago, Mariana, Lucas, Andrea, Briseida, Michele, Darvin, Camila pelas discussões sobre comportamento animal e por compartilhar experiências.

À Prof ${ }^{\mathrm{a}}$ Dr $^{\mathrm{a}}$ Vera Bussab pelo carinho e incentivo durante o mestrado.

À Sulene B. Rosa Medeiros, vice-diretora da E. E. João Amos Comenius, por entender as faltas durante o emprego como professora na escola.

Aos meus alunos por compreenderem as faltas da professora.

À CAPES pela concessão da bolsa.

Aos secretários do Departamento de Psicologia Experimental - USP pelos auxílios burocráticos.

A todos os amigos pela força e amizade.

Aos macacos-prego pelas aventuras e histórias na mata. 


\section{Resumo}

NAKAI, E. S. Fissão-fusão em Cebus nigritus: flexibilidade social como estratégia de ocupação em ambientes limitantes. 2007. 97p. Dissertação (Mestrado) - Instituto de Psicologia, Universidade de São Paulo, São Paulo.

A ordem primata apresenta uma grande diversidade de modos de organização social, desde espécies consideradas solitárias até aquelas em que os indivíduos de um grupo permanecem o tempo todo juntos. Macacos-prego (Cebus spp.) geralmente vivem em grupos estáveis e coesos, sem a formação de subgrupos. No entanto, sua organização social pode ser mais flexível. Dois estudos anteriores, conduzidos com populações de Cebus nigritus da Mata Atlântica, indicaram a divisão de grupos em subgrupos, mas não concluíram se os processos que foram observados eram de divisão permanente de um grupo grande ou se essas populações assumiam a organização social do tipo de fissão-fusão. O objetivo deste estudo foi investigar se os grupos de macacos-prego do Parque Estadual Carlos Botelho (PECB) caracterizam-se como sociedades do tipo fissão-fusão ou se a formação de subgrupos ocorre apenas como um estágio temporário pré-divisão permanente. No período de Janeiro de 2003 a Março de 2006, foram acompanhados dois grupos sociais, com os indivíduos adultos reconhecidos. Dados de outros grupos foram coletados de forma oportunística. Para verificar se o grupo estava forrageando de forma coesa ou dividido em subgrupos, era feito um censo dos membros do grupo a cada hora e, para o registro da composição dos subgrupos foi contado o número de machos adultos, de fêmeas adultas e de juvenis. Para avaliar a disponibilidade de alimento foram distribuídas 153 armadilhas "pitfall" ao longo da área de uso dos animais. Os dados sobre comportamento (locomoção, descanso, forrageamento e locomoção mais forrageamento) e dieta (frutos, invertebrados e folhas) foram registrados por amostragem de varredura, a cada 5 minutos. Também foram anotados o tempo de depleção das fontes de frutos (FTFS) e o número de indivíduos que se alimentaram juntos na mesma árvore (tamanho da subunidade de alimentação). Todos os grupos de macacos-prego observados no PECB organizaram-se em sociedades de fissão-fusão, dividindo-se constantemente em subgrupos de tamanho e composição variável, com associações preferenciais entre pares de macho e fềmea, composição multi-macho/multi-fêmea e ausência de dominância entre as fêmeas. Todas essas características observadas se assemelham com as características de chimpanzés e de primatas neotropicais que se organizam em fissão-fusão. A principal diferença entre os macacos-prego e essas espécies é a dispersão sexual do grupo natal. Em macacos-prego os machos migram entre grupos, enquanto em sociedades de fissãofusão os machos são filopátricos. Em relação aos dados ecológicos, o FTFS e o tamanho das subunidades de alimentação tiveram valores baixos para todos os grupos de macacos-prego, indicando que as fontes de frutos não sustentam todo o grupo por ter recursos de pobre qualidade. Houve uma relação entre tamanho de subgrupo e padrão da oferta de alimento: quanto maiores e mais uniformemente distribuídas as fontes de frutos no habitat das quais os animais estavam se alimentando, maior o subgrupo. Portanto, os macacos-prego do PECB ajustam o tamanho de grupo para reagir às variações ecológicas, em função de baixa disponibilidade de frutos e assim, essa grande flexibilidade permite que eles se adaptem a novos ambientes e se comportem de modo a aumentar sua aptidão.

Palavras-chave: macacos-prego; etologia animal; gregariedade (animal); ecologia; tamanho do grupo; primatas (não-humanos). 


\begin{abstract}
NAKAI, E. S. Fission-fusion in Cebus nigritus: social flexibility as occupation strategy in limitants environments. 2007. 97p. Master Thesis - Institute of Psychology, University of São Paulo, São Paulo.

The primate order presents a great diversity of social organization, from species considered solitary to those where the individuals of a group remain together all the time. Capuchin monkeys (Cebus spp.) generally live in stable and cohesive groups, without the formation of subgroups. However, their social organization can be more flexible. Two former studies on two populations of Cebus nigritus from the Atlantic Forest suggested the occurrence of subgrouping, but the authors could not conclude whether the observed processes were due to a permanent division of a large group or whether these populations were actually fission-fusion societies. The objective of this study was to investigate whether the capuchin monkey groups of the State Park Carlos Botelho (PECB) can be characterized as a fission-fusion society or subgrouping is a temporary strategy prior to a permanent division of a large group. From January 2003 to March 2006, two social groups were followed, with the adult individuals recognized. Data from other groups were collected in an opportunistic way. To verify whether the group was foraging in a cohesive way or divided in subgroups, a census of the group members was performed at each hour and, and the number of adult males, adult females and juveniles were counted to analyze the composition of the subgroups. In order to evaluate the food availability 153 pitfall traps were distributed along the long home range. Data about behavior (locomotion, rest, foraging and locomotion more foraging) and diet (fruits, invertebrates and leaves) were registered by scan sampling every 5 minutes. The depletion time of fruit sources (FTFS) and the number of individuals that fed together in the same tree (size of feeding subunity) were recorded. All the capuchin monkey groups observed in the PECB were organized as a fission-fusion society, splitting into subgroups of variable size and composition, with preferential associations between pairs of male and female, composition multi-male/multi-female and absence of dominance among females. All these observed characteristics are similar to chimpanzees and neotropical primates which present fissionfusion. The main difference among capuchin monkeys and these species are the sexual dispersion from natal group. In capuchin monkeys the males migrate among groups, while in fission-fusion societies the males are philopatric. In relation to the ecological data, the FTFS and the feeding subunity size had low values for all the capuchin monkey groups, indicating that the fruit sources at PECB are poor quality resources and do not support all group members. There was a relation between subgroup size and pattern of food availability: the largerer and more uniformly distributed the fruit sources the animals were feeding, the larger the subgroup. Therefore, capuchin monkeys at PECB adjust their group size in response to the ecological variations, due to the low fruit availability and thus, this great flexibility allows them to adapt to a new environment and to behave in order to increase their fitness.
\end{abstract}

Key words: capuchin monkeys; animal behavior; gregariousness (animal); ecology; group size; primates (not-humans). 


\section{Lista de Figuras}

Figura 1 - Localização do Parque Estadual "Carlos Botelho" no Estado de São Paulo, detalhando os limites do parque na Serra do Mar - (imagem do site www.iflorestsp.br) p. 14

Figura 2 - Tempo (em horas) de esforço de campo e de observação de Cebus nigritus, de 2003 a 2006, no PECB. OBS = tempo de observação direta dos animais; ESF = esforço amostral

Figura 3 - Posicionamento das armadilhas de frutos (bandeja de alumínio) e de invertebrados (copo de plástico) enterrados no solo do PECB

Figura 4 - Histograma de freqüência de tamanho de subgrupos do grupo Pimenta no PECB, entre Maio de 2003 e Dezembro de 2005

Figura 5 - Tamanho de subgrupos do grupo Pimenta no PECB, com número máximo, médio e mínimo de indivíduos, entre Maio de 2003 e Dezembro de 2005.

Figura 6 - Histograma de freqüência de tamanho de subgrupos do grupo Laranja no PECB, entre Janeiro de 2003 e Julho de 2005.

Figura 7 - Tamanho de subgrupos do grupo Laranja no PECB, com número máximo, médio e mínimo de indivíduos, entre Janeiro de 2003 e Julho de 2005.

Figura 8 - Histograma de freqüência de tamanho de subgrupos de outros grupos no PECB, entre Janeiro de 2003 e Dezembro de 2005 .p. 30

Figura 9 - Tamanho de subgrupos de outros grupos no PECB, com número máximo, médio e mínimo de indivíduos, entre Janeiro de 2003 e Dezembro de 2005. p. 30

Figura 10 - Tamanho médio dos subgrupos dos grupos Pimenta, Laranja e outros grupos. p. 31 
Figura 11 - Tamanho médio dos subgrupos dos indivíduos, adulto e sub-adulto, do grupo Pimenta. (FA - fêmea adulta; MA - macho adulto; MS - macho subadulto)

Figura 12 - Proporção de diferentes composições de subgrupos (baseadas em classes de sexo e idade) do grupo Pimenta. (m - macho; $\mathrm{f}$ - fêmea; fs - fêmeas; js juvenis) p. 33

Figura 13 - Proporção de diferentes composições de subgrupos (baseadas em classes de sexo e idade) do grupo Laranja. (m - macho; f - fêmea; fc/c - fêmea com filhote; js juvenis).

Figura 14 - Proporção de diferentes composições de subgrupos (baseadas em classes de sexo e idade) de outros grupos. (m - macho; $\mathrm{f}$ - fềmea; js juvenis) .p. 34

Figura 15 - Número de machos em função do número de fêmeas em subgrupos do grupo Pimenta. O traço em negrito mostra a freqüência mediana da composição, o retângulo mostra a faixa de variação mais freqüente $\mathrm{e}$ as barras mostram os casos extremos p. 35

Figura 16 - Freqüência de associações entre fêmeas adultas (FF), entre machos e fêmeas adultos (MF) e entre machos adultos (MM) de acordo com o índice de Jaccard médio. p. 38

Figura 17 - Histograma de tempo de depleção das árvores visitadas pelo grupo Pimenta, entre Maio de 2003 e Março de 2006. ..p. 43

Figura 18 - Histograma de freqüência de tamanho de subunidades de alimentação do grupo Pimenta, entre Maio de 2003 e Dezembro de 2005 p. 43

Figura 19 - Correlação entre número de indivíduos na fonte e de tempo de depleção. p. 45 
Figura 20 - Histograma de tempo de depleção das árvores visitadas pelo grupo Laranja, entre Janeiro de 2003 a Julho de 2005. p. 45

Figura 21 - Histograma de freqüência de tamanho de subunidades de alimentação do grupo Laranja ao longo dos meses de 2003 a 2006. p. 46

Figura 22 - Histograma de tempo de depleção das árvores visitadas de todos os outros grupos, entre Janeiro de 2003 a Janeiro de 2006 p. 46

Figura 23 - Histograma de freqüência de tamanho de subunidades de alimentação de outros grupos ao longo dos meses de 2003 a 2006 p. 47

Figura 24 - PCIM médio de 2002, 2003, 2004, 2005 do grupo Pimenta. p. 48

Figura 25 - PCIM corrigido médio para 2002, 2003, 2004, 2005 e Junho 2002. p. 48

Figura 26 - Média, máxima e mínima de temperatura mensal $\left({ }^{0} \mathrm{C}\right)$ e total mensal de pluviosidade (mm) de 2003 a 2006 no PECB p. 51

Figura 27 - Variação mensal da umidade relativa do ar (\%) de 2003 a março 2006 no PECB. p. 52

Figura 28 - Biomassa de frutos e invertebrados (kg/ha) coletados de Fevereiro de 2004 a Março de 2006 ..p. 53

Figura 29 - Variação mensal na biomassa de frutos maduros (kg/ha) no PECB em 2002, 2004,2005 e 2006 p. 54

Figura 30 - Variação mensal na biomassa de invertebrados (kg/ha) no PECB, em 2002, 2004, 2005 e 2006 p. 54

Figura 31 - Correlação entre biomassa de invertebrados e temperatura média mensal $\left({ }^{0} \mathrm{C}\right)$ em $2002(\bullet), 2004(x)$ e 2005 (०) p. 55

Figura 32 - Correlação entre biomassa de frutos, temperatura média mensal $\left({ }^{0} \mathrm{C}\right)$, porcentagem de chuva e total de chuva (mm) em 2002 (•), 2004 (x) e 2005 (०) p. 56 
Figura 33 - Porcentagem de tempo de forrageamento dedicado a diferentes itens alimentares do grupo Pimenta ao longo dos meses de 2003 a 2006. .p. 58

Figura 34 - Número de espécies de fontes com frutos utilizados na dieta pelos grupos de macacos-prego no PECB ao longo dos meses no ano de 2003 a 2006. p. 59 


\section{Lista de Tabelas}

Tabela 1 - Características das sociedades de fissão-fusão. ..p.03

Tabela 2 - Índice de Jaccard para os indivíduos adultos e sub-adultos do grupo Pimenta no PECB durante o ano de 2003. (FA - fêmea adulta; MA - macho adulto) p. 39

Tabela 3 - Índice de Jaccard para os indivíduos adultos e sub-adultos do grupo Pimenta no PECB durante o ano de 2004. (FA - fêmea adulta; MA - macho adulto; MS - macho subadulto)

Tabela 4 - Índice de Jaccard para os indivíduos adultos e sub-adultos do grupo Pimenta no PECB durante o ano de 2005. (FA - fêmea adulta; MA - macho adulto; MS - macho subadulto) p. 40

Tabela 5 - Índice de Jaccard para os indivíduos adultos e sub-adultos do grupo Pimenta no PECB durante o ano de 2006. (FA - fêmea adulta; MA - macho adulto; MS - macho subadulto) p. 40

Tabela 6 - Comparação dos macacos-prego (PECB) com diferentes espécies que realizam fissão-fusão p. 62

Tabela 7 - Comparação de Cebus nigritus entre os estudos de Lynch (2001) na EBC e o presente estudo no PECB. p. 65 


\section{Lista de Anexos}

Anexo I - Árvore Geradora Mínima para os indivíduos adultos e sub-adultos do grupo Pimenta no PECB durante o ano de 2003. $\square$ - machos; $\bigcirc$ fêmeas.. ..p.91

Anexo II - Árvore Geradora Mínima para os indivíduos adultos e sub-adultos do grupo Pimenta no PECB durante o ano de 2004. $\square$ - machos;

fêmeas ..p. 92

Anexo III - Árvore Geradora Mínima para os indivíduos adultos e sub-adultos do grupo Pimenta no PECB durante o ano de 2005. $\square$ - machos;

fêmeas p. 93

Anexo IV - Árvore Geradora Mínima para os indivíduos adultos e sub-adultos do grupo Pimenta no PECB durante o ano de 2006. $\square$ - machos; $\bigcirc$ fêmeas .p. 94

Anexo V - Resultados de ANOVA para regressão múltipla de tamanho médio de subgrupo .p. 95

Anexo VI - Modelos de regressão múltipla para tamanho médio de subgrupo p. 95

Anexo VII - Coeficientes de correlação entre variáveis independentes e tamanho médio de subgrupo em cada modelo. .p. 96

Anexo VIII - Resultados de ANOVA para regressão múltipla de tamanho máximo de subgrupo .p. 96

Anexo IX - Modelos de regressão múltipla para tamanho máximo de subgrupo 
Anexo X - Coeficientes de correlação entre variáveis independentes e tamanho máximo de subgrupo em cada modelo. .p. 97 


\section{Sumário}

Resumo p. viii

Abstract. p. ix

Lista de figuras .p. $x$

Lista de tabelas. p. xiv

Lista de anexos p. XV

1. Introdução ..p. 01

1.1. Sociedades de fissão-fusão. .p. 01

1.2. Evolução de sistemas sociais de primatas. p. 05

1.3. Organização social e estrutura social de Cebus nigritus. .p. 07

2. Objetivos p. 12

3. Materiais e métodos. p. 13

3.1. Área de estudo. p. 13

3.2. Grupos de estudo. .p. 15

3.3. Esforço de campo e Tempo de observação p. 16

3.4. Procedimentos .p. 17

3.4.1. Definição dos termos. ..p. 17

3.4.2. Fissão-Fusão p. 18

3.4.2.1. Tamanho do grupo p. 18

3.4.2.2. Composição dos subgrupos .p. 19

3.4.2.3. Índice de Associação das Díades p. 19

3.4.2.4. Disponibilidade de alimento. p. 20

3.4.2.5. Comportamento alimentar e Dieta. p. 21

3.4.2.6. Competição por alimento. p. 22 
4.1. Os grupos de macacos-prego apresentam organização social do tipo fissão e fusão?

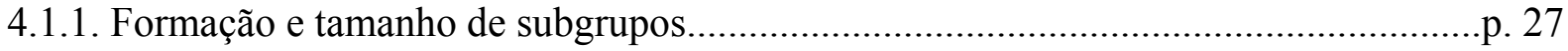

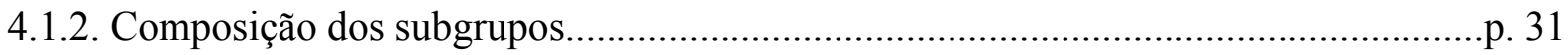

4.1.2.1. Associações diádicas do grupo Pimenta................................................................... 37

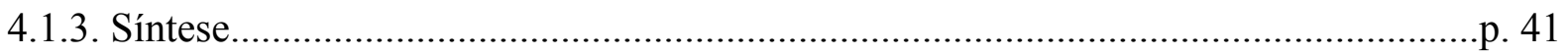

4.2. Focal de árvore de alimentação (FTFS) e subunidades de

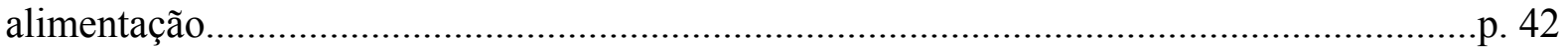

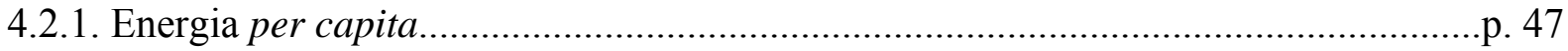

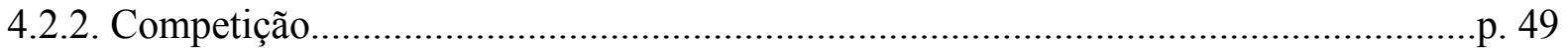

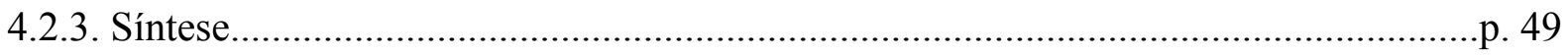

4.3. O tamanho dos subgrupos se relaciona com a oferta de alimento?............................... 50

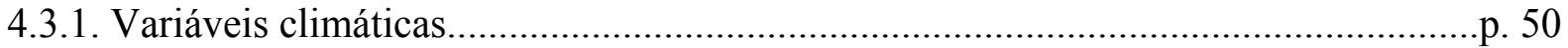

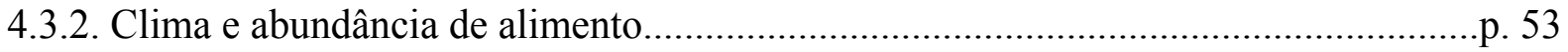

4.3.3. Distribuição e tipos da fonte de alimento................................................................p. 56

4.4. Relação entre tamanho de subgrupos e padrões de oferta de alimento..........................p. 57

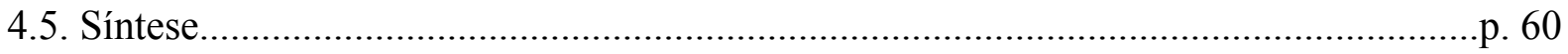

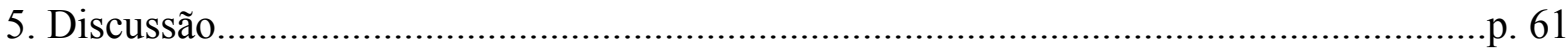

5.1. Organização social de Cebus nigritus: comparação com outras populações.................p. 63

5.2. Fatores ecológicos que afetam o tamanho dos subgrupos...........................................p. 64

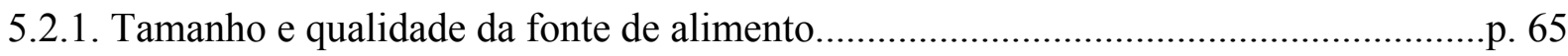

5.2.2. Competição intra e entre grupos........................................................................p. 67

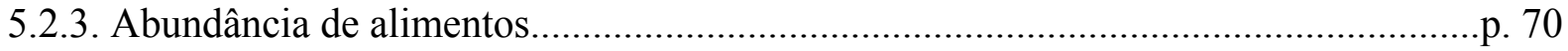


5.2.4. Risco de predação.

.p. 71

5.3. Fatores sociais que afetam o tamanho de subgrupo............................................... 71

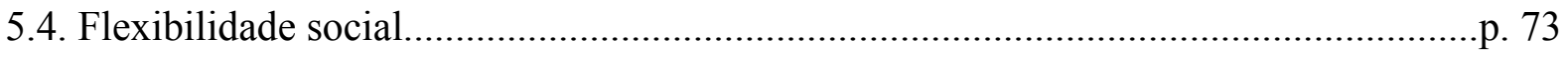

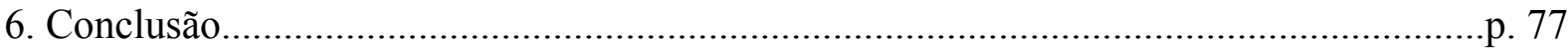

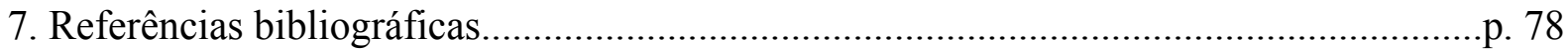

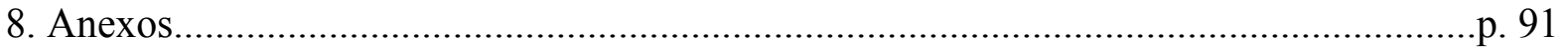




\section{Introdução}

\subsection{Sociedades de fissão-fusão}

Primatas apresentam uma grande diversidade de organização social, desde espécies consideradas solitárias, outras em que pequenos grupos se unem em grandes bandos para dormir, até aquelas em que os indivíduos de um grupo social permanecem todo o tempo juntos (Lee, 1994). A sociedade do tipo fissão-fusão é caracterizada pela fluidez, isto é, o grupo social freqüentemente se subdivide em subgrupos cujo tamanho e composição variam constantemente ao longo do tempo (Chapman, 1990a; Kappeler \& van Schaik, 2002). É observada entre os chimpanzés (Pan troglodytes, Nishida \& Hiraiwa-Hasegawa, 1987) e entre primatas neotropicais atelíneos, como macaco-aranha (Ateles belzebuth, Klein, 1972), muriqui (Brachyteles arachnoides, Milton, 1984 e B. hypoxanthus, Dias \& Strier, 2003) e macacobarrigudo (Lagothrix lagotricha, Defler, 1996).

Essas espécies apresentam várias características em comum (Tabela 1). Possuem grande tamanho corporal, o que os torna menos vulneráveis a predadores (Sterck et al., 1997). Alimentam-se tanto de fontes de alimento uniformemente distribuídas (como folhas e/ou invertebrados), ou pequenas e de baixa qualidade nutricional, quanto de fontes agregadas de alta qualidade (como frutos), esporadicamente disponíveis (chimpanzés: Matsumoto-Oda et al., 1998; macaco-aranha: Wallace, 2005; muriqui: Milton, 1984; macaco-barrigudo: Stevenson et al., 1994). Apresentam composição multi-macho/multi-fêmea e são patrilineares, com dispersão das fêmeas do grupo natal. Além disso, todas essas espécies vivem em grupos (ou comunidades, no caso de chimpanzés) grandes, com até cerca de 100 indivíduos, que se subdividem em subgrupos com composição sexual mista ou unissexual. O tamanho de grupo varia em função da sazonalidade na oferta de alimento: durante a estação úmida, com maior abundância de frutos, os subgrupos são maiores. Em função da dispersão de fêmeas, essas são mais comumente observadas forrageando solitariamente do que os machos, os quais formam 
fortes vínculos entre si (chimpanzés: Nishida \& Hiraiwa Hasegawa, 1987; White \& Wrangham, 1988; Doran, 1997; macaco-aranha: Aureli et al., 2006). A freqüência de fissãofusão varia entre as espécies, desde aquelas em que os indivíduos podem realizar atividades divididos em subgrupos durante o dia e se reunir à noite, ou até ficar semanas ou meses sem se reunir (Chapman, 2004).

Por outro lado, nos gêneros Ateles, Brachyteles e Lagothrix pode-se observar grande variação no grau de coesão intragrupo (Strier, 1992). Há grupos mais fluidos como em macaco-aranha e outros mais coesos como em macaco-barrigudo, o que reflete uma diversidade de estratégias ecológicas e modelos de organização social (Di Fiore \& Campbell, 2005). Macacos-aranha são os mais semelhantes aos chimpanzés (Symington, 1990; Chapman et al., 1995). Já o macaco-barrigudo é uma espécie pouco estudada na natureza (Stevenson et al., 1994; Defler, 1996), cujos grupos dividem-se em subgrupos menos freqüentemente que outros atelíneos (Di Fiore, 2004), deslocam-se de forma dispersa, de 100 a 200 metros, em subgrupos distintos que mantêm contato vocal (Stevenson et al., 1994; Defler, 1996), principalmente durante a estação seca. Stevenson et al. (1994) propõem que a alta proporção de artrópodes na dieta seja um mecanismo que permite maior coesão dos grupos de macacosbarrigudo em comparação com muriquis e macacos-aranha. As diferenças entre os muriquis e os chimpanzés e macacos-aranha são: a associação heterossexual mesmo na ausência de fêmeas sexualmente receptivas e o uso de toda a área de uso do grupo, sem a preferência das fêmeas para ocuparem a área núcleo (Strier et al., 1993). 
Tabela 1 - Características das sociedades de fissão-fusão

\begin{tabular}{|c|c|c|c|c|c|c|}
\hline Espécie & $\begin{array}{l}\text { Tamanho de } \\
\text { grupo/ } \\
\text { comunidade }\end{array}$ & $\begin{array}{l}\text { Tamanho de } \\
\text { subgrupo }\end{array}$ & $\begin{array}{l}\text { Duração das } \\
\text { associações }\end{array}$ & $\begin{array}{l}\text { Fatores que influenciam } \\
\text { tamanho de subgrupo }\end{array}$ & $\begin{array}{l}\text { Composição de } \\
\text { subgrupo }\end{array}$ & Observações \\
\hline Chimpanzé & $\begin{array}{l}20 \text { a mais de } 100 \\
\text { indivíduos } 1\end{array}$ & $\begin{array}{l}1 \text { a } 77 \\
\text { indivíduos, } \\
\text { raramente } \\
\text { excede um } \\
\text { terço da } \\
\text { comunidade }^{2}\end{array}$ & $\begin{array}{l}\text { poucos } \\
\text { minutos a } \\
\text { vários dias }\end{array}$ & $\begin{array}{l}\text { fatores climáticos: } \\
\text { subgrupos maiores na } \\
\text { estação úmida do que } \\
\text { em outros períodos do } \\
\text { ano }^{4} \\
\text { presença de fêmea em } \\
\text { estro: quanto mais } \\
\text { fêmeas na comunidade, } \\
\text { mais machos se } \\
\text { associam a elas } 5\end{array}$ & $\begin{array}{l}\text { mistos ou unissexuais } \\
\text { fêmeas preferem } \\
\text { associar-se com machos } \\
\text { do que entre si; machos } \\
\text { se associam mais às } \\
\text { fêmeas do que entre si }{ }^{7}\end{array}$ & $\begin{array}{l}\text { tamanho da comunidade } \\
\text { afeta a fluidez e o grau de } \\
\text { coesão dos subgrupos: } \\
\text { pequenas comunidades, os } \\
\text { subgrupos permanecem } \\
\text { estáveis, com menor fluidez } \\
\text { e maior coesão ao contrário } \\
\text { das grandes comunidades }\end{array}$ \\
\hline $\begin{array}{l}\text { Macaco- } \\
\text { aranha }\end{array}$ & $\begin{array}{l}15 \text { a } 25 \\
\text { indivíduos, } \\
\text { geralmente com } \\
\text { menos de } 40 \\
\text { animais }\end{array}$ & $\begin{array}{l}3 \text { ou } \\
\text { indivíduos } \\
\text { solitários }^{10}\end{array}$ & $\begin{array}{l}\text { a cada duas } \\
\text { horas }^{11}\end{array}$ & $\begin{array}{l}\text { abundância de alimento: } \\
\text { maiores nos meses em } \\
\text { que os recursos são } \\
\text { abundantes e menores } \\
\text { durante a escassez de } \\
\text { recursos }^{12}\end{array}$ & $\begin{array}{l}\text { multi-macho/ multi- } \\
\text { fêmea }^{13} \\
\text { fêmeas são mais } \\
\text { solitárias do que os } \\
\text { machos }^{14}\end{array}$ & $\begin{array}{l}\text { machos associam-se uns aos } \\
\text { outros com a mesma } \\
\text { freqüência em todas as } \\
\text { estações do ano. Fêmeas } \\
\text { associam se umas às outras } \\
\text { mais freqüentemente na } \\
\text { estação com abundância de } \\
\text { frutos e dependendo do } \\
\text { estado reprodutivo } \\
\text { fêmeas com infantes se } \\
\text { associam mais a machos e } \\
\text { fêmeas do que as fêmeas } \\
\text { sem infantes }\end{array}$ \\
\hline
\end{tabular}


Continuação da Tabela 1

\begin{tabular}{|c|c|c|c|c|c|c|}
\hline Muriqui & $\begin{array}{l}18 \text { a } 100 \\
\text { indivíduos }^{17}\end{array}$ & $\begin{array}{l}1 \text { a } 9 / \\
14 \text { a } 43 \\
\text { indivíduos }^{18}\end{array}$ & $\begin{array}{l}\text { mãe-filhote é } \\
\text { permanente }^{19}\end{array}$ & $\begin{array}{l}\text { competição, clima e } \\
\text { composição florística do } \\
\text { habitat }^{20}\end{array}$ & $\begin{array}{l}\text { multi-macho/ multi- } \\
\text { fêmea ou unissexuais } \\
{ }^{21} \\
\text { machos associam-se } \\
\text { para forragear enquanto } \\
\text { a grande maioria das } \\
\text { fêmeas alimenta-se de } \\
\text { forma solitária }^{22}\end{array}$ & $\begin{array}{l}\text { tamanhos de subgrupos } \\
\text { variam de acordo com a área } \\
\text { de estudo, por exemplo, } B \text {. } \\
\text { arachnoides formam } \\
\text { subgrupos menores e menos } \\
\text { coesos no PECB, do que } B \text {. } \\
\text { hypoxanthus, na EBC }\end{array}$ \\
\hline $\begin{array}{l}\text { Macaco- } \\
\text { barrigudo }\end{array}$ & $\begin{array}{l}14 \text { a } 33 \\
\text { indivíduos }^{24}\end{array}$ & & $\begin{array}{l}\text { grupos mais } \\
\text { coesos, mas } \\
\text { subgrupos } \\
\text { permanecem } \\
\text { próximos um } \\
\text { ao outro } 25\end{array}$ & $\begin{array}{l}\text { disponibilidade e } \\
\text { abundância de } \\
\text { alimento }^{26}\end{array}$ & $\begin{array}{l}\text { multi-macho/multi- } \\
\text { fêmea }^{27} \\
\text { fêmeas preferem se } \\
\text { associar mais com os } \\
\text { machos do que com } \\
\text { outras fêmeas, sendo } \\
\text { responsáveis por } \\
\text { estabelecer e manter }^{28} \\
\text { essas relações }^{28}\end{array}$ & \\
\hline
\end{tabular}

1 - Nishida \& Hiraiwa Hasegawa, 1987

2 - Boesch, 1996; Bo

2 - Boesch, 1996; Boesch \& Boesch, 2000

14, 15, 16 - Shimooka, 2003

4 - Sakura, 1994; Doran, 1997; Matsumoto Oda et al., 1998; Boesch \& Boesch, 2000; Basabose, 2004; Murray et al., 2006

5 - Sakura, 1994; Boesch \& Boesch, 2000

6 - Doran, 1997; Matsumoto Oda et al., 1998; Boesch \& Boesch, 2000; Williams et al., 2002

7, 8 - Boesch, 1996; Boesch \& Boesch, 2000

9 - van Roosmalen, 1985; Dew, 2005

10 - Robinson \& Jason, 1987; Shimooka, 2003

11 - Chapman, 1988

12 - Robinson \& Jason, 1987; Symington, 1988; Chapman, 1990a; Shimooka, 2003

17 - Milton, 1984; Strier et al., 1993

18 - Strier et al., 1993; Carvalho Junior, 1996

19 - Milton, 1984, 1985; Carvalho Junior, 1996

20, 21 - Carvalho Junior, 1996; Moraes et al, 1998

20, 21 - Carvalho Junior, 1996; Moraes et al., 1998

22 - Milton, 1984; Strier, 1990; Dias \& Strier, 2003

24 - Robinson \& Jason, 1987; Stevenson et al., 1994; Defler, 1996; Dew, 2005

25 - Di Fiore, 2004; Dew, 2005

26 - Di Fiore, 2004

13 - Dew, 2005

28 - Stevenson et al., 1994; Defler, 1996; Dew, 2005; Di Fiore \& Fleischer, 2005 


\subsection{Evolução de sistemas sociais de primatas}

A ordem primata apresenta uma grande diversidade de sistemas sociais que instiga os pesquisadores a compreender as causas dessa variabilidade. Sistemas sociais compreendem a organização social (tamanho e composição do grupo), a estrutura social (relações sociais entre os indivíduos do grupo) e o sistema de acasalamento. Considera-se que um sistema social resulta de estratégias individuais selecionadas para lidar com pressões seletivas, tais como risco de predação e competição por recursos limitantes, principalmente pelo alimento e por parceiros reprodutivos (Kappeler \& van Schaik, 2002).

A relação entre os sistemas sociais e pressões seletivas, principalmente o padrão de relações sociais entre fêmeas de uma espécie de primata, podem ser explicados pelos modelos socioecológicos (Wrangham, 1980; van Schaik, 1989; Isbell, 1991; Sterck et al., 1997). Esses modelos assumem que o comportamento do indivíduo é afetado por variáveis ecológicas que limitam o sucesso reprodutivo dos indivíduos e influenciam na formação das relações sociais.

A aptidão de machos e de fêmeas é limitada por fatores distintos, dadas as diferenças na fisiologia reprodutiva e no investimento parental, com altos custos energéticos para as fêmeas devido aos períodos de gestação e lactação (Trivers, 1972). Além disso, entre primatas, a ocorrência de grupos coesivos é associada com a alta vulnerabilidade aos predadores (van Schaik, 1989). Assim, a distribuição das fêmeas no habitat deve ocorrer em função da distribuição dos riscos de predação e dos recursos alimentares, enquanto que os machos distribuem-se em função da disponibilidade de fêmeas sexualmente receptivas.

Considera-se que o padrão de relações sociais entre fêmeas de uma espécie de primata foi selecionado pela pressão de predação e da competição intra e entre grupos por alimento, a qual é determinada pela distribuição, tamanho e abundância de recursos alimentares (Isbell \& Young, 2002). Os modelos assumem, então, que deve haver uma influência da competição por alimento sobre o padrão de distribuição de fêmeas. 
Os modelos socioecológicos de van Schaik (1989) e de Sterck et al. (1997) atribuem ao risco de predação um papel importante, por afetar as relações sociais entre fêmeas, considerando que a vida social em primatas evoluiu devido à redução do risco de predação e da competição por recursos limitantes entre os membros do grupo (van Schaik, 1983; van Hoof \& van Schaik, 1992). Esses modelos prevêem que em habitats com baixo risco de predação, grupos de primatas tendem a ser menos coesos, por não precisarem da colaboração de outros indivíduos para a vigilância à predação enquanto se alimentam, e a ocorrer em alta densidade populacional. Como conseqüência, as fêmeas estão sujeitas a alta competição entre grupos e espera-se que formem grupos que freqüentemente se dividem em subgrupos para diminuir a competição intragrupo. Também se espera que esses grupos se reúnam para competir diretamente com outros grupos por grandes fontes de alimento.

A formação de subgrupos permite a redução da competição intragrupo nas fontes pequenas e dispersas durante o forrageamento. A união dos subgrupos ocorre quando as fontes são grandes o suficiente para sustentar todo o grupo e compensam defendê-las contra outros grupos.

Nas espécies que evoluíram sob significativa pressão de predação, o tipo e a intensidade da competição por alimentos determinam o padrão de organização social entre fêmeas. Assume-se que há uma vantagem das fêmeas aparentadas permanecerem no grupo e defenderem a área e os recursos alimentares, quando existe competição por alimento. Se é preciso formar um grupo para evitar a predação, e com isso enfrentar os custos da competição por alimento, então a aliança com parentes permite uma maior aptidão à fêmea (Wrangham, 1980). Assim, o padrão de organização social entre fêmeas pode assumir quatro formas: a) Dispersora-Igualitária ("Dispersal-Egalitarian"): quando a competição direta intra e entre grupos é baixa, as fêmeas transferem-se de seus grupos natais e formam relacionamentos igualitários entre si, b) Residente-Igualitária (“Resident-Egalitarian”): quando a competição 
direta intragrupo é baixa e a competição direta entre grupos é alta, as fêmeas permanecem em seus grupos natais (formando uma coalizão para defesa de fontes alimentares contra outros grupos) e formam relacionamentos igualitários, c) Residente-Nepotista (“ResidentNepotistic"): quando a competição direta intragrupo é alta e a competição direta entre grupos é baixa, as fêmeas permanecem em seus grupos natais e formam hierarquia de dominância linear, nepotista e despótica, com alianças entre fêmeas aparentadas e coalizões mutualísticas entre fêmeas não aparentadas e d) Residente-Nepotista-Tolerante ("Resident-NepotisticTolerant”): quando a competição direta intra e entre grupos é alta, as fêmeas permanecem em seus grupos natais e formam hierarquia de dominância linear, nepotista e tolerante, com coalizões entre fêmeas. A hierarquia é tolerante para que as fêmeas subordinadas não abandonem o grupo e auxiliem na defesa das fontes alimentares.

\subsection{Organização social e estrutura social de Cebus nigritus}

Os macacos da espécie Cebus nigritus, comumente chamados de macaco-prego, são primatas neotropicais que habitam as matas do sul e sudeste do Brasil e o noroeste da Argentina. Até recentemente, o gênero Cebus era dividido em dois grupos: as espécies sem tufo (C. albifrons, C. capucinus e C. olivaceus) e a espécie com tufos (C. apella), com diversas subespécies de acordo com a região geográfica de ocorrência, dentre as quais, $C$. apella nigritus, típica do sul do Rio Doce em Minas Gerais e Espírito Santo, do Rio de Janeiro, de São Paulo e do norte do Paraná e do noroeste da Argentina (Rylands et al., 2005). Recentemente, Groves (2001) fez uma revisão do gênero, alçando quatro subespécies ao nível de espécie, C. nigritus, C. apella, C. xanthosternus e C. libidinosus.

A espécie em estudo é C. nigritus que apresenta duas subespécies, C. nigritus nigritus e C. nigritus robustus (Rylands et al., 2005). A maior parte da literatura refere-se à classificação taxonômica antiga de C. apella, sem referência a subespécies. Assim, neste 
trabalho, é feita uma revisão das características descritas para C. apella, apenas fazendo-se referência a C. nigritus quando havia dados disponíveis.

Os macacos-prego são onívoros (Freese \& Oppenheimer, 1981). A dieta é constituída principalmente por polpa de frutos maduros, complementada por insetos, brotos, flores e sementes (Izawa, 1979; Terborgh, 1983; Janson et al., 1986; Peres, 1993, 1994; Galetti \& Pedroni, 1994; Zhang, 1995). Ocasionalmente podem predar pequenos vertebrados, incluindo aves e mamíferos (Freese \& Oppenheimer, 1981; Galetti, 1990; Ferreira et al., 2002; Resende et al., 2004).

O tamanho médio dos grupos varia de 5 a 40 indivíduos, com o número de fêmeas maior ou igual ao número de machos, que varia de um a dois machos adultos no grupo (Freese \& Oppenheimer, 1981).

Segundo Fragaszy et al. (2004b), a estrutura social de grupos selvagens de macacosprego é comumente caracterizada como multi-macho e multi-fêmea com hierarquia de dominância, mas diversos estudos mostram diferenças quanto às relações de dominância estabelecidas pelos grupos. As diferenças entre relações de dominância dos diversos grupos parecem ocorrer em função da disponibilidade de recursos alimentares. Grupos submetidos a situações de escassez de alimento podem estabelecer relações de dominância mais rígidas do que grupos que têm alimento abundante (Izar, 1994; Izar \& Sato, 1997).

As fêmeas de macacos-prego são filopátricas, isto é, permanecem no grupo natal enquanto os machos dispersam. Vivem em grupos coesos, sem a formação de subgrupos, e estáveis na composição com mudança apenas devido a nascimentos, mortes e emigração (Jason, 1984; Robinson \& Jason, 1987; Kinzey, 1997; Di Bitetti, 2001). A maior parte dos estudos com macacos-prego foi realizada em florestas Amazônicas e semi-decíduas da Argentina (Janson, 1985; Robinson \& Janson, 1987; Sterck et al., 1997; Di Bitetti, 2001). No entanto, macacos-prego apresentam uma ampla distribuição geográfica, ocupando habitats 
diversos (Izar, 1999), provavelmente devido à sua grande plasticidade comportamental (Fragaszy et al., 1990). Geralmente, essa plasticidade é observada no comportamento de forrageio, tanto pela diversidade de itens incorporados na dieta em ambientes distintos, como pelo emprego de técnicas complexas, incluindo o uso de ferramentas em uma área de semiliberdade (Ottoni \& Mannu, 2001) e na natureza (Fragaszy et al., 2004a). Em ambos os estudos, machos, fêmeas e infantes utilizam espontaneamente pedras como martelo e uma superfície dura como bigorna para a quebra de cocos.

Raros são os estudos que analisam a variabilidade de organização social como um dos elementos importantes para a capacidade de ocupar ambientes distintos (Izar \& Ferreira, no prelo). Essa falta de estudos pode ocorrer devido à prevalência dos modelos socioecológicos que consideram os diferentes sistemas sociais de primatas como características adaptadas, produto da seleção natural como resposta ao tipo de dieta adotado pelas espécies ao longo de sua evolução.

Alguns estudos, no entanto, têm indicado que a organização social de primatas pode ser mais flexível do que consideram os modelos (Korstjens et al., 2002). Ao estudar duas espécies de colobus (Procolobus badius badius e Colobus polykomos polykomos), com diferentes nichos numa mesma floresta tropical, os autores verificaram que a dispersão de um dos sexos do grupo e a competição alimentar entre grupos não possuem uma relação tão forte como sugerido pelos modelos socioecológicos, mas a competição alimentar entre fêmeas parece refletir as adaptações às características alimentares através do tempo que os indivíduos gastam ao se alimentarem e da qualidade da fonte de alimento.

De fato, alguns estudos revelam indícios de que as populações de Cebus não são tão coesas quanto explicam os modelos socioecológicos. A formação de subgrupos em Cebus foi observada durante o processo de divisão de um grupo grande ou pré-fissão (Izawa, 1994; Di Bitetti, 2001). Izawa (1994) observou a divisão de um grupo após alguns conflitos agonísticos 
durante a mudança de hierarquia de dominância dos machos. Depois da divisão, as fêmeas da alta hierarquia permaneceram no grupo maior e as fêmeas de baixa hierarquia no grupo menor. Di Bitetti (2001) registrou a divisão de um grupo grande em dois grupos e depois um desses grupos se fundiu a um outro grupo que utilizava a mesma área de uso.

Outros dois estudos não concluíram se os processos que foram observados eram de divisão permanente de um grupo grande ou se realmente essas populações se parecem com as sociedades de fissão-fusão (Lynch, 2001; Izar, 2004). Num estudo em que analisou relações sociais de fêmeas de Cebus nigritus em área de Mata Atlântica (Parque Estadual Carlos Botelho - PECB, São Paulo) à luz dos modelos socioecológicos, Izar (2004) observou um padrão de organização social inesperado para a espécie: a fissão de grupos com conseqüente transferência de fêmeas entre grupos. Nesse estudo, realizado durante o período de junho de 2001 a dezembro de 2002, os macacos se alimentavam tanto de frutos quanto de recursos uniformemente dispersos (invertebrados e bromélias) e as fêmeas estavam submetidas à competição direta e indireta por alimentação, tanto intra quanto entre grupos. Juntamente com a redução drástica na oferta de frutos maduros em fontes grandes, foi observada uma fissão, que consistiu na divisão permanente de grupos sociais estáveis. Também houve uma diminuição significativa na obtenção per capita de energia, medida em função do tempo de depleção das fontes de frutos e do número de membros dos grupos que se alimentam ao mesmo tempo nessas fontes. Quando a oferta aumentou, essas pequenas unidades reagruparam-se em novas formações. Ao longo de outros períodos de observação, os animais alimentaram-se principalmente em fontes pequenas de frutos. Como discutido anteriormente, o forrageamento em fissão-fusão é esperado em espécies que se alimentam de recursos agregados disponíveis em fontes pequenas e também de recursos uniformemente distribuídos no habitat. Este é exatamente o caso de macacos-prego no Parque Estadual Carlos Botelho (Izar, 2004). 
Em um estudo recente com populações de Cebus nigritus, Lynch (2001) observou a formação de subgrupos desta espécie, na Estação Biológica de Caratinga (EBC), Minas Gerais, também uma área de Mata Atlântica. A autora observou uma fluidez sazonal no tamanho dos subgrupos, com as fêmeas dominantes e o macho alfa em grandes subgrupos e os outros indivíduos de hierarquia mais baixa permaneciam subgrupos menores. No entanto, ela não pode descartar a possibilidade de ser um fenômeno relacionado ao grande tamanho do grupo, anterior a uma divisão permanente ou se seria essa uma estratégia típica da população estudada para regular o tamanho do grupo em algumas estações do ano sem a permanente divisão do grupo.

A população do Parque Estadual Carlos Botelho já vem sendo estudada desde junho de 2001, compreendendo mais de 40 meses de observação. A análise da organização social de grupos de C. nigritus permite investigar se a plasticidade comportamental da espécie, já observada em técnicas de forrageamento, estende-se também ao padrão de organização social. 


\section{Objetivos}

O objetivo do presente trabalho foi investigar se os grupos de macacos-prego do PECB caracterizam-se como sociedades do tipo fissão-fusão, dividindo-se constantemente em subgrupos de tamanho e composição variável, ou se a formação de subgrupos ocorre apenas como um estágio temporário pré-divisão permanente.

Neste trabalho, testo a hipótese, oriunda dos modelos sócio-ecológicos, de que há uma relação entre fatores ecológicos, como o padrão de oferta de alimentos e o risco de predação, e a organização social da população de macacos-prego do PECB. Pelos modelos, espera-se uma relação entre coesão dos grupos sociais e padrão de distribuição do alimento: quanto maior e mais produtivas as fontes, maior a coesão do grupo e quanto menores as fontes de alimento, maior a freqüência de formação de subgrupos.

As características ecológicas deste habitat, já constatadas por Izar (2004), de baixo risco de predação e alimento distribuído em fontes pequenas, de baixa qualidade e pouco produtivas, favoreceriam a organização em fissão-fusão, porque as fontes não sustentariam muitos indivíduos do grupo ao mesmo tempo, os quais poderiam forragear independentemente sem submeter-se a um maior risco de predação.

Espera-se que a formação de subgrupos esteja relacionada ao padrão de oferta de alimento no PECB. Assim, a formação de subgrupos e o tamanho desses subgrupos, a cada mês, estariam relacionados ao número de indivíduos que conseguem se alimentar ao mesmo tempo em uma fonte alimentar. A coesão do grupo de macacos-prego seria maior em épocas de frutificação de árvores com grande produtividade e com alta qualidade de frutos e, conseqüentemente, a formação de subgrupos ocorreria em épocas de baixa produtividade e em copas que não sustentam o grupo todo. Espera-se também uma correlação negativa entre competição por alimento entre grupos e intragrupo e formação de subgrupos para forrageamento. 


\section{Materiais e Métodos}

\section{1. Área de estudo}

Este trabalho foi realizado no Parque Estadual Carlos Botelho (PECB), localizado na Serra de Paranapiacaba, entre os municípios de São Miguel Arcanjo, Sete Barras, Tapiraí e Capão Bonito, no estado de São Paulo, entre as coordenadas $24^{\circ} 03^{\prime} 15^{\prime \prime a} 24^{\circ} 04^{\prime} 00^{\prime \prime}$ Sul e 4759’00" a 4800'00" Oeste. Possui uma área de 37.797,43 ha, fazendo limites com o Parque Estadual de Intervales, o Parque Estadual Turístico do Alto Ribeira e a Estação Ecológica de Xitué, constituindo uma das maiores áreas remanescentes de Mata Atlântica contínua, com 116.836,99 hectares (Figura 1).

O clima é subtropical úmido, sem déficit hídrico. A precipitação anual média é de $1683,2 \mathrm{~mm}$. A média anual de temperatura é $19,01^{\circ} \mathrm{C}$, com mínima de $3^{\circ} \mathrm{C}$ e máxima de $29^{\circ} \mathrm{C}$ (Dias et al., 1995).

A altitude do PECB varia de 30 a 1.003 metros. O estudo foi realizado no Núcleo São Miguel Arcanjo do PECB, localizado na região que Domingues e Silva (1988) denominaram Planalto da Guapiara, pertencente ao Planalto Atlântico, com altitude variando entre 720 e 975 metros acima do nível do mar. O relevo é caracterizado por morros paralelos e morrotes baixos (Pfeifer et al., 1986). Segundo Pfeifer et al. (1986), os solos desta área são desenvolvidos, dos tipos B latossólicos e B texturais. Os rios formam uma densa rede de drenagem pertencente à bacia hidrográfica do Rio Paranapanema. 


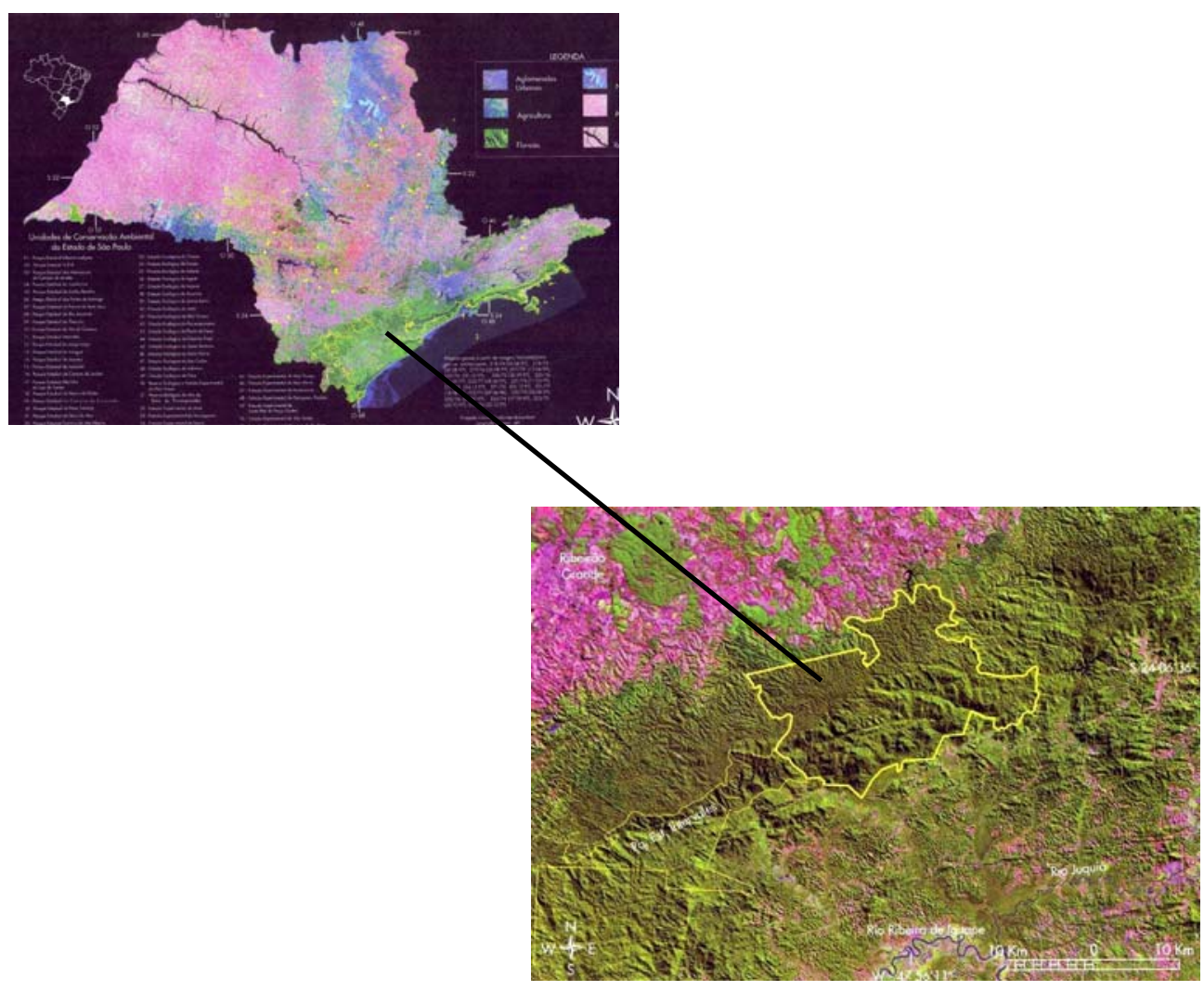

Figura 1 - Localização do Parque Estadual "Carlos Botelho" no Estado de São Paulo, detalhando os limites do parque na Serra do Mar - (imagem do site www.iflorestsp.br).

A cobertura vegetal é de Floresta Ombrófila Densa, com denominação equivalente à Floresta Pluvial Tropical, e conhecida por Mata Atlântica (Aguiar, 2003). De acordo com Dias et al. (1995), o PECB "possui a maior parte de sua cobertura vegetal representada por floresta não perturbada ou com perturbações pouco significativas" (p. 127), mas existem alguns pequenos trechos que possuem vegetação secundária. As famílias mais representativas são Myrtaceae, Arecaceae, Euphorbiaceae, Leguminosae, Sapotaceae, Lauraceae e Rubiaceae, de acordo com o índice de valor de importância, IVI (Negreiros et al., 1995). As duas famílias mais importantes, Myrtaceae e Arecaceae, são representadas principalmente por espécies de sub-bosque, com diâmetro basal igual ou inferior a $0,5 \mathrm{~m}$. As famílias com maior riqueza de espécies são Myrtaceae, Lauraceae, Fabaceae e Sapotaceae (Dias, 2005). 
No PECB ocorrem três espécies de primatas, Brachyteles arachnoides, Alouatta fusca e Cebus nigritus. Existem cinco espécies de carnívoros potencialmente predadores de primatas Panthera onca, Puma concolor, Leopardus pardalis, Felis sp e Eira barbara (Beisiegel, 1999). Há apenas um grande predador aéreo, Spizaetus tyrannus e mais nove espécies menores de Accipitridae (Izar, 2004). No PECB, o risco de predação é considerado baixo, pois desde novembro de 2001 não foi observado nenhum evento de predação e encontros com predadores são raros (Izar, 2004; obs. pessoal).

\subsection{Grupos de estudo}

No estudo de Izar (2004), realizado durante o período de junho de 2001 a dezembro de 2002, a fissão observada consistiu na divisão permanente de grupos sociais estáveis, associada à redução drástica na oferta de frutos maduros. Quando a oferta de alimento aumentou, essas pequenas unidades reagruparam-se em novas formações. Segundo a autora, fora desse período de escassez de frutos, os grupos eram grandes e coesos. Naquele estudo, foram observados seis grupos de macacos-prego, com esforço de amostragem sistemática maior para dois deles, denominados grupo Laranja e grupo Pimenta. Naquele período, o grupo Laranja apresentou uma modificação em sua composição após o período de fissão permanente.

No presente estudo, foram acompanhados os grupos Pimenta e Laranja para dar continuidade a essas observações. Ambos os grupos já estavam habituados à presença de observadores.

\section{Grupo Pimenta}

Os indivíduos adultos eram reconhecidos individualmente, através da coloração do pêlo, tamanho do corpo e forma do topete. Durante o estudo, o grupo Pimenta era composto por 21 indivíduos, sendo dois machos adultos, dois machos sub-adultos, sete fêmeas adultas, 
oito juvenis e dois infantes. Foram coletados dados sobre comportamento alimentar, tamanho das fontes de alimento e composição dos grupos ou subgrupos, no período de Maio a Setembro de 2003 e de Fevereiro de 2004 a Março de 2006, totalizando 164 dias de observação do grupo.

\section{Grupo Laranja}

O grupo Laranja era composto por 17 indivíduos, incluindo dois machos adultos, quatro fêmeas adultas, nove juvenis e dois infantes. Foram registrados 52 dias de observação do grupo Laranja, de 2003 a 2006.

Dados sobre outros grupos (grupo Ribeirão Grande, grupo Marrom, grupo Saracura e de outros grupos) foram coletados de forma oportunística, totalizando 56 dias de observação de 2003 a 2006.

\subsection{Esforço de campo e Tempo de observação}

Ao longo de 3698,38 horas de esforço de campo, obtive um total de 964,63 horas de observação de macacos-prego (Figura 2). O tempo de observação do grupo Pimenta foi de 639,36 horas, já para o grupo Laranja e de outros grupos, o tempo de observação somado foi de 325,27 horas. Houve uma grande dificuldade de acompanhar os grupos devido à declividade da área do PECB, que é caracterizada por morros paralelos e morrotes baixos. Assim, quando os animais deslocavam-se rapidamente, a chance de perdê-los era maior, principalmente em áreas de topografia acidentada, do que quando se deslocavam em velocidade menor. 


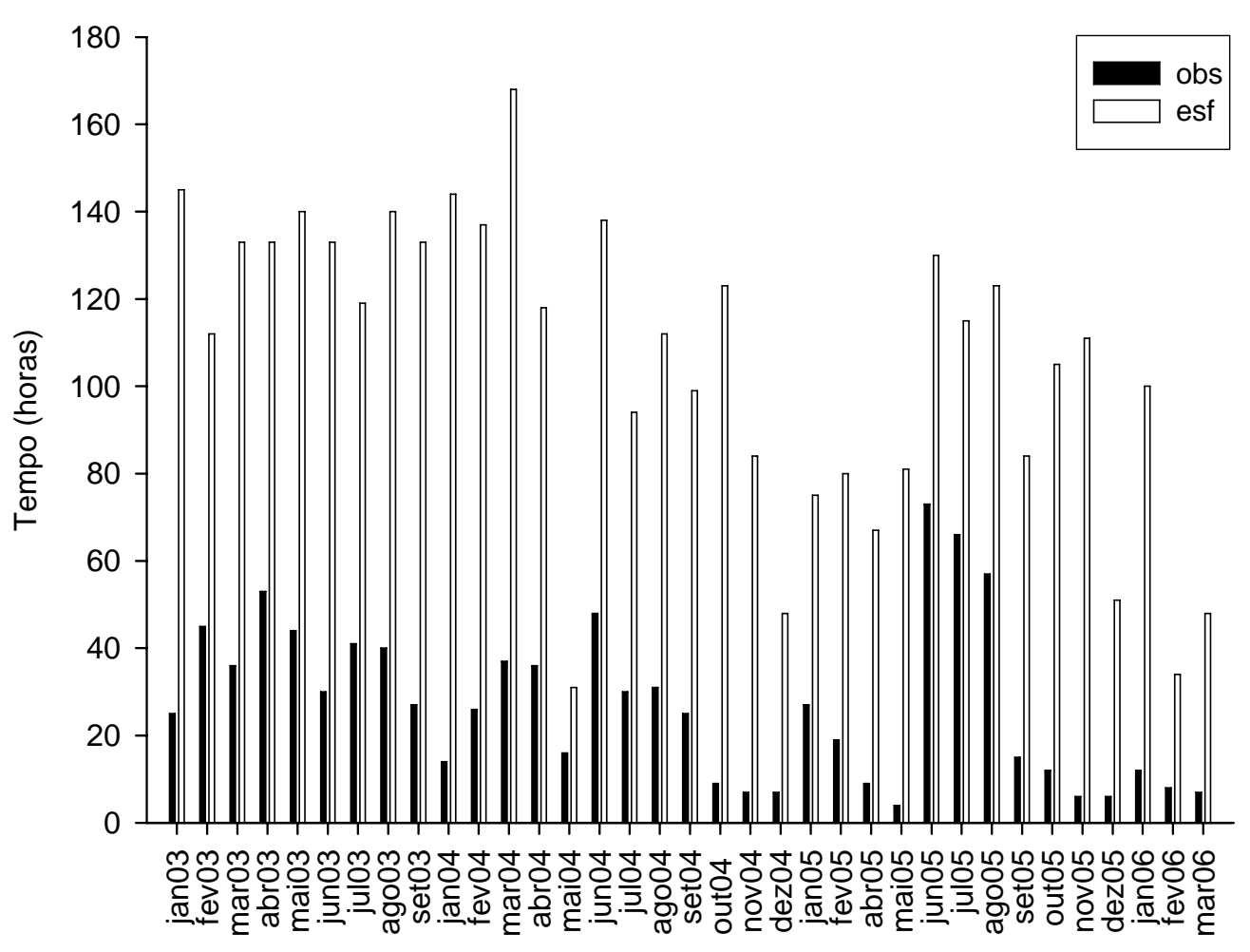

Figura 2 - Tempo (em horas) de esforço de campo e de observação de Cebus nigritus, de 2003 a 2006, no PECB. OBS = tempo de observação direta dos animais; ESF = esforço amostral.

\subsection{Procedimentos}

\subsubsection{Definição dos termos}

A literatura sobre primatas que se organizam em fissão-fusão ainda apresenta diferentes definições para subgrupos devido a diferentes metodologias para determinar seu tamanho e composição (Chapman et al., 1993, 1994; Boesch, 1996; Boesch \& Boesch, 2000). O grau de habituação, a visibilidade da área de estudo e identificação dos indivíduos influenciam a definição de subgrupos (Chapman et al., 1993, 1994; Boesch, 1996; Boesch \& Boesch, 2000). Por exemplo, pode-se considerar como um subgrupo: (a) somente os indivíduos avistados, ou (b) os indivíduos em contato auditivo, ou (c) os indivíduos presentes dentro de certa distância um do outro, ou (d) os indivíduos avistados a cada scan feito dentro de um determinado intervalo de tempo (Chapman et al., 1994; Boesch, 1996; Boesch \& 
Boesch, 2000). O critério de tamanho do subgrupo também pode variar se o observador incluir todos os indivíduos ou excluir os infantes dependentes (Matsumoto-Oda et al., 1998).

Assim, é importante definir claramente os termos adotados neste trabalho: um grupo é a maior unidade social estável em que todos os membros interagem sem um freqüente comportamento agonístico, mesmo quando os indivíduos permanecem separados por um tempo e depois se reúnem (Chapman, 1990 a, b). Um subgrupo é qualquer número de indivíduos menor que o número total do grupo (Chapman, 1990 a, b), incluindo indivíduos solitários. O mesmo conceito de subgrupo foi utilizado por Lynch (2001), o que permite uma comparação entre os estudos. Além disso, foi considerado que o tamanho de subgrupos é o número de indivíduos, incluindo os infantes, observados durante o dia com o subgrupo inicial, isto é, os indivíduos que foram acompanhados desde o momento em que acordaram (Matsumoto-Oda et al., 1998; Lynch, 2001; Basabose, 2004). Também foi registrado, neste trabalho, o tamanho da subunidade de alimentação, que é o número de indivíduos que se alimentam juntos, ao mesmo tempo, em uma mesma árvore.

\subsubsection{Fissão-Fusão}

\subsubsection{Tamanho do grupo}

Os grupos de estudo foram acompanhados ao longo de 5 a 20 dias consecutivos de cada mês, do nascer ao pôr do sol, sempre que possível. Seguindo a metodologia de Lynch (2001), a fim de verificar se o grupo estava forrageando de forma coesa ou dividido em subgrupos, era feito um censo dos membros do grupo a cada hora para verificar se houve mudança na composição do grupo. Devido às dificuldades de observação da área de estudo (ver Izar, 2004), por vezes não eram encontrados os grupos ou eram perdidos ao longo do dia. Quando isso acontecia, eram percorridas as trilhas ao longo da área de uso e a localização do grupo era feita por meio de pistas indiretas, como restos de bromélias e palmitos comidos 
encontrados no solo, ou diretamente, após a audição de vocalizações ou avistamentos. Quando o grupo era localizado, a identidade e número de indivíduos presentes eram registrados e o censo a cada hora era retomado.

\subsubsection{Composição dos subgrupos}

Para o registro da composição dos subgrupos foram contados os números de machos adultos, de fêmeas adultas e de juvenis. Para as análises, os dois machos sub-adultos foram considerados como adultos. Foi totalizada a freqüência de ocorrência de subgrupos com: 0 a 4 machos adultos; 0,1 ou mais de uma fêmea adulta; 0,1 ou mais um juvenil e indivíduos solitários.

\subsubsection{3. Índice de Associação das Díades}

Os dados de composição individual dos subgrupos foram analisados através do método de Árvores Geradoras Mínimas (Izar et al., 2005), com a construção de árvores mostrando a associação das díades de indivíduos adultos e sub-adultos. Os dados transcritos formaram uma matriz de indivíduos (coluna) x scans (linha). A cada scan, foi atribuído o valor 1 para os indivíduos amostrados que forrageavam juntos e 0 para os ausentes. Essa matriz foi convertida em uma matriz de similaridade indivíduos $\mathrm{x}$ indivíduos, em que as caselas representam o Índice de Jaccard para cada díade:

$$
\mathrm{Sj}=\frac{\mathrm{a}}{\mathrm{a}+\mathrm{b}+\mathrm{c}}
$$

( $\mathrm{a}$ = número de scans em que os indivíduos $\mathrm{X}$ e Y foram observados no mesmo subgrupo de forrageamento, $\mathrm{b}=$ número de scans em que $\mathrm{X}$ foi observado e $\mathrm{Y}$ não, $\mathrm{c}=$ número de scans em que Y foi observado e X não). O Índice de Jaccard é calculado pelo programa Simejjac, 
desenvolvido pelo Dr. Takechi Sato, do Departamento de Psicologia Experimental. Essa matriz foi convertida em uma matriz de dissimilaridade através da transformação complementar 1 - $\mathrm{S}_{\mathrm{ij}}$, a partir da qual é construída uma Árvore Geradora Mínima, um método oriundo da Teoria dos Grafos que representa graficamente as relações mais fortes do grupo social (Izar et al., 2005).

Essa análise permitiu verificar se existem associações preferenciais entre indivíduos para o forrageamento.

\subsubsection{Disponibilidade de alimento}

A oferta mensal de frutos maduros na mata foi avaliada de acordo a metodologia utilizada por Izar (2004). Foram utilizados coletores de frutos distribuídos na mata para amostrar a quantidade de frutos que caem das copas. Esse método permite estimar a massa de frutos maduros $(\mathrm{kg})$ por unidade de área do habitat $\left(\mathrm{km}^{2}\right)$. Os coletores consistiam de bandejas de alumínio ( $25 \times 16,5 \mathrm{~cm}$ ) com área de $412,5 \mathrm{~cm}^{2}$, enterradas no solo para melhor fixação no local de coleta. Foram distribuídos 153 coletores em pontos sorteados ao longo de trilhas (1 metro de distância lateral) dentro da área de uso do grupo estudado, a uma distância mínima de 50 metros entre cada coletor. Os coletores foram esvaziados no final de cada mês e a massa de frutos maduros coletados foi pesada.

Ainda seguindo a metodologia de Izar (2004), foi avaliada a variação mensal de abundância (biomassa) de invertebrados no habitat, utilizando o método de armadilhas "pitfall", que é mais indicado para avaliar a abundância de insetos ativos que vivem na superfície, em vegetação baixa ou solo nu. Embora os animais estudados nessa pesquisa possam alimentar-se de uma grande variedade de invertebrados, com diferentes hábitos, foi considerado que esse método fornece um índice confiável da variação mensal na oferta deste item alimentar no habitat. 
Armadilhas "pitfall" consistem de recipientes enterrados no solo de modo a capturar os insetos que caem na sua superfície. Foram utilizados 153 copos descartáveis de plástico como recipientes, com área de $38,5 \mathrm{~cm}^{2}$, preenchidos com água (o método já foi utilizado com sucesso, optando-se pelo procedimento com água em lugar de álcool ou formol, devido ao risco de transbordamento e conseqüente contaminação do ambiente). As armadilhas foram distribuídas seguindo o mesmo procedimento de distribuição de coletores de frutos, os copos plásticos estavam localizados ao lado das bandejas (Figura 3). No final de cada mês, as armadilhas eram esvaziadas e a massa de insetos capturados foi pesada.

Os frutos foram identificados, quando possível, e os insetos foram somente pesados. Amostras de frutos e folhas foram guardadas em exsicatas e fotografadas para identificação botânica.

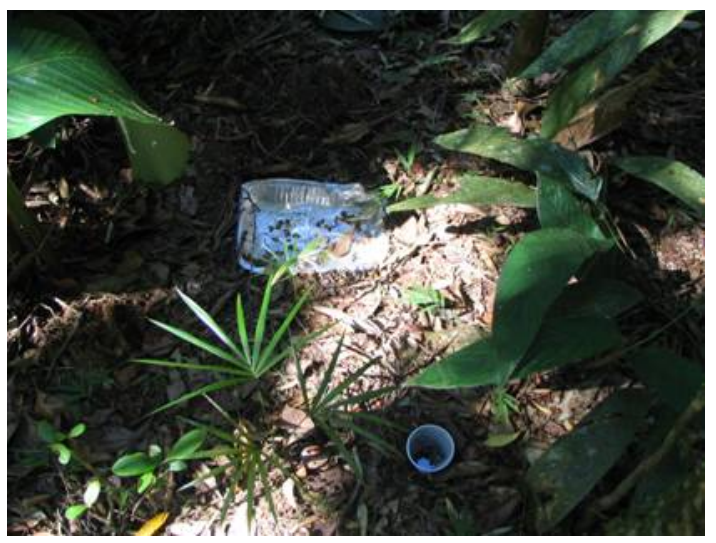

Figura 3 - Posicionamento das armadilhas de frutos (bandeja de alumínio) e de invertebrados (copo de plástico) enterrados no solo do PECB.

\subsubsection{Comportamento alimentar e Dieta}

Seguindo a metodologia de Izar (2004), as observações foram realizadas através do método de "amostragem de scan instantâneo" (Altmann, 1974), com duração de 1 minuto a intervalos de 5 minutos, registrando-se a atividade de cada indivíduo - locomoção, descanso, forrageamento, e locomoção mais forrageamento (segundo Terborgh, 1983). 
Nos dados sobre o forrageamento, quando possível, foram identificados os itens alimentares consumidos. Os dados de frutos foram utilizados para calcular o número de espécies de frutos das quais os animais se alimentavam a cada dia e por mês, e o número médio de árvores visitadas por dia e por mês, como indicativos da abundância de frutos no habitat. Seguindo a mesma metodologia, foi determinado o tamanho das fontes de alimento, usando 'focal de árvore de alimentação' (FTFS - “Feeding tree focal samples”, Strier, 1989), que é o intervalo de tempo entre o momento em que primeiro indivíduo do grupo entra e o momento em que o último sai de uma árvore de alimentação. Simultaneamente, foi registrado o número de indivíduos que se alimentaram juntos na mesma árvore, sendo essa a medida de subunidade de alimentação.

\subsubsection{Competição por alimento}

Mensalmente, também foi avaliada a competição intragrupo por alimento, para os grupos Pimenta e Laranja, calculada através da obtenção de energia per capita por mês. Seguindo Janson (1988), como medida de obtenção de energia per capita, calculou-se o PCIM - "Per capita individual minutes": número de minutos de alimentação em uma fonte vezes o número de membros do grupo que se alimentaram (IM - "Individual minute"), dividido pelo tamanho total do grupo.

PCIM $=\frac{\text { tempo de alimentação } \times \mathrm{n}^{\mathrm{o}} \text { indivíduos que alimentam juntos }}{\mathrm{n}^{\mathrm{o}} \text { total de indivíduos do grupo }}$

Outro método utilizado foi o de "todas as ocorrências" (Altmann, 1974), para o registro de:

1. conflito agonístico entre membros do grupo: exibições de expressão facial ameaçadora e atitudes de submissão, onde os indivíduos que brigavam sem agressão física, por 
motivos diversos: fonte alimentar, estro, conflito mãe - infante, defesa do infante pela mãe;

2. coalizões: os indivíduos se juntam para expulsar ou brigar com outro;

3. catação: limpeza de parasitas, manter relação de dominância e outros comportamentos sociais, como atração ao sexo oposto e apoio na coalizão;

4. brincadeira;

5. partilha de alimento: quando um indivíduo reparte o alimento para dividir com outro; Para os itens de 1 a 5 foram identificados, quando possível, os indivíduos envolvidos e o contexto;

6. encontro entre grupos sociais em que eram anotados o local, o contexto (fonte alimentar, locomoção), o comportamento dos animais, o número de indivíduos de cada grupo e o resultado do encontro;

7. presença de potenciais predadores, registrou-se a reação dos animais, o contexto e o resultado do encontro.

\subsection{Análise dos dados}

A análise para verificar se os animais forrageiam em fissão-fusão foi feita através do registro diário de todos os membros do grupo que foram observados pelo menos uma vez durante o dia com o grupo ou o subgrupo (os animais que foram seguidos desde que deixaram a árvore de dormida), seguindo Lynch (2001), para comparação dos dados. Esses dados permitiram calcular os tamanhos médio, máximo e mínimo dos subgrupos por mês e analisar o tipo de composição de subgrupos em termos de classes de sexo e idade dos grupos Pimenta, Laranja e de todos os outros grupos. Os subgrupos em que nem todos os indivíduos adultos eram identificados foram excluídas da análise. 
Para testar a hipótese de que fissão-fusão é um fenômeno restrito ao maior grupo (Pimenta), ou típico de toda a população, foi efetuada uma análise de variância (ANOVA) em que foram comparados os tamanhos médio, máximo e mínimo dos subgrupos por mês de acordo com o fator grupo: Pimenta, Laranja e todos os outros grupos.

Para testar a hipótese nula de que não há diferença na freqüência de ocorrência dos tamanhos de subgrupos entre os grupos (Pimenta, Laranja e Outros), foi efetuado um Teste Qui-quadrado para os subgrupos dos grupos Pimenta, Laranja e todos os outros grupos.

Para testar a hipótese nula de que não há diferença entre indivíduos adultos do grupo Pimenta quanto ao tamanho do subgrupo à qual se associam foi efetuada uma análise de variância (ANOVA) para comparar o tamanho do subgrupo de acordo com fator indivíduo.

Para testar a hipótese nula de que não há diferença na freqüência de ocorrência dos diferentes tipos de composição de subgrupo foi efetuado um Teste Qui-quadrado para os grupos Pimenta, Laranja e todos os outros grupos.

Para verificar se há correlação entre o número de machos, de fêmeas, de jovens e de infantes num subgrupo, do grupo Pimenta, foi efetuado o teste de Kendall.

Para testar a hipótese nula de que não há diferença nas associações entre indivíduos do grupo Pimenta de acordo com o gênero foi efetuada uma análise de variância (ANOVA) em que foram comparados os índices de Jaccard de duplas macho-macho, fêmea-fêmea e machofêmea.

Para verificar se há relação entre o tempo de alimentação em fontes de frutos e o tamanho das subunidades de alimentação foi feito o teste de correlação de Pearson. Este teste permitiu verificar se o FTFS, ou seja, o intervalo de tempo entre o momento em que primeiro indivíduo do grupo Pimenta entra e o momento em que o último sai de uma árvore de alimentação, estava correlacionado com o tamanho das subunidades. 
Para testar a hipótese nula de que não havia diferença na obtenção de energia per capita entre os anos 2002 e 2003 a 2006, foi efetuada uma análise de variância (ANOVA). Como a fissão permanente de grupos em 2002 foi relacionada a uma diminuição significativa na obtenção de energia per capita (Izar, 2004), foram comparados os valores médios de PCIM obtidos no presente estudo com os valores obtidos em 2002. Para esse teste, foi considerado cada ano de 2003, 2004 e 2005, como fatores, todos os meses de 2002 exceto Junho, como outro fator e Junho de 2002, quando a divisão dos grupos ocorreu, como outro fator.

Para testar a hipótese nula de que não há relação entre as condições climáticas (temperatura pluviosidade e umidade) e a biomassa de frutos e insetos na área de estudo, foi feita uma análise de Modelo Linear Geral.

Para testar a hipótese nula de que não há diferença na biomassa de frutos e insetos entre os anos de estudo, foi efetuada uma análise de variância (ANOVA).

Para testar a hipótese nula de que não há relação entre o tamanho de subgrupos e a abundância de frutos e tamanho das fontes de alimento, foi feita uma análise de regressão múltipla com tamanho médio (nindmed), máximo (nindmax) e mínimo (nindmin) de subgrupo por mês como variáveis dependentes. Neste teste, foram utilizados cinco conjuntos de variáveis independentes: (1) distribuição das fontes: número total de espécies visitadas por mês (nspmes), número máximo de espécies visitadas em um dia por mês (nspmax), número mínimo de espécies visitadas em um dia por mês (nspmin), número médio de espécies visitadas por dia por mês (nspmed), número médio de árvores visitadas por dia por mês (narvmed), número máximo de árvores visitadas por dia por mês (narvmax), número mínimo de árvores visitadas por dia por mês (narvmin); (2) tamanho das fontes: tamanho médio mensal das subunidades de alimentação (medindfont), tamanho máximo mensal das subunidades de alimentação (maxindfont), FTFS médio por mês (medtemfont), FTFS máximo por mês (maxtemfont), PCIM médio por mês (immed); (3) abundância de alimento: biomassa 
de frutos por mês (fruha), e biomassa de invertebrados por mês (inha); (4) estações seca (abril a setembro) e úmida (outubro a março); e (5) dados mensais climáticos como temperatura média, máxima e mínima; umidade relativa do ar média, máxima e mínima e total de chuva. As variáveis independentes dos dois primeiros conjuntos foram altamente correlacionadas entre si, assim, foram utilizadas apenas (nspmed) e (medindfont) como variáveis independentes para distribuição e tamanho das fontes de frutos. 


\section{Resultados}

\subsection{Os grupos de macacos-prego apresentam organização social do tipo fissão e fusão?}

\subsubsection{Formação e tamanho de subgrupos}

Os dados de tamanho dos subgrupos do grupo Pimenta foram agrupados por dia e mês de 2003 a 2006. O tamanho dos subgrupos variou de 1 a 18 indivíduos, com os tamanhos mais freqüentes entre 7 e 10 indivíduos, seguidos de indivíduos solitários (Figura 4). O tamanho médio mensal variou a cada mês ao longo do período de estudo, havendo grande variação entre os dias de cada mês (Figura 5). Todos os indivíduos do grupo foram visto juntos apenas um dia.

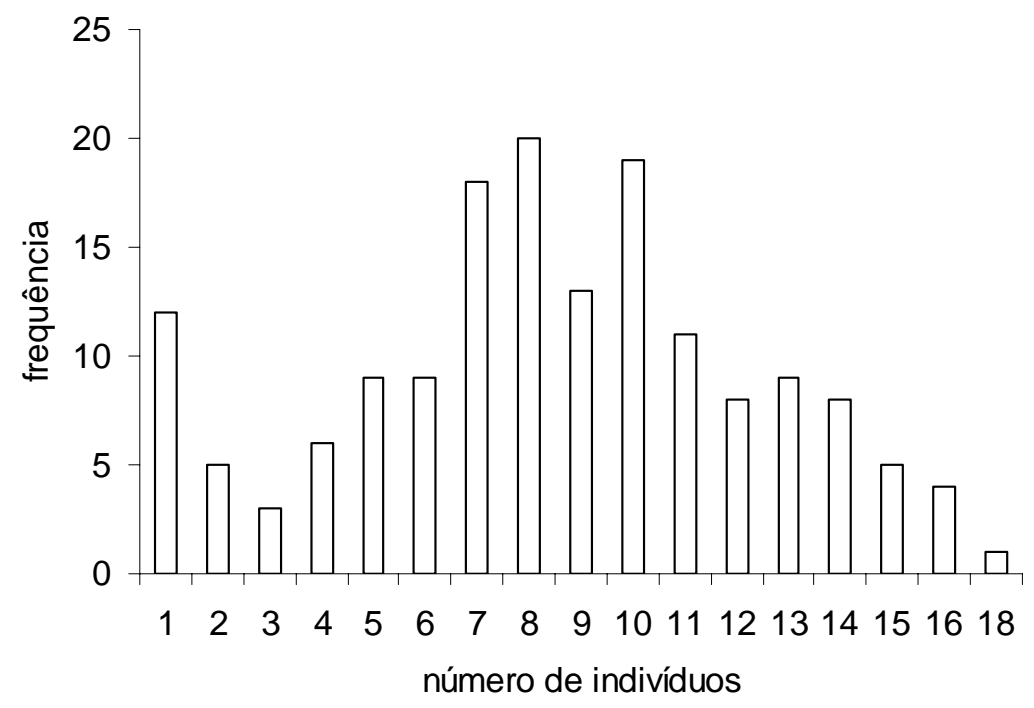

Figura 4 - Histograma de freqüência de tamanho de subgrupos do grupo Pimenta no PECB, entre Maio de 2003 e Dezembro de 2005.

Para o grupo Laranja, o tamanho dos subgrupos variou entre 1 a 15 indivíduos e o tamanho de subgrupo mais freqüente foi de 7 a 8 indivíduos (Figura 6), o tamanho médio mensal também variou a cada mês (Figura 7). Para os outros grupos, o tamanho também variou de 1 a 15 indivíduos, sendo mais freqüente a observação de 5 a 8 indivíduos (Figura 8), com variação do tamanho médio mensal a cada mês (Figura 9). 


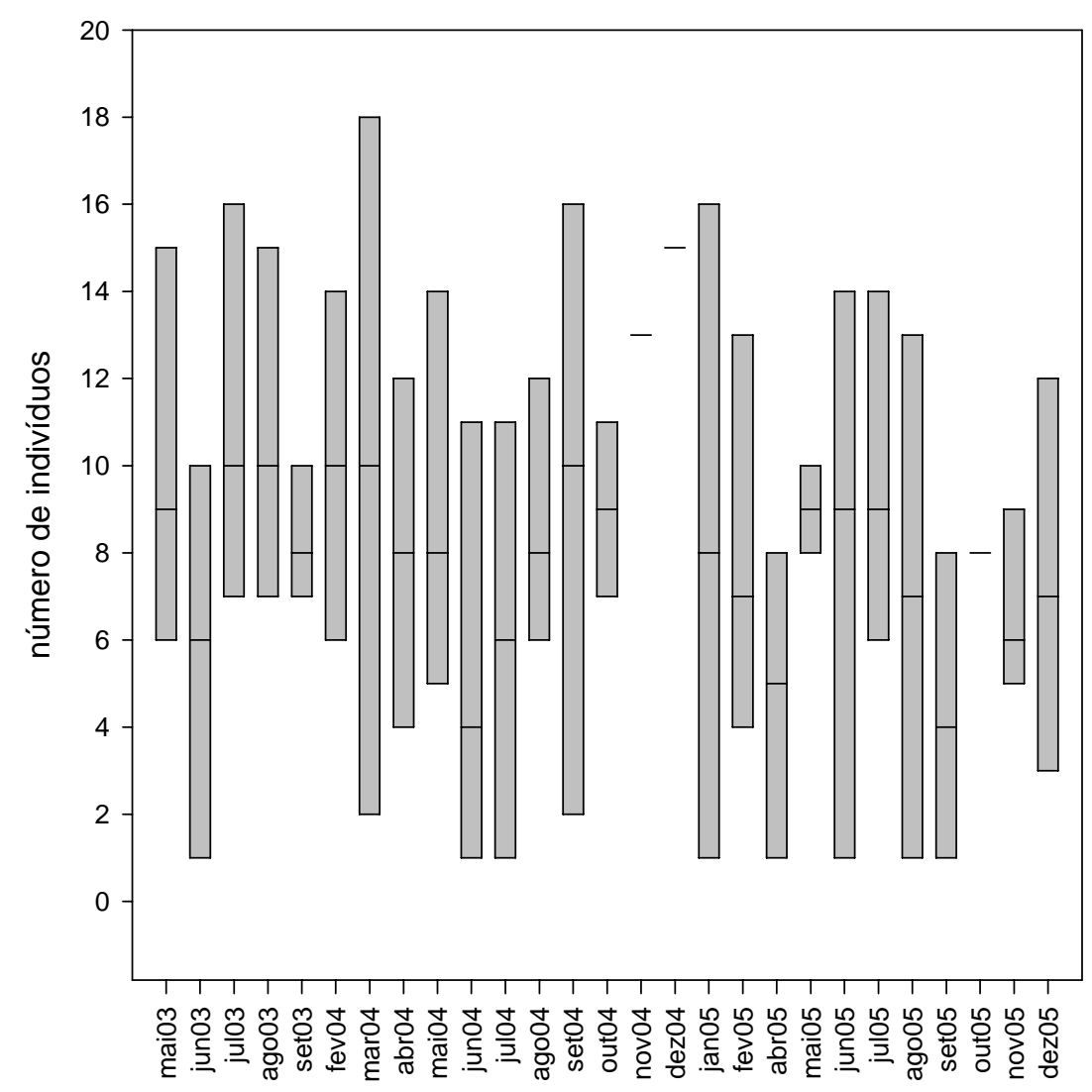

Figura 5 - Tamanho de subgrupos do grupo Pimenta no PECB, com número máximo, médio e mínimo de indivíduos, entre Maio de 2003 e Dezembro de 2005.

Ao longo do período de estudo, houve variação significativa do tamanho dos subgrupos de acordo com o grupo $(\mathrm{F}=8,356 ; \mathrm{gl}=2 ; \mathrm{p}<0,001)$. Os subgrupos do grupo Pimenta foram significativamente maiores (média $\pm \mathrm{dp}=8,43 \pm 3,94 ; \mathrm{LSD}=1,67 ; \mathrm{p}<0,005$ ) que os do Grupo Laranja (média $\pm \mathrm{dp}=6,76 \pm 3,07 ; \mathrm{LSD}=1,67 ; \mathrm{p}<0,005$ ) e de que todos os outros grupos (média $\pm \mathrm{dp}=6,43 \pm 3,02 ; \mathrm{LSD}=2,00 ; \mathrm{p}<0,005$ ) observados no PECB (Figura 10). Não houve diferença entre o tamanho dos subgrupos do grupo Laranja e de todos os outros grupos observados.

Não houve diferença na freqüência de ocorrência dos diferentes tamanhos de subgrupos entre os grupos Pimenta, Laranja e todos os outros grupos $\left(\chi^{2}=34,56 ; \mathrm{gl}=32 ; \mathrm{p}=\right.$ $0,346)$. 


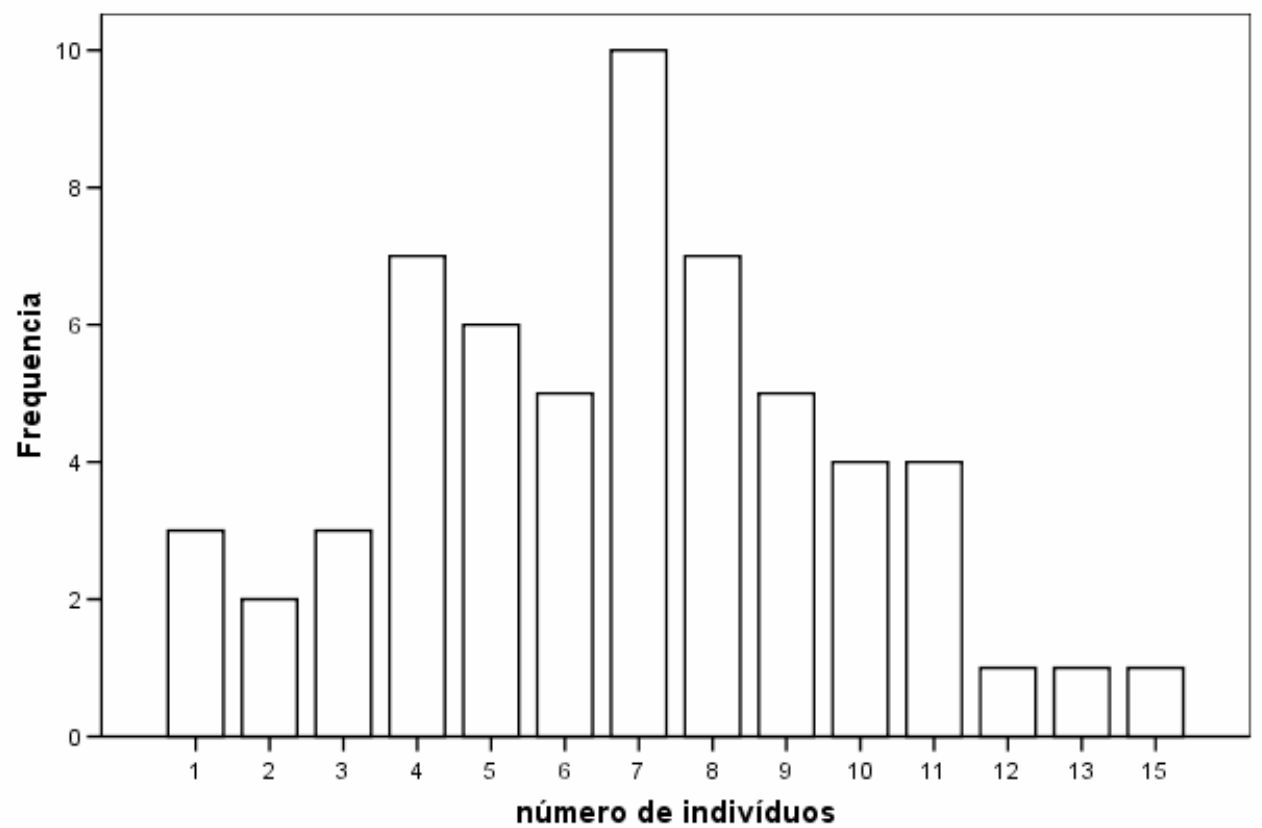

Figura 6 - Histograma de freqüência de tamanho de subgrupos do grupo Laranja no PECB, entre Janeiro de 2003 e Julho de 2005.

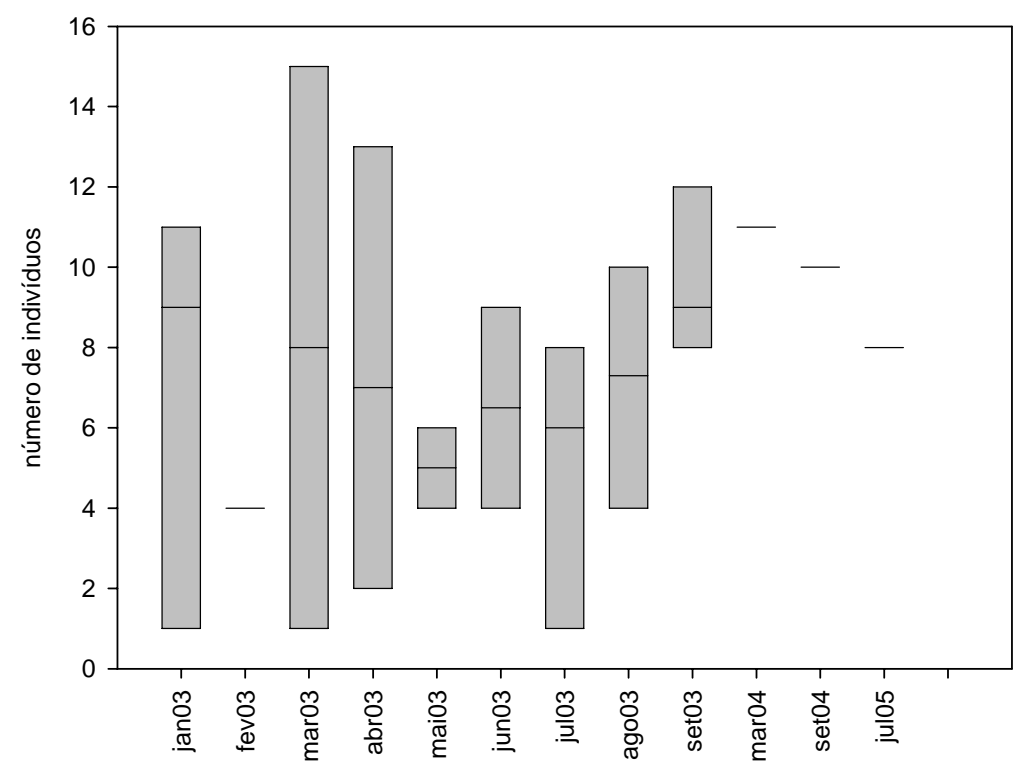

Figura 7 - Tamanho de subgrupos do grupo Laranja no PECB, com número máximo, médio e mínimo de indivíduos, entre Janeiro de 2003 e Julho de 2005. 


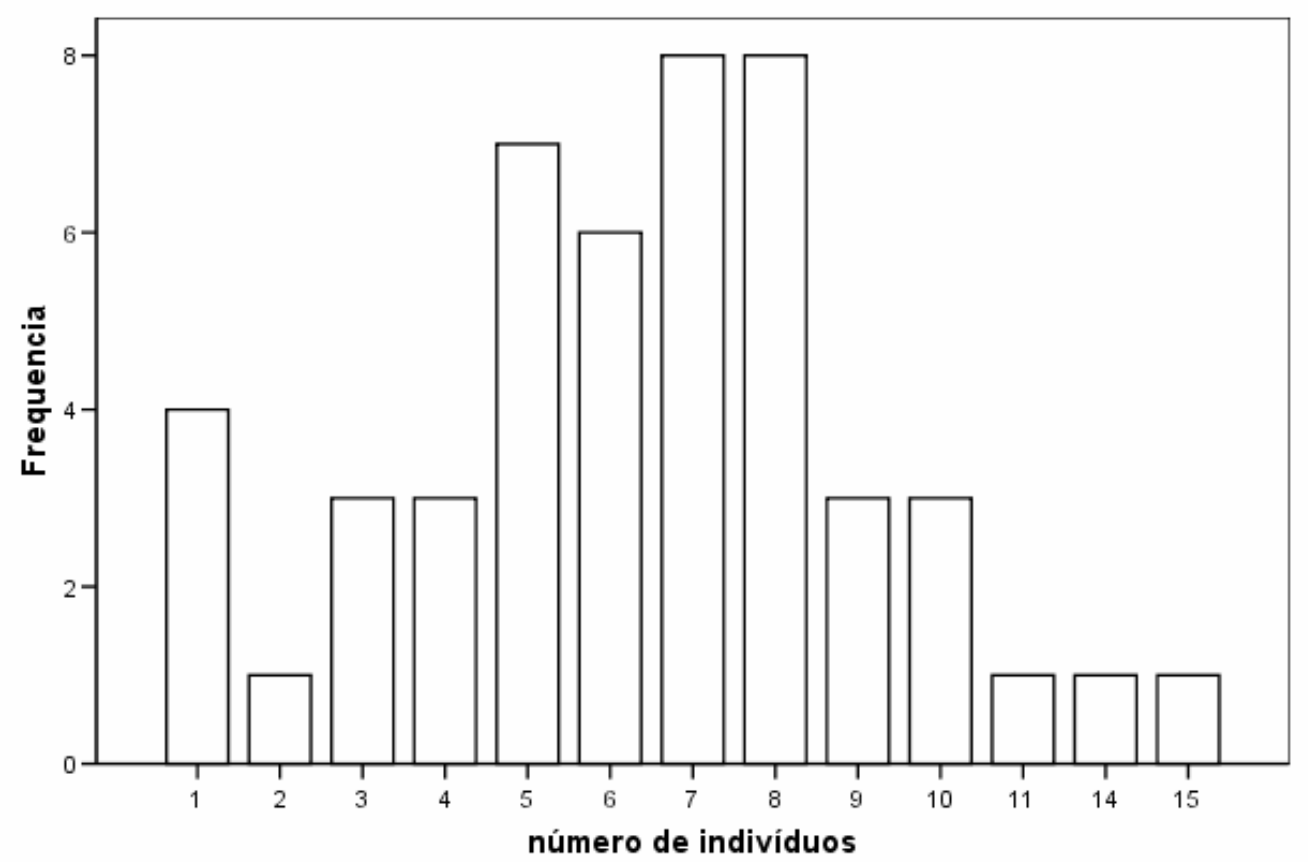

Figura 8 - Histograma de freqüência de tamanho de subgrupos de outros grupos no PECB, entre Janeiro de 2003 e Dezembro de 2005.

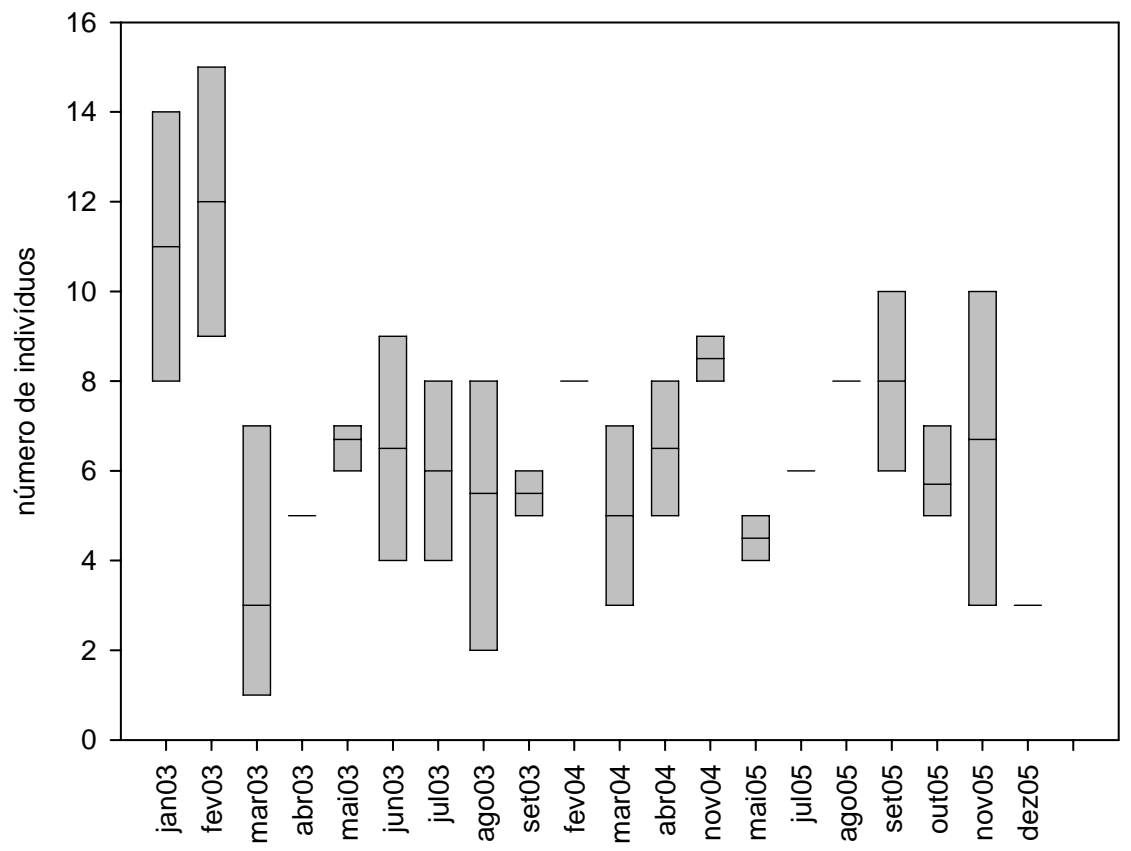

Figura 9 - Tamanho de subgrupos de outros grupos no PECB, com número máximo, médio e mínimo de indivíduos, entre Janeiro de 2003 e Dezembro de 2005. 


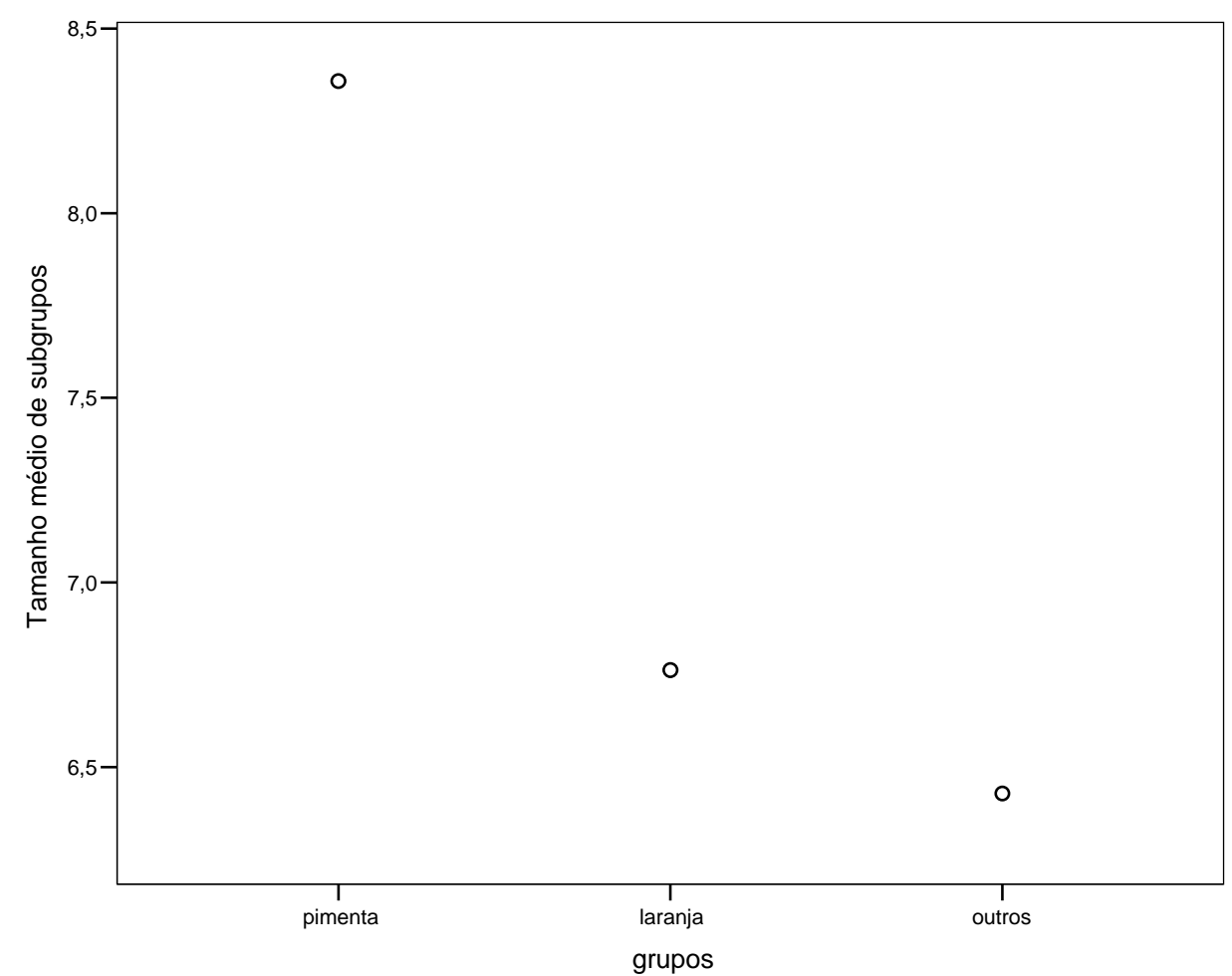

Figura 10 - Tamanho médio dos subgrupos dos grupos Pimenta, Laranja e outros grupos.

Para o grupo Pimenta, não houve diferença entre os indivíduos adultos quanto à presença em subgrupos de diferentes tamanhos $(\mathrm{F}=1,11 ; \mathrm{gl}=12 ; \mathrm{p}<0,5$; Figura 11). A média do tamanho de subgrupos para cada indivíduo adulto e sub-adulto variou de 10,5 a 12,19 indivíduos. Essa análise não foi efetuada para o grupo Laranja e para os outros grupos.

\subsubsection{Composição dos subgrupos}

Para o grupo Pimenta, foram observadas vinte e uma composições diferentes de subgrupos com respeito ao número de machos adultos, de fêmeas adultas e de juvenis, as quais diferiram em freqüência de ocorrência $\left(\chi^{2}=130,369 ; \mathrm{gl}=20 ; \mathrm{p}<0,001\right)$.

Os subgrupos eram compostos, mais freqüentemente, por: a) dois machos, três fêmeas, mais de um juvenil, seguido por b) um macho, duas fêmeas, mais de um juvenil e c) um macho, três fêmeas, mais de um juvenil. Subgrupos com uma ou mais de uma fêmea adulta foram mais comuns que aqueles contendo apenas machos. Subgrupos com um e dois machos 
seguidos de fêmeas e juvenis foram mais comuns do que três ou quatro machos. Subgrupos com os quatro machos foram vistas apenas duas vezes, uma em 2004 e outra em 2005 (Figura 12).

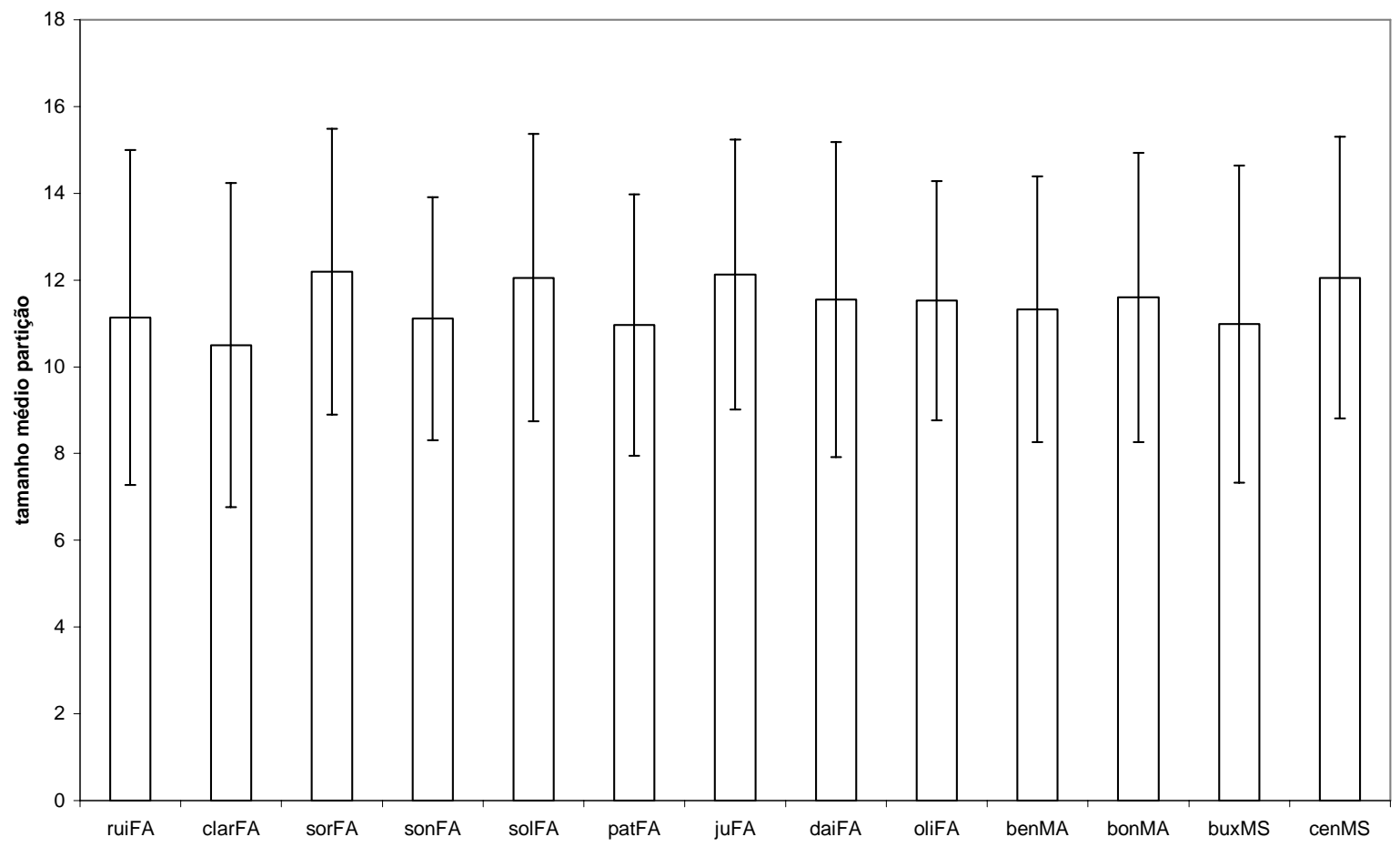

Figura 11 - Tamanho médio dos subgrupos dos indivíduos, adulto e sub-adulto, do grupo Pimenta. (FA - fêmea adulta; MA - macho adulto; MS - macho sub-adulto)

Para o grupo Laranja, foram observadas quinze composições diferentes de subgrupos com respeito ao número de machos adultos, de fêmeas adultas e de juvenis, as quais diferiram em freqüência de ocorrência $\left(\chi^{2}=68,207 ; \mathrm{gl}=14 ; \mathrm{p}<0,001\right)$.

Os subgrupos eram compostos, mais freqüentemente por: a) um macho, duas fêmeas, mais de um juvenil, b) seguido pela mesma formação com apenas uma fêmea e c) dois machos, duas fêmeas, mais de um juvenil. Juvenis foram observados mais freqüentemente com as fêmeas do que com machos. Não houve subgrupos com os quatro machos (Figura 13). 


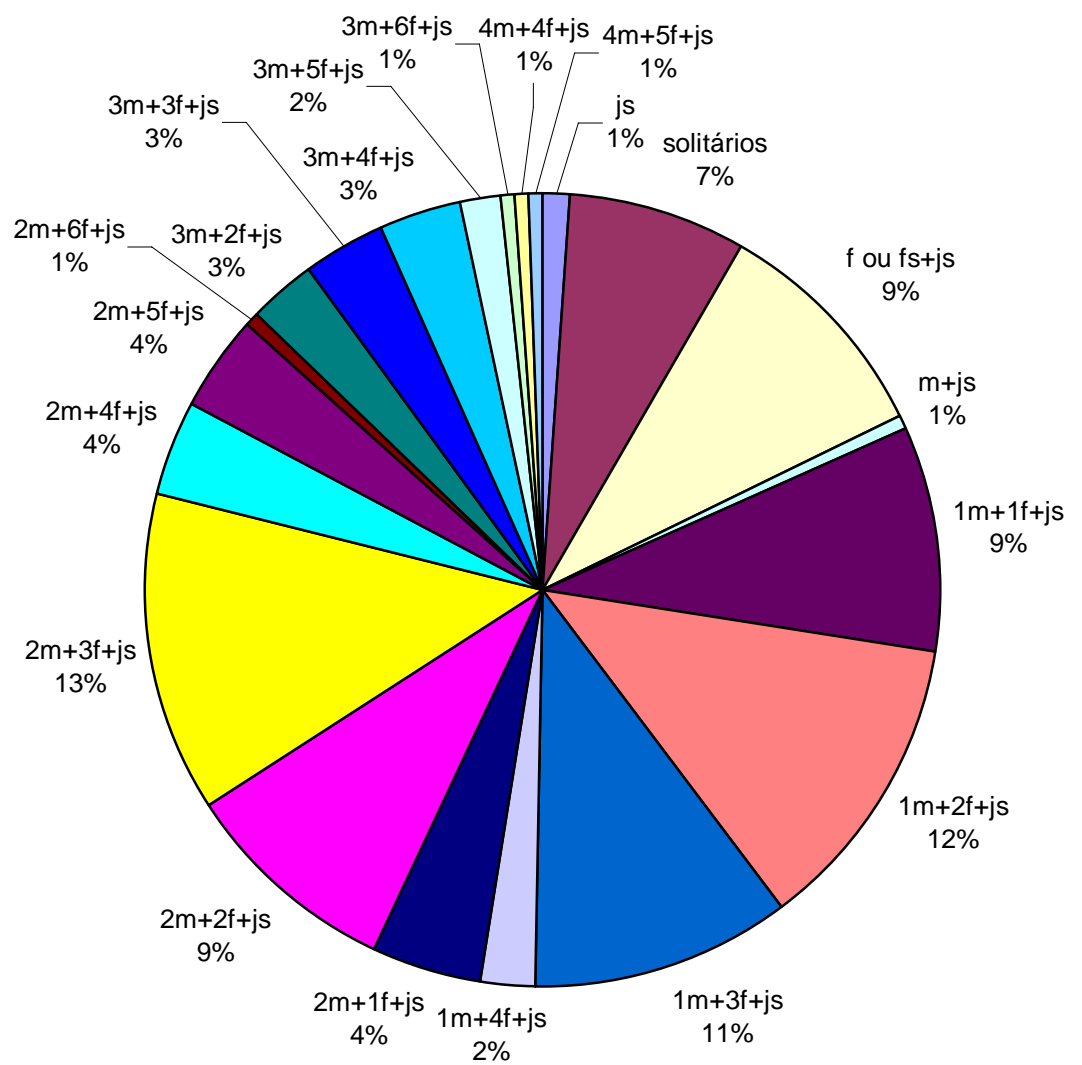

Figura 12 - Proporção de diferentes composições de subgrupos (baseadas em classes de sexo e idade) do grupo Pimenta. (m - macho; f - fêmea; fs - fêmeas; js - juvenis)

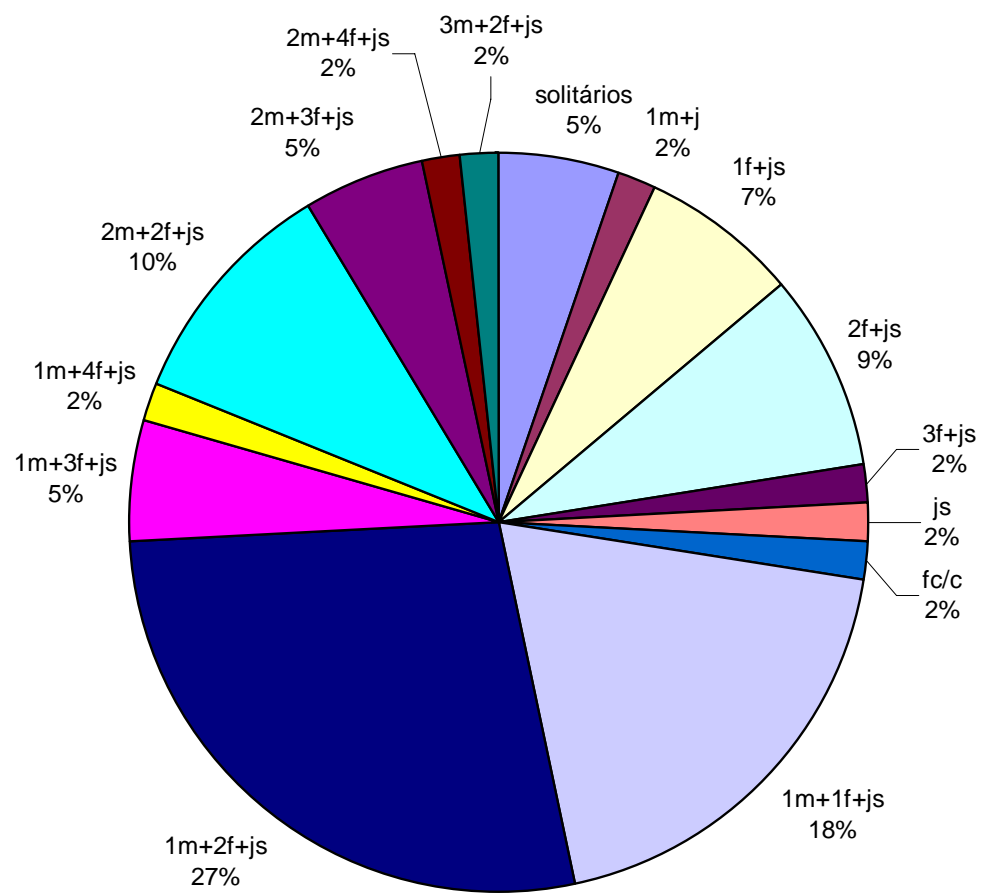

Figura 13 - Proporção de diferentes composições de subgrupos (baseadas em classes de sexo e idade) do grupo Laranja. (m - macho; $\mathrm{f}$ - fêmea; fc/c - fêmea com filhote; js - juvenis) 
Para os outros grupos, foram observadas quinze composições diferentes de subgrupos com respeito ao número de machos adultos, de fêmeas adultas e de juvenis, as quais diferiram em freqüência de ocorrência $\left(\chi^{2}=21,102 ; \mathrm{gl}=14 ; \mathrm{p}<0,001\right)$.

Os subgrupos eram compostos, mais freqüentemente por: a) um macho, duas fêmeas, mais de um juvenil, b) pela mesma formação com apenas uma fêmea e c) dois machos, duas fêmeas, mais de um juvenil e também por um macho, três fêmeas, mais de um juvenil. Houve a mesma proporção de indivíduos solitários e de juvenis com as fêmeas (Figura 14).

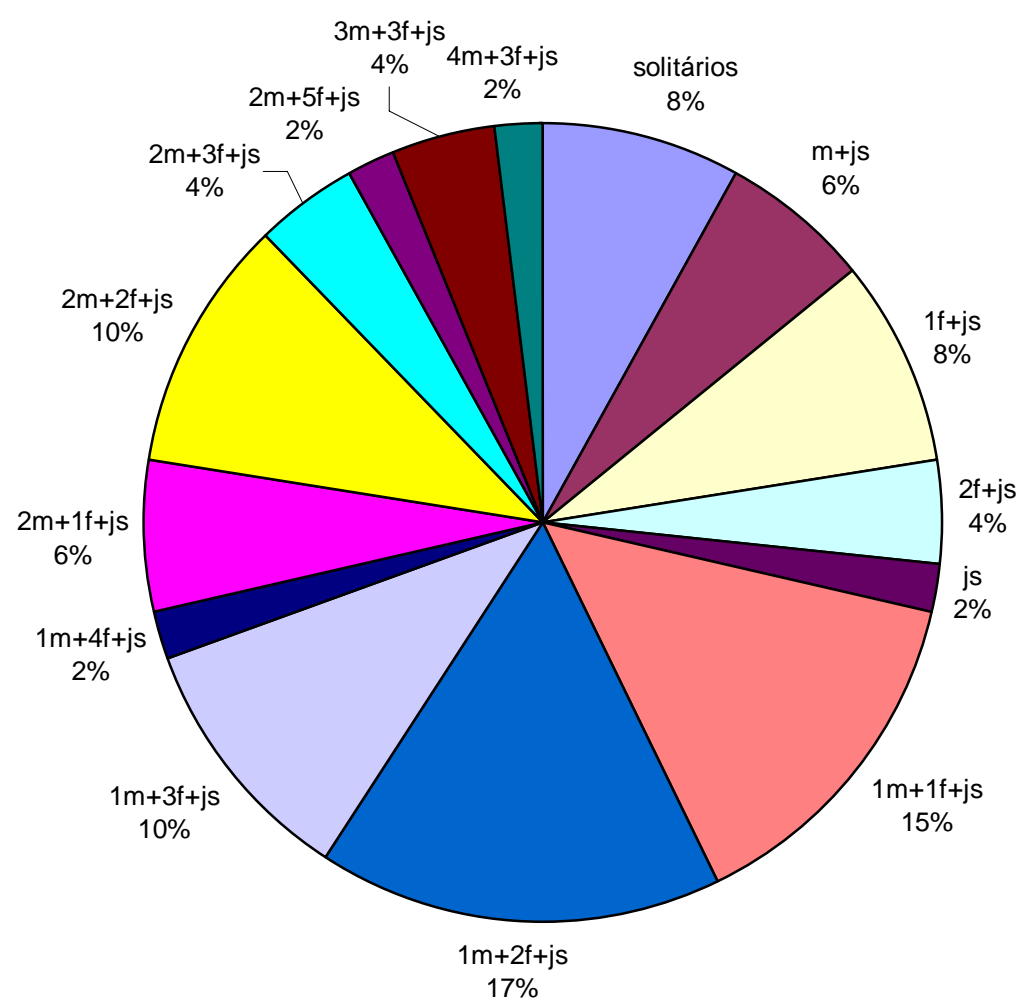

Figura 14 - Proporção de diferentes composições de subgrupos (baseadas em classes de sexo e idade) de outros grupos. (m - macho; f - fêmea; js - juvenis)

Para o grupo Pimenta, o número de machos por subgrupo foi proporcional ao número de fêmeas (Figura 15). O coeficiente de concordância de Kendall (W) mostrou que o número de machos adultos foi proporcional ao número de fêmeas adultas ( $\mathrm{W}=0,531 ; \mathrm{p}<0,001)$, e ao de jovens $(\mathrm{W}=0,442 ; \mathrm{p}<0,001)$. Já o número de fêmeas adultas foi proporcional ao número 
de machos sub-adultos ( $\mathrm{W}=0,210 ; \mathrm{p}<0,001)$, de jovens $(\mathrm{W}=0,475 ; \mathrm{p}<0,001)$ e de infantes $(\mathrm{W}=0,314 ; \mathrm{p}<0,001)$. O número de machos sub-adultos foi proporcional ao número de jovens $(\mathrm{W}=0,256 ; \mathrm{p}<0,001)$ e de infantes $(\mathrm{W}=0,389 ; \mathrm{p}<0,001)$. Essa análise não foi efetuada para o grupo Laranja e para os outros grupos.

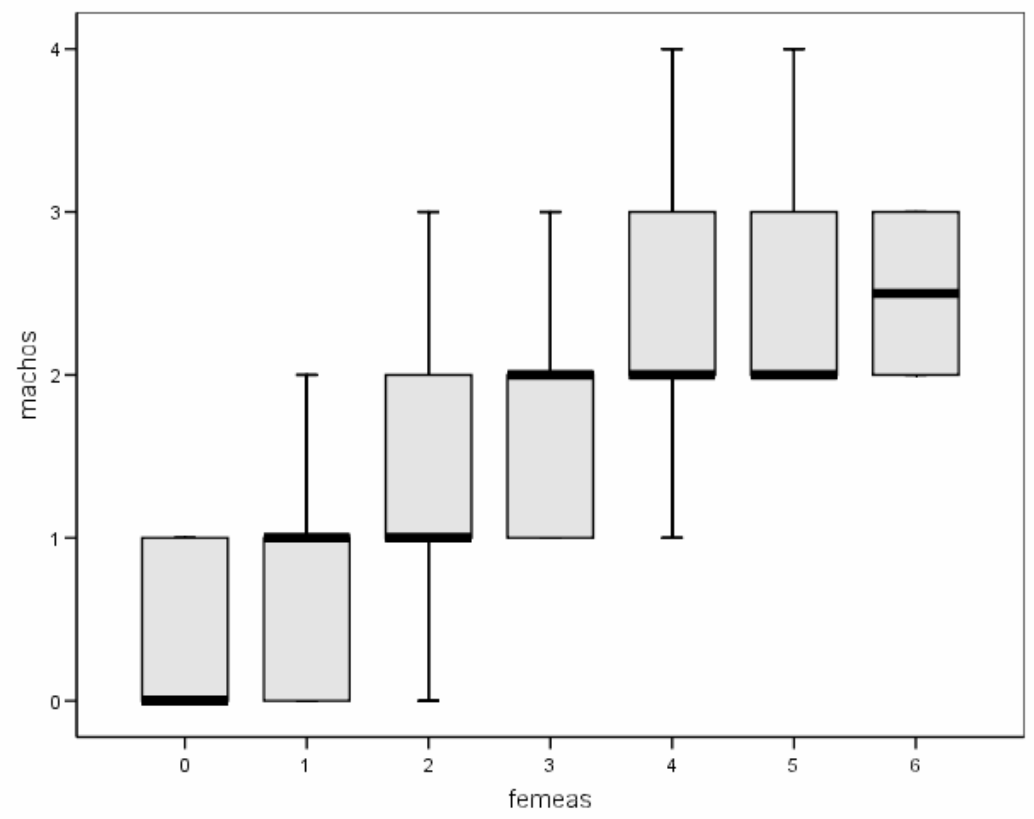

Figura 15 - Número de machos em função do número de fêmeas em subgrupos do grupo Pimenta. O traço em negrito mostra a freqüência mediana da composição, o retângulo mostra a faixa de variação mais freqüente e as barras mostram os casos extremos.

Para o grupo Pimenta, houve uma mudança na composição ao longo de 4 anos de estudo, com a imigração de machos sub-adultos e uma fêmea sub-adulta e emigração de fêmeas adultas.

Em 2003, duas fêmeas adultas, BEA e CLE, não foram mais vistas com o grupo, a partir de julho e de setembro, respectivamente. A fêmea adulta SOL não foi mais vista com o grupo após maio de 2004, e a fêmea adulta SOR, após abril de 2005. Dois novos machos subadultos passaram a serem observados com o grupo em 2004: BUX, a partir de fevereiro e CEN, a partir de setembro. Finalmente, a partir de junho de 2005, uma nova fêmea sub-adulta, OLI, passou a integrar o grupo. 
Os machos sub-adultos, BUX e CEN, apresentaram um comportamento semelhante ao tentar entrar no grupo Pimenta, sempre forrageando na periferia, a aproximadamente 20 metros do macho dominante. Quando se aproximavam das fruteiras, ocorriam brigas e a expulsão deles. Durante os quinze dias do mês de março em que o grupo Pimenta foi acompanhado, BUX foi perseguido e expulso de perto do grupo em $26,7 \%$ do tempo pelos machos adultos BEN e BON, principalmente quando estavam nas fruteiras com as fêmeas com cria e os jovens. As brigas intragrupo com BUX ocorreram até novembro de 2004, quando as fêmeas ainda foram vistas expulsando-o da fruteira. Depois não foram registradas brigas intragrupo, ele permanecia periférico ao grupo e ainda foi visto duas vezes fora do grupo Pimenta, em junho e julho de 2004.

As brigas intragrupo associadas à presença de CEN ocorreram em alguns meses. Em setembro, ele começou a ser expulso por BEN, depois, em dezembro, (07/12/2004) a fêmea adulta PAT ameaçou CEN quando este se envolve numa briga com seu infante, em janeiro (09/01/2005), o macho adulto BEN defendeu um jovem contra ele e em fevereiro (02/02/2006), o outro macho adulto BON o afastou do grupo. Depois disso não foi visto mais esse tipo de conflito no grupo Pimenta, o CEN permanecia periférico ao grupo e longe dos machos adultos. Somente em junho de 2005, CEN foi visto fora do grupo Pimenta.

A entrada de uma fêmea sub-adulta, a OLI, no grupo Pimenta, foi um processo diferente. Ela seguia o macho dominante, BEN, apresentando exibições típicas do comportamento proceptivo característico do estro (Janson, 1984; Carosi et al., 2005), durante três dias nos meses de junho, julho e agosto. O comportamento proceptivo caracteriza-se pela fêmea como indivíduo ativo durante o estro, uma vez que ela segue, continuamente, o macho dominante do grupo. Ela se aproxima dele com caretas, vocalização distinta e postura submissa e ele a agride várias vezes por se aproximar muito durante o forrageamento. Essa preferência ao macho dominante do grupo deve ser uma estratégia para ter acesso a melhores 
fontes de alimento, principalmente nos períodos de escassez, e tolerância para ela e sua cria, pela certeza da paternidade (Janson, 1984; Izar et al., no prelo).

De acordo com a literatura, quando OLI se aproximava muito do BEN durante o forrageamento de fruteiras ou folhas, ele a expulsava de perto, mas ela permanecia a uns 5 metros de distância com vocalização de choro. No mês de julho de 2005, a fêmea adulta PAT expulsou a OLI da fruteira. Depois não houve mais brigas intragrupo e ela permanecia periférica ao grupo ou só ao lado dos jovens.

Portanto, a entrada de machos e fêmeas em um novo grupo seguiu um padrão distinto. Os machos foram perseguidos e expulsos pelo macho dominante e as fêmeas apresentaram comportamento proceptivo ao macho dominante, para serem aceitos no grupo.

\subsubsection{Associações diádicas do grupo Pimenta}

Ao longo da pesquisa, foi encontrada uma variação significativa na associação entre díades de indivíduos adultos do grupo Pimenta, de acordo com o sexo $(\mathrm{F}=3,93 ; \mathrm{gl}=2 ; \mathrm{p}<$ 0,05; Figura 16). Fêmeas formaram associações mais fortes com machos do que com fêmeas $(\operatorname{LSD}=0,09 ; \mathrm{p}<0,01)$. A média de associação entre fêmeas foi de $0,19 \pm 0,19$, entre machos foi de $0,23 \pm 0,20$ e entre macho e fêmea foi de $0,28 \pm 0,23$. Os valores máximos entre as associações foram: fêmea-fêmea $=0,80$, macho-macho $=0,67$ e macho-fêmea $=0,77$. 


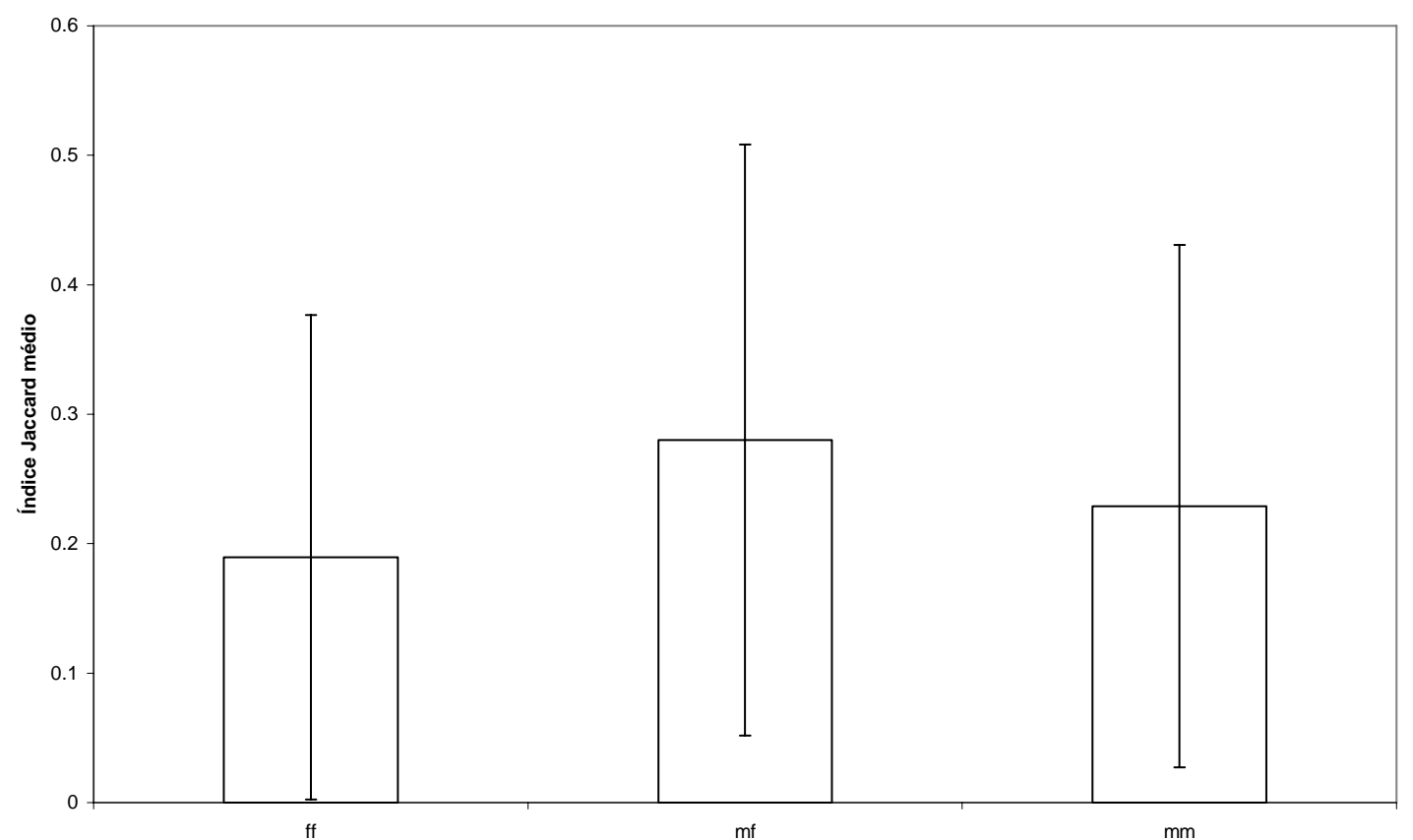

Figura 16 - Freqüência de associações entre fêmeas adultas (FF), entre machos e fêmeas adultos (MF) e entre machos adultos (MM) de acordo com o índice de Jaccard médio.

Ao observar as relações diádicas de cada indivíduo adulto e sub-adulto do grupo Pimenta, nenhuma díade teve índice igual a 1,00, o que significaria a presença conjunta dos indivíduos no mesmo subgrupo em todas as observações. Entretanto, os valores acima de 0,50 foram considerados fortes relações entre os indivíduos. Em 2003, havia fortes relações do macho BEN com as fêmeas RUI, SOR, SÔN e SOL, do macho BON com as fêmeas SOR, SÔN e SOL e uma relação forte entre as fêmeas SOR e SOL (Tabela 2). Ao contrário destes cinco indivíduos, as fêmeas BEA e CLE não formaram nenhuma díade forte e no ano seguinte não foram mais vistas com o grupo Pimenta. Em 2004, as díades mais fortes foram: do BON com as fêmeas PAT, JUL e CLA, do BUX com CLA e o BEN continuava com a SOR, mas a fêmea SOL não apresentou nenhuma díade forte e não foi mais vista no ano seguinte (Tabela 3). O ano de 2004 apresentou uma grande fluidez entre os membros do grupo, demonstrado pelos baixos valores do Índice de Jaccard, como por exemplo a fêmea RUI, que tinha uma forte relação com um macho no ano anterior e não apresentou os altos valores com nenhum indivíduo em 2004, e pela presença de novos indivíduos, sendo dois machos sub-adultos 
(BUX, CEN) e mais três fêmeas adultas (DAI, PAT, JUL), no grupo Pimenta. Já em 2005, as díades mais fortes foram entre: BEN e do CEN com as fêmeas PAT e RUI, entre BEN e CEN, entre PAT e RUI, o que demonstra a preferência de um grupo constante entre os quatro indivíduos. O macho BON apresentou uma forte relação com a fêmea JUL e a fêmea SOR obteve baixas relações com todos os membros e não foi mais vista com o grupo Pimenta no ano seguinte (Tabela 4). No começo do ano de 2006, as relações mais fortes foram entre: o macho BEN com as fêmeas PAT e OLÍ, e entre os indivíduos CLA, JUL, BON, CEN e BUX (Tabela 5). Neste ano, foram mantidas as relações do ano anterior, com exceção do CEN que demonstrou mais variação em suas associações.

Tabela 2 - Índice de Jaccard para os indivíduos adultos e sub-adultos do grupo Pimenta no PECB durante o ano de 2003. (FA - fêmea adulta; MA - macho adulto)

\begin{tabular}{c|ccccccc|cc}
\hline $\mathbf{2 0 0 3}$ & \multicolumn{10}{c|}{ FA } & \multicolumn{2}{c}{ MA } \\
\hline \multirow{7}{*}{ FA } & & cle & cla & sor & sôn & bea & sol & ben & bon \\
& rui & 0,14 & 0 & $\mathbf{0 , 5 0}$ & 0,33 & 0,14 & 0,36 & $\mathbf{0 , 6 4}$ & $\mathbf{0 , 5 0}$ \\
& cle & & 0 & 0,09 & 0 & 0 & 0 & 0,09 & 0 \\
& cla & & & 0 & 0,22 & 0 & 0,15 & 0,08 & 0,17 \\
& sor & & & & 0,43 & 0,09 & $\mathbf{0 , 7 7}$ & $\mathbf{0 , 6 9}$ & $\mathbf{0 , 5 7}$ \\
& sôn & & & & 0 & $\mathbf{0 , 5 0}$ & $\mathbf{0 , 5 4}$ & $\mathbf{0 , 5 4}$ \\
& bea & & & & & 0,08 & 0,09 & 0,09 \\
& sol & & & & & & $\mathbf{0 , 5 3}$ & $\mathbf{0 , 7 7}$ \\
\hline MA & ben & 10 & & & & & & & 0,47 \\
\hline
\end{tabular}

Tabela 3 - Índice de Jaccard para os indivíduos adultos e sub-adultos do grupo Pimenta no PECB durante o ano de 2004. (FA - fêmea adulta; MA - macho adulto; MS - macho sub-adulto)

\begin{tabular}{|c|c|c|c|c|c|c|c|c|c|c|c|}
\hline \multirow[t]{2}{*}{2004} & & \multicolumn{6}{|c|}{ FA } & \multicolumn{2}{|c|}{ MA } & \multicolumn{2}{|c|}{ MS } \\
\hline & & pat & jul & sor & cla & dai & sol & ben & bon & bux & cen \\
\hline \multirow{7}{*}{ FA } & rui & 0,29 & 0,30 & 0,18 & 0,22 & 0,22 & 0,10 & 0,26 & 0,25 & 0,26 & 0,20 \\
\hline & pat & & 0,47 & 0,17 & 0,39 & 0,40 & 0,05 & 0,16 & 0,61 & 0,43 & 0,16 \\
\hline & jul & & & 0,18 & 0,42 & 0,31 & 0,08 & 0,24 & 0,57 & 0,43 & 0,16 \\
\hline & sor & & & & 0,20 & 0,24 & 0,06 & 0,50 & 0,15 & 0,20 & 0,06 \\
\hline & cla & & & & & 0,27 & 0,10 & 0,24 & 0,53 & 0,54 & 0,06 \\
\hline & dai & & & & & & 0,10 & 0,19 & 0,37 & 0,38 & 0,14 \\
\hline & sol & & & & & & & 0,05 & 0,12 & 0,13 & 0 \\
\hline & ben & & & & & & & & 0,19 & 0,23 & 0,10 \\
\hline MA & bon & & & & & & & & & 0,50 & 0,11 \\
\hline MS & bux & & & & & & & & & & 0,12 \\
\hline
\end{tabular}


Tabela 4 - Índice de Jaccard para os indivíduos adultos e sub-adultos do grupo Pimenta no PECB durante o ano de 2005. (FA - fêmea adulta; MA - macho adulto; MS - macho sub-adulto)

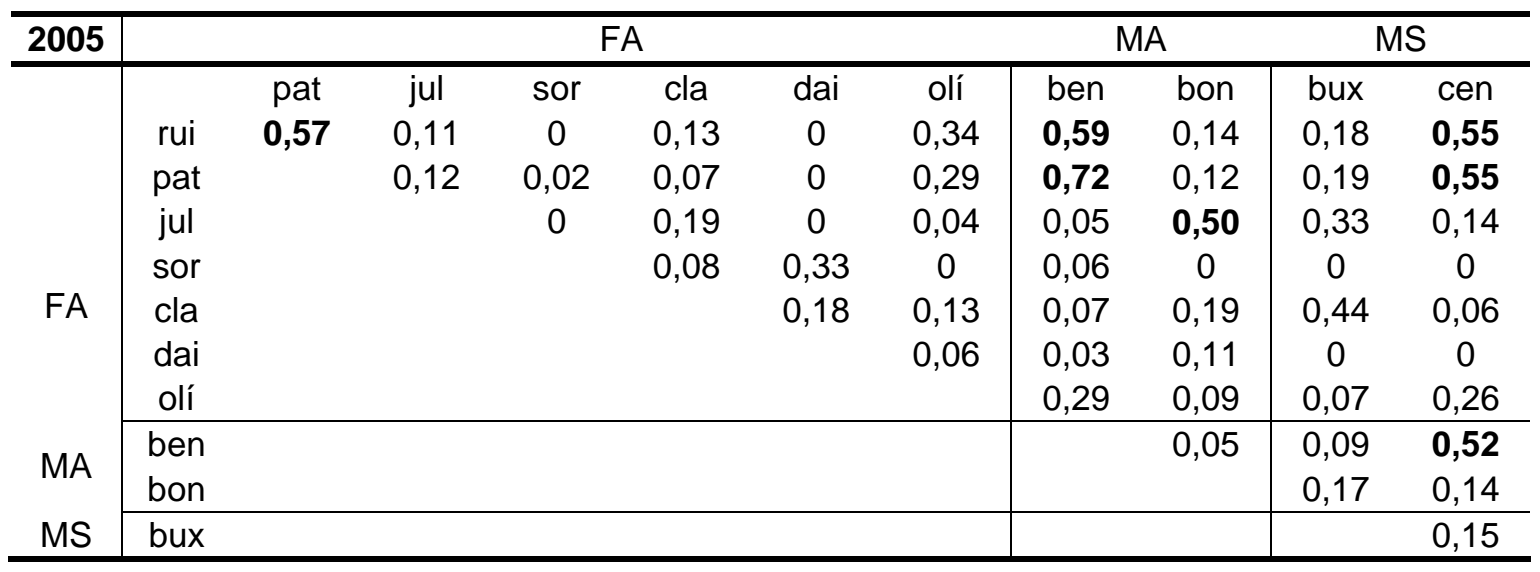

Tabela 5 - Índice de Jaccard para os indivíduos adultos e sub-adultos do grupo Pimenta no PECB durante o ano de 2006. (FA - fêmea adulta; MA - macho adulto; MS - macho sub-adulto)

\begin{tabular}{|c|c|c|c|c|c|c|c|c|c|c|}
\hline 2006 & & \multicolumn{5}{|c|}{ FA } & \multicolumn{2}{|c|}{ MA } & \multicolumn{2}{|c|}{ MS } \\
\hline \multirow{7}{*}{ FA } & & pat & jul & olí & cla & dai & ben & bon & bux & cen \\
\hline & rui & 0,40 & 0,17 & 0,40 & 0,14 & 0 & 0,25 & 0,25 & 0,40 & 0,20 \\
\hline & pat & & 0 & 0,33 & 0,13 & 0 & 0,50 & 0 & 0,14 & 0 \\
\hline & jul & & & 0,33 & 0,80 & 0,25 & 0 & 0,50 & 0,60 & 0,75 \\
\hline & olí & & & & 0,29 & 0 & 0,50 & 0,20 & 0,33 & 0,17 \\
\hline & cla & & & & & 0,20 & 0 & 0,50 & 0,50 & 0,60 \\
\hline & dai & & & & & & 0 & 0 & 0,33 & 0,33 \\
\hline \multirow{2}{*}{ MA } & ben & & & & & & & 0 & 0 & 0 \\
\hline & bon & & & & & & & & 0,20 & 0,67 \\
\hline MS & bux & & & & & & & & & 0,40 \\
\hline
\end{tabular}

A análise das Árvores Geradoras Mínimas (AGMs) construídas para cada ano de observação revelaram que $\mathrm{BEN}$, o macho dominante, sempre esteve ligado a mais de uma fêmea dentro do grupo, o que só aconteceu com BON, o macho beta, no ano de 2004 . Na AGM de 2003, CLE e BEA, fêmeas adultas, aparecem como periféricas e depois elas desapareceram do grupo. O macho BEN está ligado a três fêmeas (RUI, SOR, SON) e o macho BON somente com a fêmea SOL. Na AGM de 2004, o macho BEN continua ligado com as fêmeas RUI e SOR em um braço isolado da árvore e o macho BON passa a estar ligado a três fêmeas (JUL, PAT, CLA) em outro braço da árvore. A fêmea SOL está ligada somente ao macho sub-adulto BUX e no ano seguinte não foi mais vista junto ao grupo 
Pimenta. Outro macho sub-adulto (CEN) apareceu no grupo e permaneceu ligado somente a fêmea RUI. Na AGM de 2005, CEN e OLI ocupam posições periféricas do grupo com braços isolados para cada um, o macho BEN ficou ligado a duas fêmeas (RUI e PAT) e o macho BON continua ligado a apenas uma fêmea JUL, já o macho sub-adulto BUX está ligado a três fêmeas (JUL, CLA, PAT). A fêmea SOR está ligada somente a fêmea DAI e no ano seguinte não foi mais vista junto ao grupo Pimenta. Dentre os machos sub-adultos que entraram no grupo, BUX aparece integrado a mais indivíduos em 2004 e 2005, que CEN. Na AGM de 2006, os indivíduos sub-adultos ocupam posições mais integradas ao grupo, com o BUX ligado a três fêmeas (JUL, DAI, RUI) e CEN ligado ao BON e a JUL. O macho adulto BEN está em um braço da árvore mais isolado do grupo com as fêmeas PAT e OLÍ (Anexo I, II, III e IV).

\subsubsection{Síntese}

Os dados apresentados possibilitam responder a pergunta do tópico 4.1.: os grupos de macacos-prego apresentam organização social do tipo fissão e fusão? De fato, de janeiro de 2003 a março de 2006, todos os grupos de macacos-prego observados no PECB apresentavam variação no tamanho e na composição dos subgrupos, de acordo com o esperado para as sociedades de fissão-fusão.

De maio de 2003 a março de 2006, o grupo Pimenta permaneceu em subgrupos com tamanho de aproximadamente metade do grupo na maioria das observações e com grande fluidez. Essa variação ocorreu ao longo do dia e ao longo de cada mês. A composição dos subgrupos variou em vinte e um tipos, os quais diferiram em freqüência de ocorrência.

O grupo Laranja também permaneceu com tamanho de aproximadamente metade do grupo na maioria das observações, em um grupo de até quinze indivíduos. Foram observadas quinze composições diferentes de subgrupos, as quais diferiram em freqüência de ocorrência. 
Nos outros grupos, o tamanho também variou de 1 a 15 indivíduos. Foram observadas quinze composições diferentes, as quais diferiram em freqüência de ocorrência.

No grupo Pimenta, não houve diferença entre os indivíduos adultos nos subgrupos de tamanhos diferentes, também não houve a presença conjunta dos indivíduos no mesmo subgrupo durante as observações deste estudo.

Para saber se a fissão dos grupos foi devida ao padrão de oferta de frutos, abaixo procederam-se às análises do tamanho de subgrupos do grupo Pimenta com o número de espécies de frutos, tamanho das fontes, tempo de forrageamento e competição intragrupo.

\subsection{Focal de árvore de alimentação (FTFS) e subunidades de alimentação}

O FTFS médio de todas as árvores visitadas pelos animais do grupo Pimenta $(\mathrm{N}=$ 1097) foi $8,10 \pm 8,53$ minutos, significativamente menor que o FTFS médio de 2002 (T-test $=$ -8,18; $\mathrm{gl}=1419 ; \mathrm{p}<0,001)$. Cinqüenta e cinco por cento das árvores foram depletadas em 5 minutos ou menos e 74,6 \% em 10 minutos ou menos (Figura 17). O FTFS foi positivamente correlacionado com tamanho da subunidade de alimentação (Pearson's $r=0,282 ; p<0,01 ; N$ $=1571)$.

O tamanho médio da subunidade de alimentação foi também pequeno, 2,85 $\pm 1,78$ indivíduos (Figura 18). Oitenta e quatro e meio por cento das árvores foram visitadas por quatro indivíduos ou menos, e o forrageamento solitário foi mais freqüente $(26,6 \%)$ que a alimentação com parceiros. Nunca foram observados todos os membros do grupo alimentando se ao mesmo tempo na fonte de alimento. 


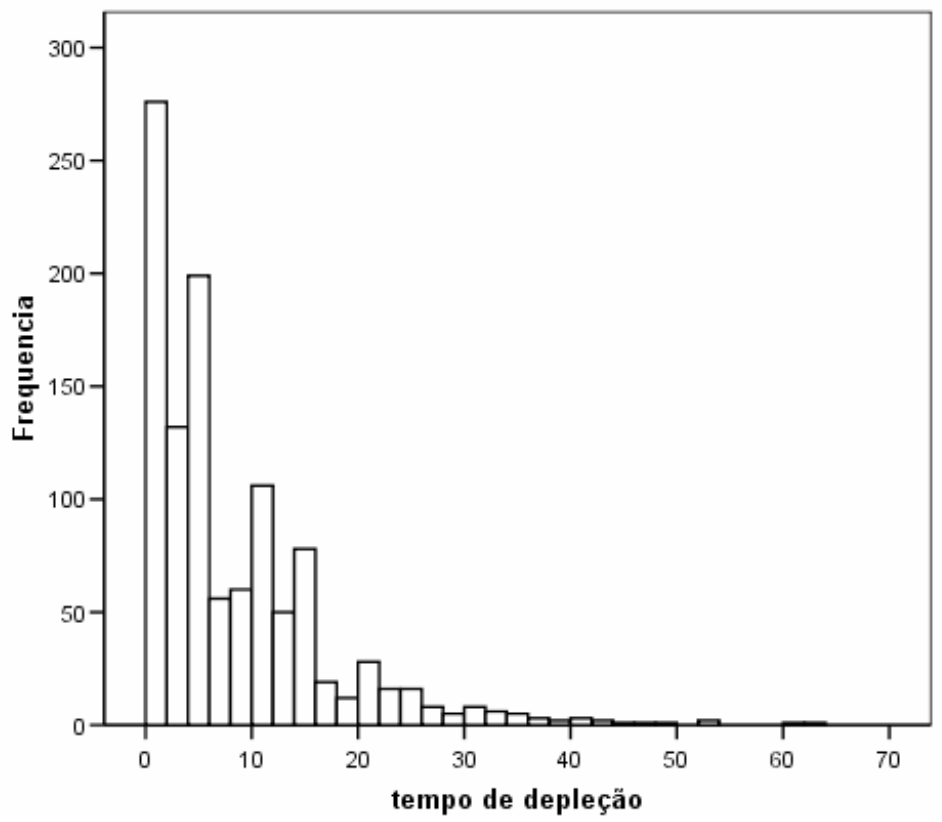

Figura 17 - Histograma de tempo de depleção das árvores visitadas pelo grupo Pimenta, entre Maio de 2003 e Março de 2006.

Houve correlação entre número de indivíduos na fonte de frutos e tempo de depleção (Coef. de Pearson $=0,538 ; \mathrm{p}<0,005, \mathrm{~N}=1097$, Figura 19). As subunidades permaneciam nas árvores entre 5 a 10 minutos na maioria das observações do grupo Pimenta.

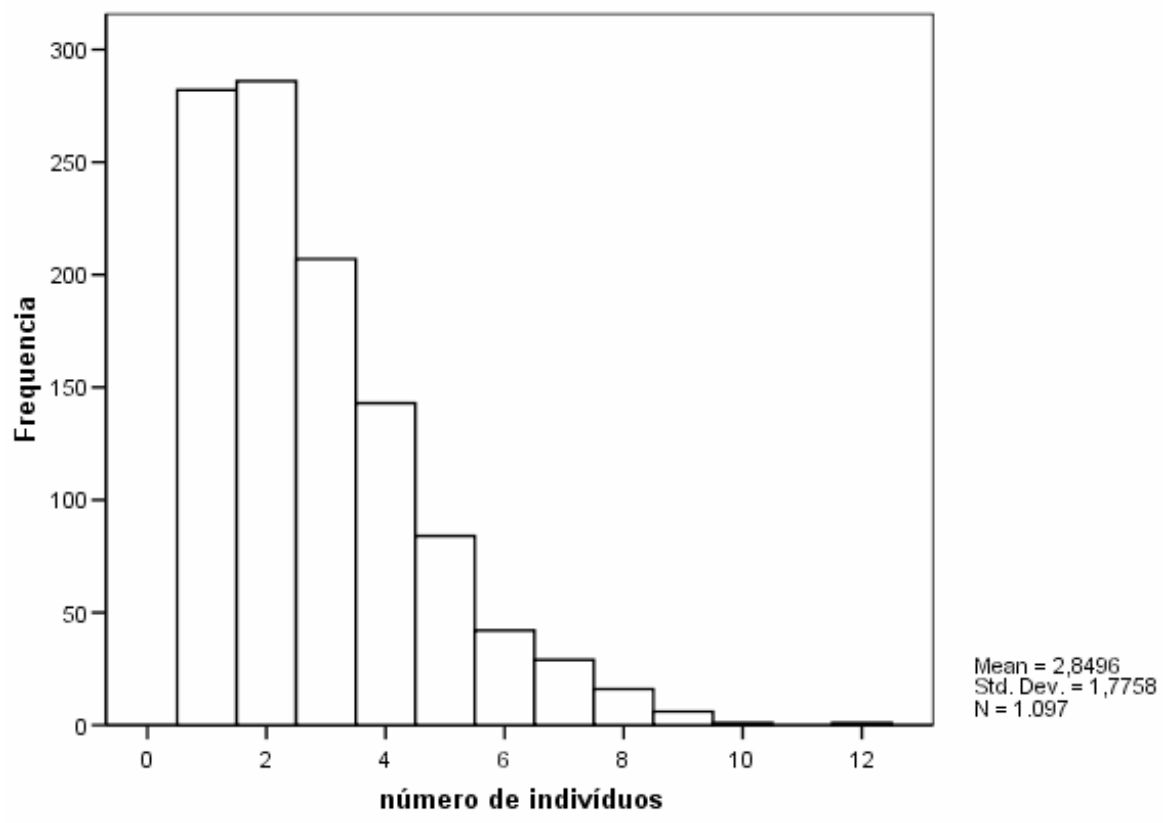

Figura 18 - Histograma de freqüência de tamanho de subunidades de alimentação do grupo Pimenta, entre Maio de 2003 e Dezembro de 2005. 
O FTFS médio de todas as árvores visitadas pelos animais do grupo Laranja $(\mathrm{N}=404)$ foi 11,59 $\pm 11,02$ minutos de Janeiro de 2003 a Julho de 2005 (Figura 20). Quarenta e um e meio por cento das árvores foram depletadas em 5 minutos ou menos e 60,64\% em 10 minutos ou menos.

O tamanho médio da subunidade de alimentação foi também pequeno, 3,06 $\pm 1,74$ indivíduos (Figura 21). Vinte por cento das árvores foram visitadas por mais de cinco indivíduos, e o forrageamento solitário foi $18,32 \%$ de árvores visitadas.

O FTFS médio de todas as árvores visitadas pelos animais de outros grupos $(\mathrm{N}=70)$ foi de 9,86 $\pm 10,64$ minutos de Janeiro de 2003 a Janeiro de 2006. Cinqüenta e um e meio por cento das árvores foram depletadas em 5 minutos ou menos e 67,14\% em 10 minutos ou menos (Figura 22).

O tamanho médio da subunidade de alimentação foi também pequeno, 3,06 $\pm 1,74$ indivíduos (Figura 23). Vinte e sete por cento das árvores foram visitadas por mais de cinco indivíduos, e o forrageamento solitário foi $25,71 \%$ de árvores visitadas.

Ao comparar os grupos Pimenta e Laranja no ano de 2003, verificou-se que o Pimenta forrageou em subunidades de alimentação significativamente maiores que o Laranja (Pimenta $=3,94 \pm 2,27 ;$ Laranja $=3,07 \pm 1,73 ; \mathrm{t}=4,53, \mathrm{gl}=265,25, \mathrm{p}<0,001)$, e despendeu tempos significativamente maiores nas fontes de frutos $($ Pimenta $=15,03 \pm 11,83 ;$ Laranja $=11,72 \pm$ $11,06 ; \mathrm{t}=3,22, \mathrm{gl}=569, \mathrm{p}<0,005)$. A comparação com outros grupos não foi feita em função do pequeno número amostral para o ano de 2003. E a comparação entre o Pimenta e o Laranja foi restrita ao ano de 2003, quando o tamanho das amostras para os dois grupos era similar. 


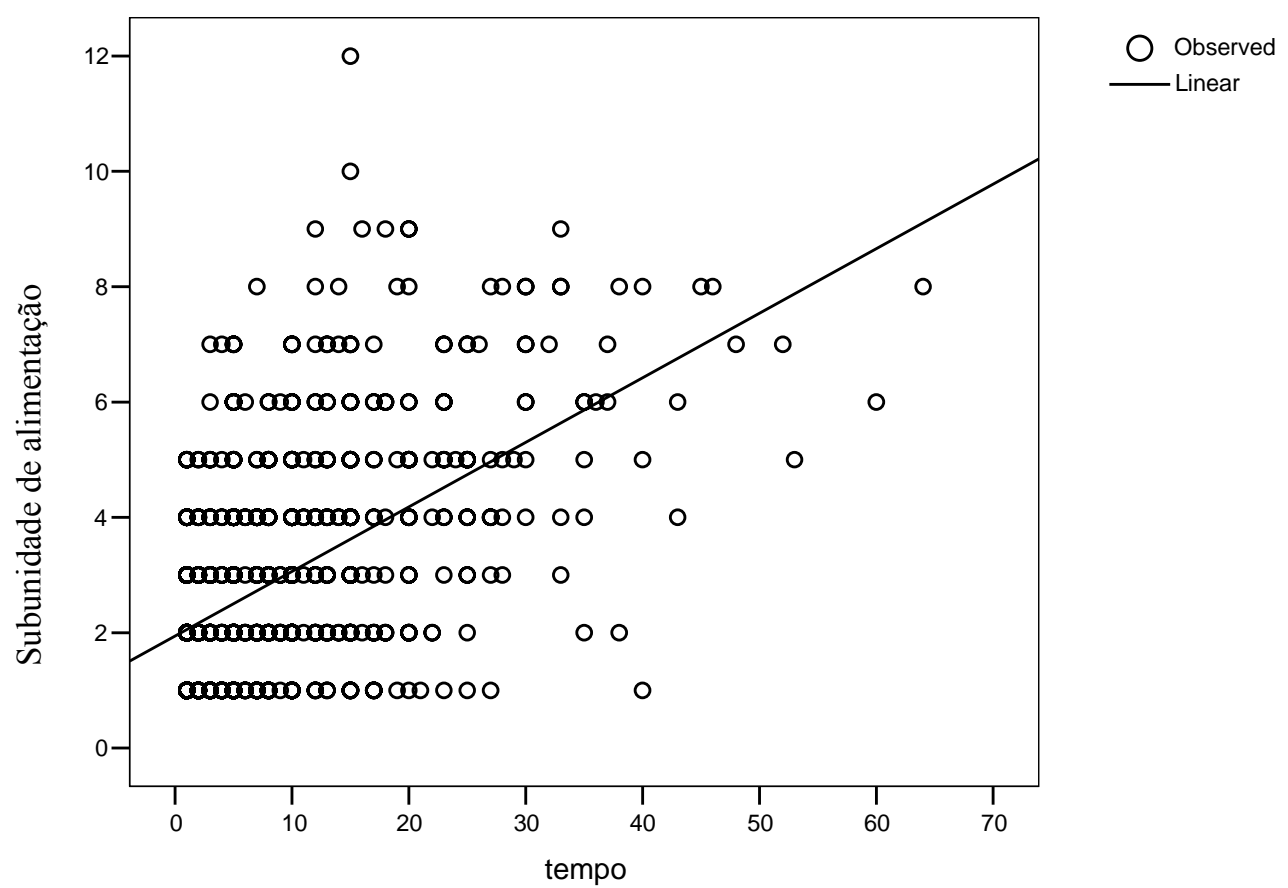

Figura 19 - Correlação entre número de indivíduos na fonte e de tempo de depleção.

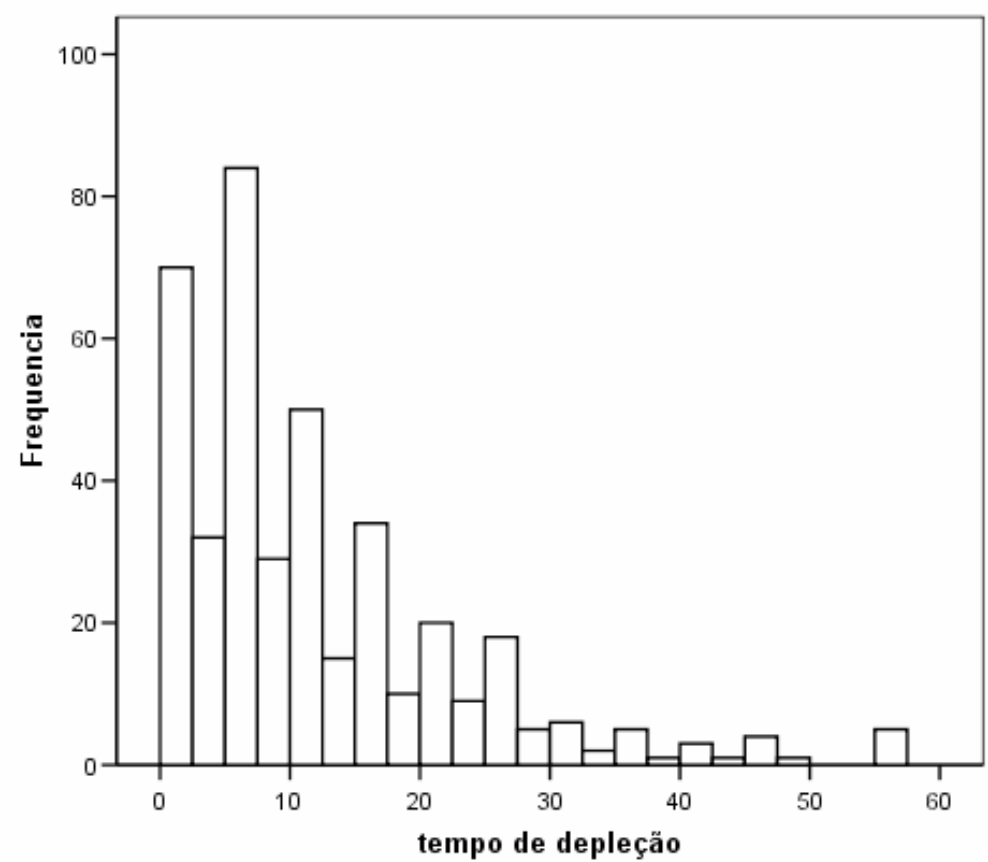

Mean $=11,594$

Std. Dev. $=11,02236$ $N=404$

Figura 20 - Histograma de tempo de depleção das árvores visitadas pelo grupo Laranja, entre Janeiro de 2003 a Julho de 2005. 


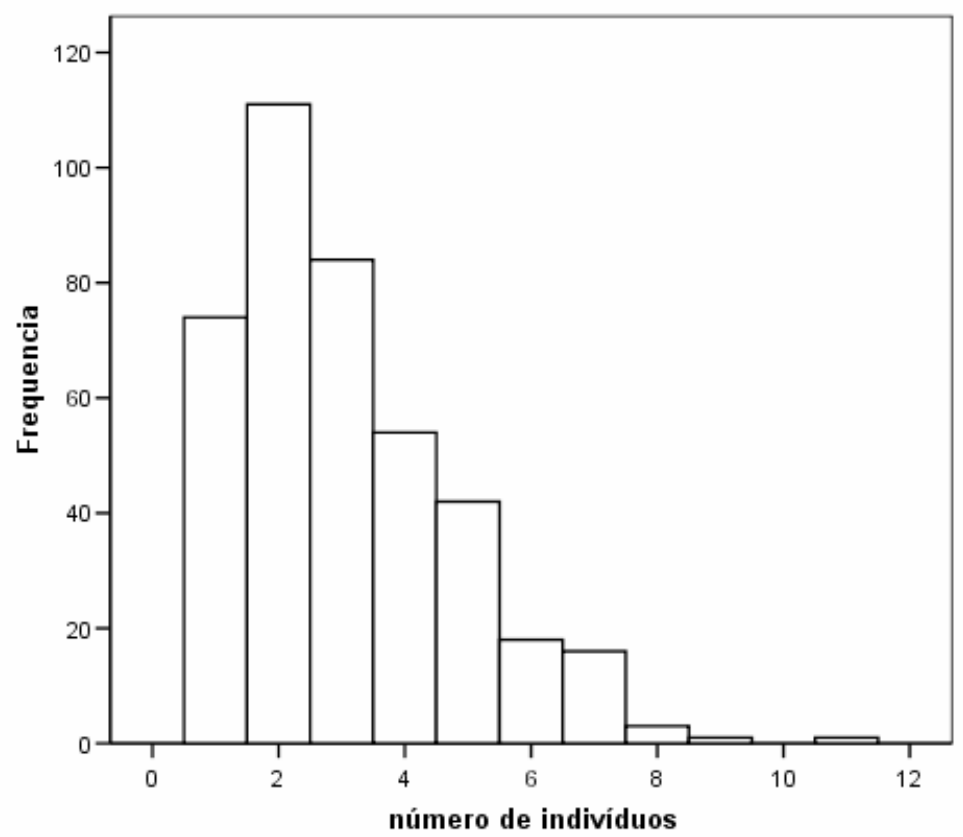

Mean $=3,0644$
Std. Dev. $=1,7401$ Std. Dev. $=1,74015$ $\mathrm{N}=404$

Figura 21 - Histograma de freqüência de tamanho de subunidades de alimentação do grupo Laranja ao longo dos meses de 2003 a 2006.

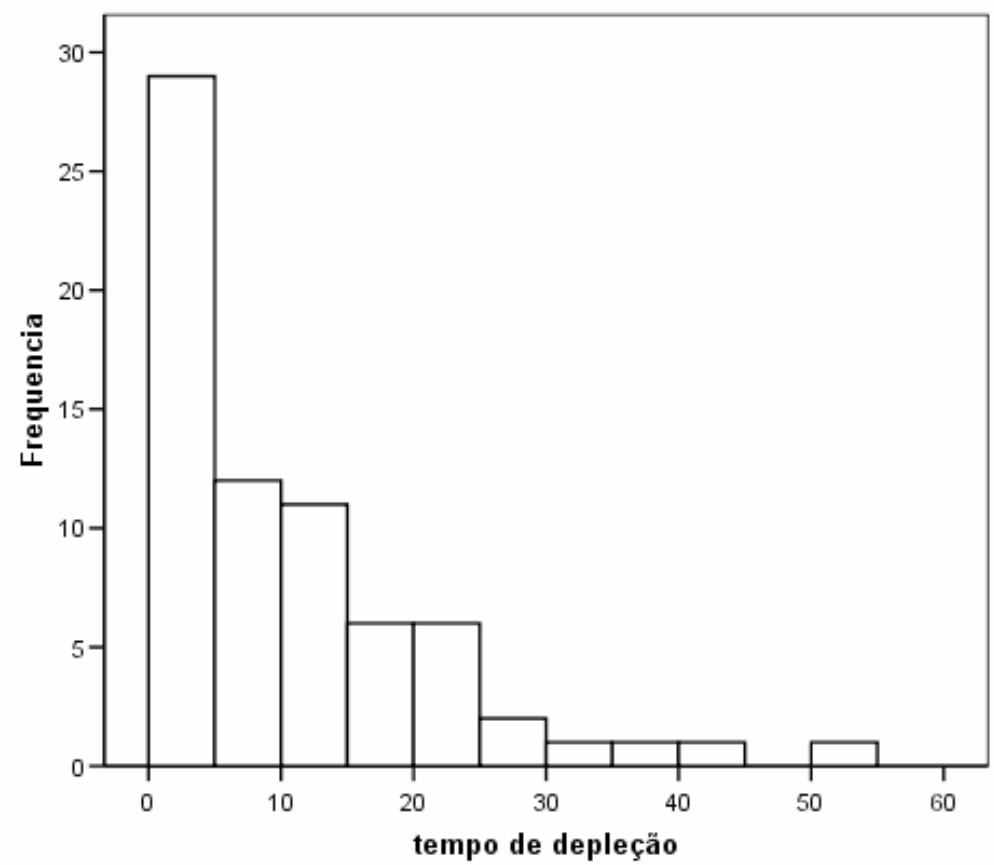

Mean $=9,8571$ Std. Dev $=10,64076$ $N=70$

Figura 22 - Histograma de tempo de depleção das árvores visitadas de todos os outros grupos, entre Janeiro de 2003 a Janeiro de 2006. 


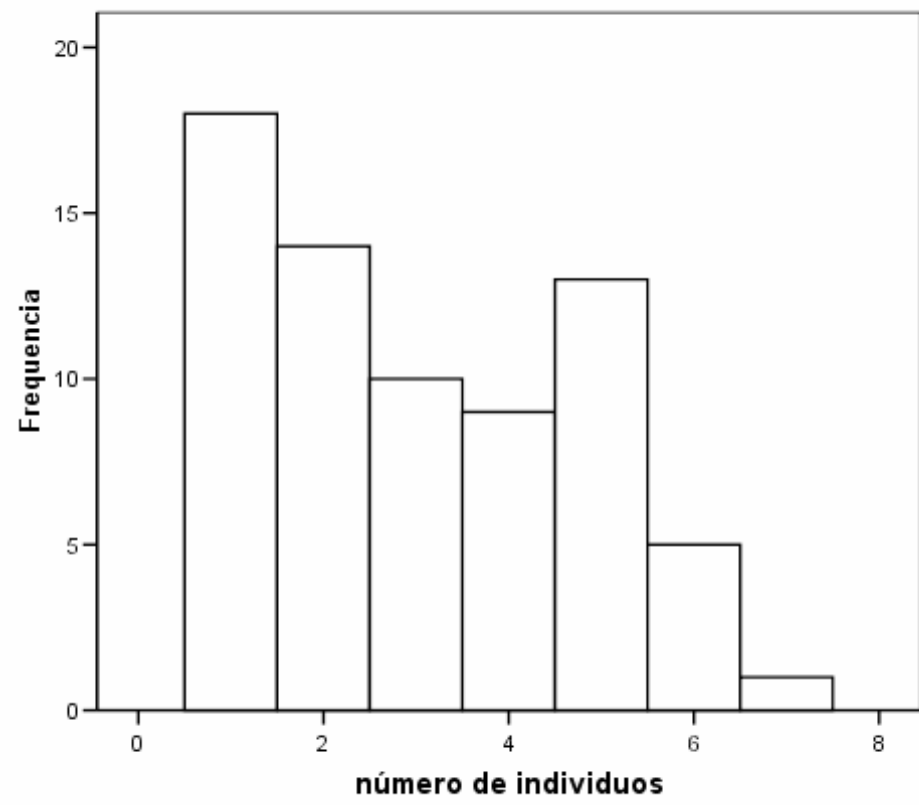

Mean $=3,0571$
Std. Dev. $=1,73528$ Std. Dev.
$N=70$

Figura 23 - Histograma de freqüência de tamanho de subunidades de alimentação de outros grupos ao longo dos meses de 2003 a 2006.

\subsubsection{Energia per capita}

A comparação dos valores de PCIM do grupo Pimenta obtidos entre 2003 e 2005 com o valor de PCIM do grupo Laranja em 2002 revelou uma variação significativa $(\mathrm{F}=37,5 ; \mathrm{gl}=$ 3; $\mathrm{p}<0,001$; Figura 24). O PCIM do grupo Laranja em 2002 (exceto por Junho) foi significativamente maior que o PCIM do grupo Pimenta.

Entretanto, o PCIM é calculado com base no tamanho total do grupo. Quando foi considerado o tamanho médio de subgrupos observados por mês para o cálculo de PCIM do grupo Pimenta nos anos de 2003, 2004 e 2005, verificou-se um aumento significativo (T-test $=-16,40 ; \mathrm{gl}=1390 ; \mathrm{p}<0,001 ;$ média \pm sd de PCIM considerando tamanho de grupo total $=$ 3,32 $\pm 6,59 ;$ média \pm sd de PCIM tamanho médio de subgrupos $=4,65 \pm 7,89$ ). Quando foram comparados esses valores corrigidos de PCIM para os anos 2003, 2004, e 2005 com o período de estudo anterior (PCIM do grupo Laranja em 2002), houve uma variação significativa (F = 42,33; $\mathrm{gl}=4 ; \mathrm{p}<0,001)$, mas os testes post-hoc mostraram não haver diferença entre $2004 \mathrm{e}$ 2005 e o mês de Junho de 2002, e entre 2003 e 2002 (Figura 25). Esses resultados indicam que a condição ecológica de escassez de alimento observada em Junho de 2002, que levou à 
divisão dos grupos sociais de macacos-prego na época, estava presente durante o período do presente estudo.

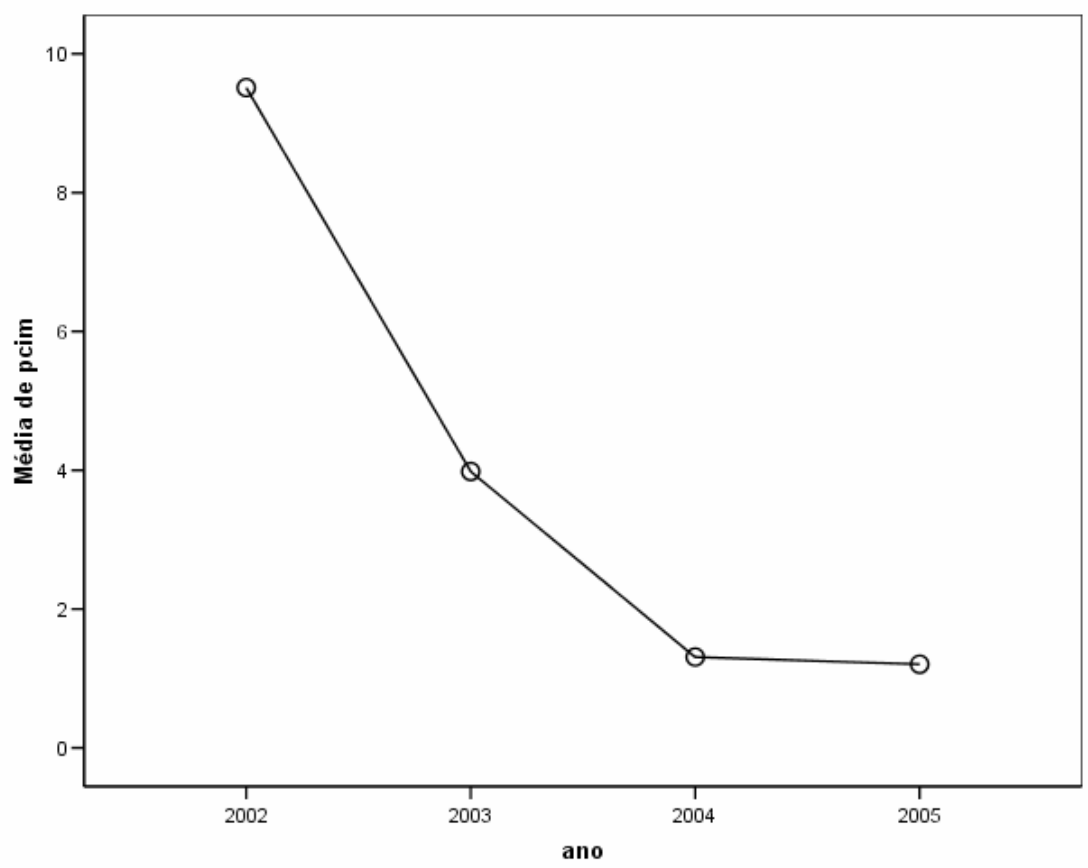

Figura 24 - PCIM médio de 2002, 2003, 2004 e 2005 do grupo Pimenta.

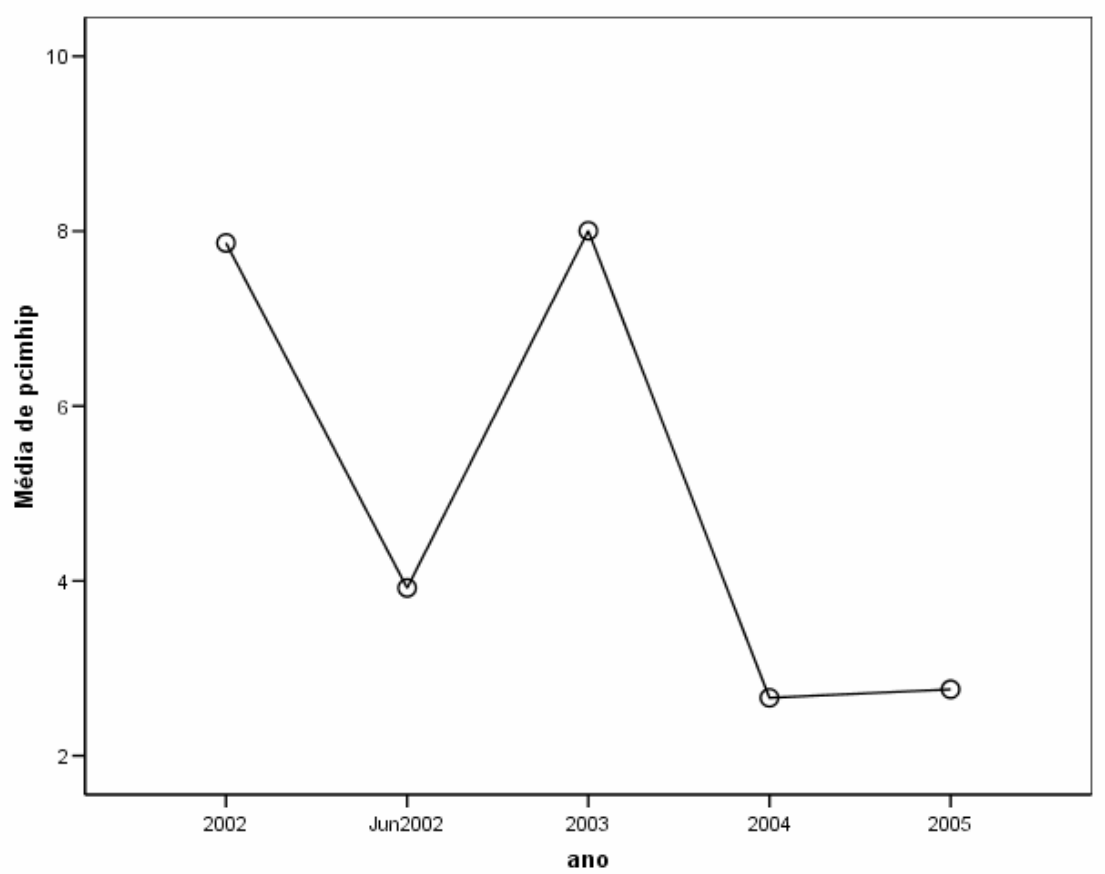

Figura 25 - PCIM corrigido médio para 2002, 2003, 2004, 2005 e Junho 2002. 


\subsubsection{Competição}

Finalmente, no estudo anterior, a competição direta entre grupos ocorreu a uma taxa de 0,06 encontros por hora de observação, enquanto não houve registro de encontro entre grupos em 2003, 2004 e 2005. Embora não tenha sido possível uma análise estatística, é razoável afirmar que a competição por alimento entre grupos diminuiu no segundo período de estudo, em relação ao anterior.

As brigas entre os membros do grupo Pimenta ocorreram em 105 episódios de 2003 a 2005, a uma taxa de $0,26 \mathrm{ep} / \mathrm{h}$ em 2003; 0,28 ep/h em 2004 e 0,14 ep/h em 2005. Em $68.6 \%$ dos episódios foi possível identificar o contexto $(\mathrm{N}=72) .54,2 \%$ ocorreram em contexto de fruteiras $(\mathrm{N}=39), 26,4 \%$ ocorreu entre jovens $(\mathrm{N}=19)$ e $19,4 \%$ foi para expulsar subadultos próximos ao grupo ou afastar fêmea em cio ou no sítio de dormida $(\mathrm{N}=14)$. Houve apenas uma interação agonística entre fêmeas. Em 2002, período do estudo anterior, a competição agonística intragrupo ocorreu a uma taxa de $0,58 \mathrm{ep} / \mathrm{h}$, significativamente maior que em 2003 a $2005\left(\chi^{2}=91,94 ; \mathrm{gl}=3 ; \mathrm{p}<0,001\right)$.

\subsubsection{Síntese}

O tempo de depleção e o tamanho das subunidades de alimentação tiveram valores baixos para todos os grupos de macacos-prego no PECB. O tamanho médio da subunidade de alimentação foi de três indivíduos e com mais da metade das árvores depletadas de 5 a 10 minutos para todos os grupos de macacos-prego.

A energia per capita caiu com o passar dos anos. Houve uma diferença significativa dos valores de PCIM entre os grupos Pimenta e Laranja. No grupo Pimenta, houve uma variação significativa nos valores de IM entre 2002 e 2005. 
Em relação à competição, não houve briga entre grupos durante o período de estudo e mais da metade da competição intragrupo ocorreu durante o forrageamento. Ao comparar com o estudo anterior (Izar, 2004), a competição por alimento intra e entre grupos diminuíram.

Para saber se a variação do tamanho dos subgrupos está relacionada com o padrão de oferta de alimento, procederam-se às análises das variáveis climáticas, da biomassa de frutos e de invertebrados e distribuição das fontes de alimento.

\subsection{O tamanho dos subgrupos se relaciona com a oferta de alimento?}

\subsubsection{Variáveis climáticas}

Durante a pesquisa, observou-se uma variação sazonal da pluviosidade e da temperatura na área de estudo, com menores índices dessas variáveis entre os meses de maio a setembro e maiores índices entre outubro e março (Figura 26). Ao longo do período de janeiro de 2003 a março de 2006, observa-se um aumento gradual das temperaturas média, máxima e mínima. Em conseqüência desse aquecimento, observou-se uma queda correspondente na umidade relativa do ar (Figuras 27). 


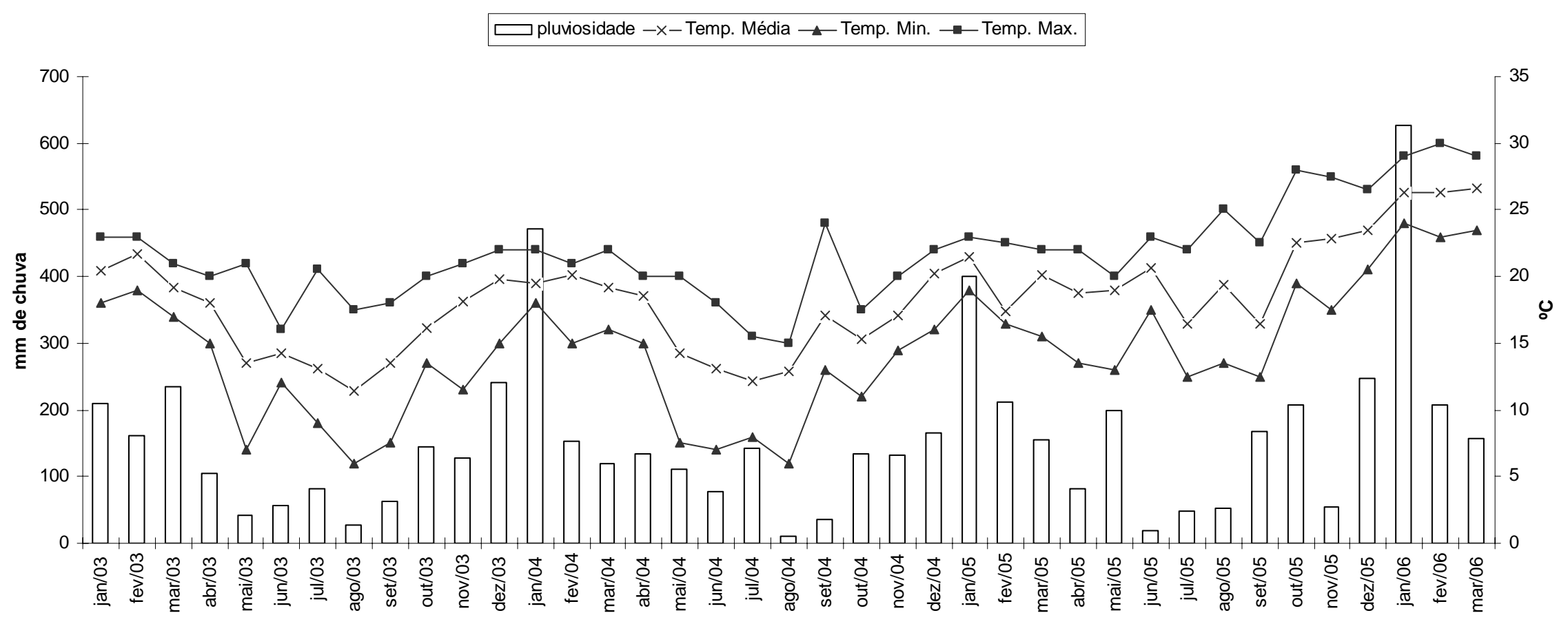

Figura 26 - Média, máxima e mínima de temperatura mensal $\left({ }^{\circ} \mathrm{C}\right)$ e total mensal de pluviosidade (mm) de 2003 a 2006 no PECB. 
$\neg$ média $-x-$ máxima $\triangle-$ mínima

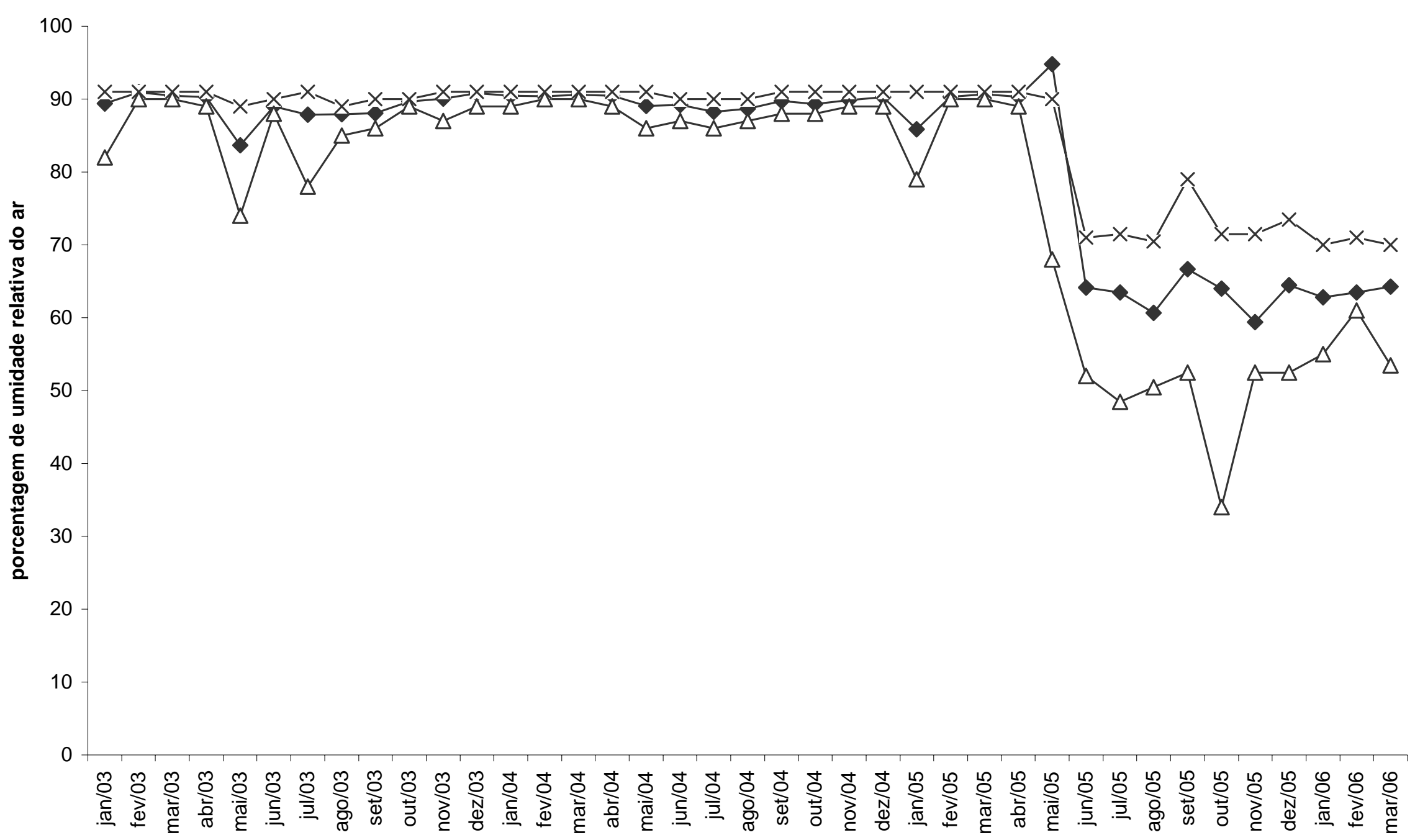

Figura 27 - Variação mensal da umidade relativa do ar (\%) de 2003 a março 2006 no PECB. 


\subsubsection{Clima e abundância de alimento}

Os dados de disponibilidade de alimento foram coletados a cada mês, desde fevereiro de 2004 até março de 2006. Esses dados revelaram um padrão sazonal na oferta de frutos com maior oferta nos meses mais quentes e chuvosos (outubro a março) e menor oferta nos meses mais frios e com menor pluviosidade (abril a agosto), conforme o padrão descrito na literatura para florestas neotropicais (Peres, 1994; Zhang, 1995). Já o padrão de oferta de invertebrados não revelou sazonalidade tão clara, como também seria esperado de acordo com a literatura (Izar, 1999), provavelmente devido à acentuada queda observada a partir do início da estação chuvosa 2004 e 2005 (Figura 28).

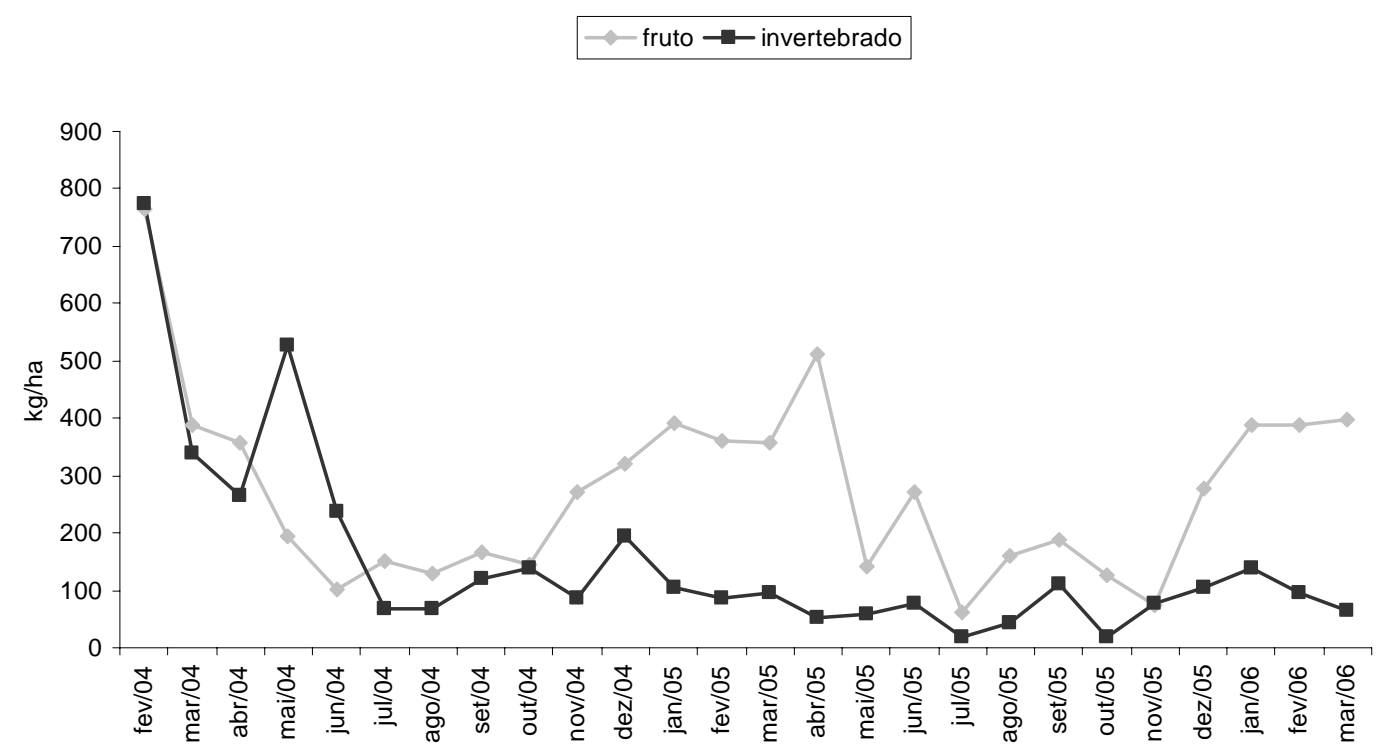

Figura 28 - Biomassa de frutos maduros e invertebrados (kg/ha) coletados de Fevereiro de 2004 a Março de 2006.

Comparando-se os dados de 2002, 2004 e 2005, houve um aumento da produtividade de frutos nos anos de $2004(3382,0 \mathrm{~kg})$ e de 2005 (2927,0 kg), em comparação com 2002 (1312,6 kg; Izar, dados não publicados). Já para a oferta de invertebrados, observou-se fenômeno oposto, com maior disponibilidade em 2002 (14578,6 kg), em comparação com $2004(2921,5 \mathrm{~kg})$ e 2005 (841,8 kg) (Figura 29 e 30). 


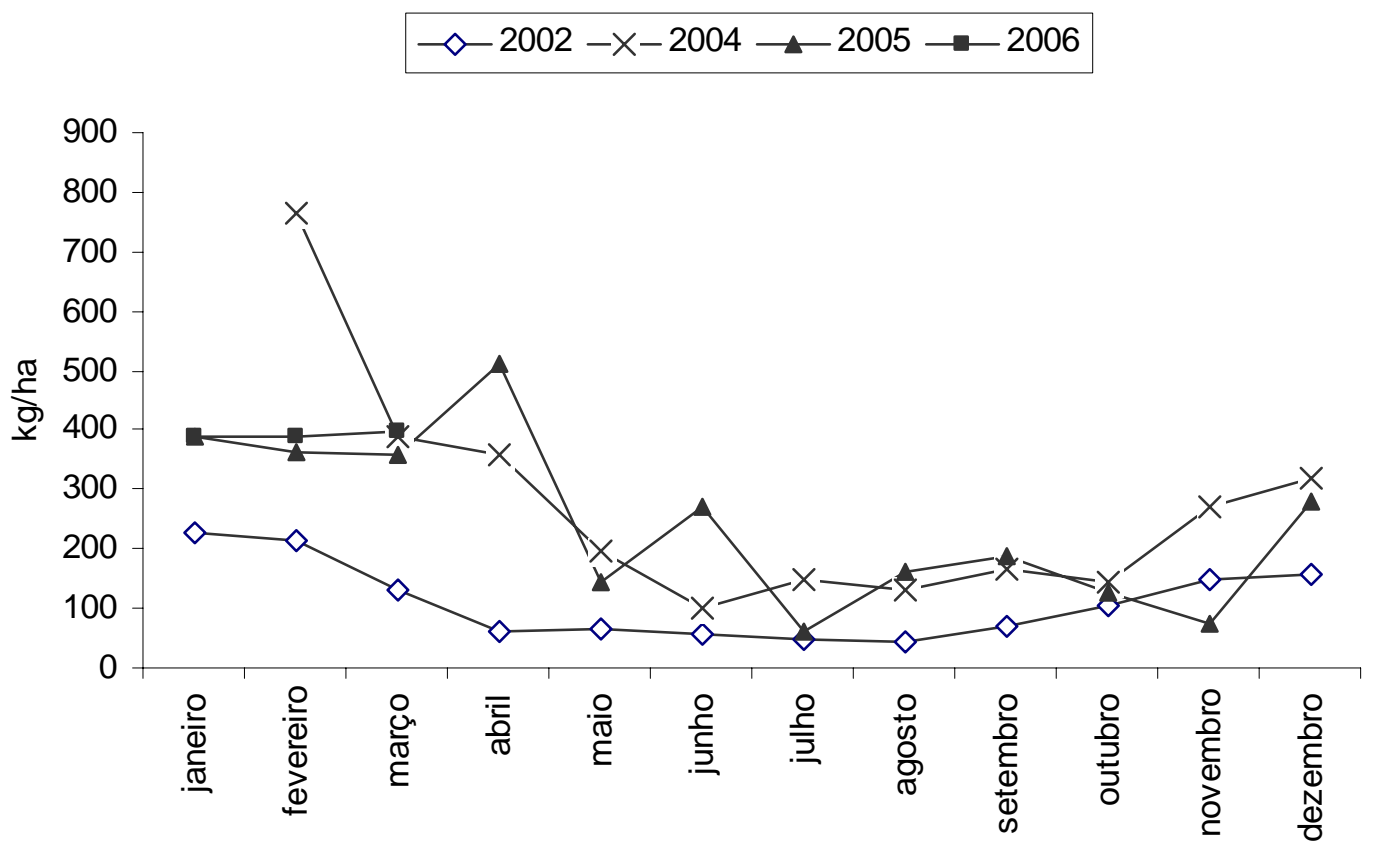

Figura 29 - Variação mensal na biomassa de frutos maduros (kg/ha) no PECB em 2002, 2004, 2005 e 2006.

$$
\leadsto-2002-x-2004 \multimap-2005 \rightarrow-2006
$$

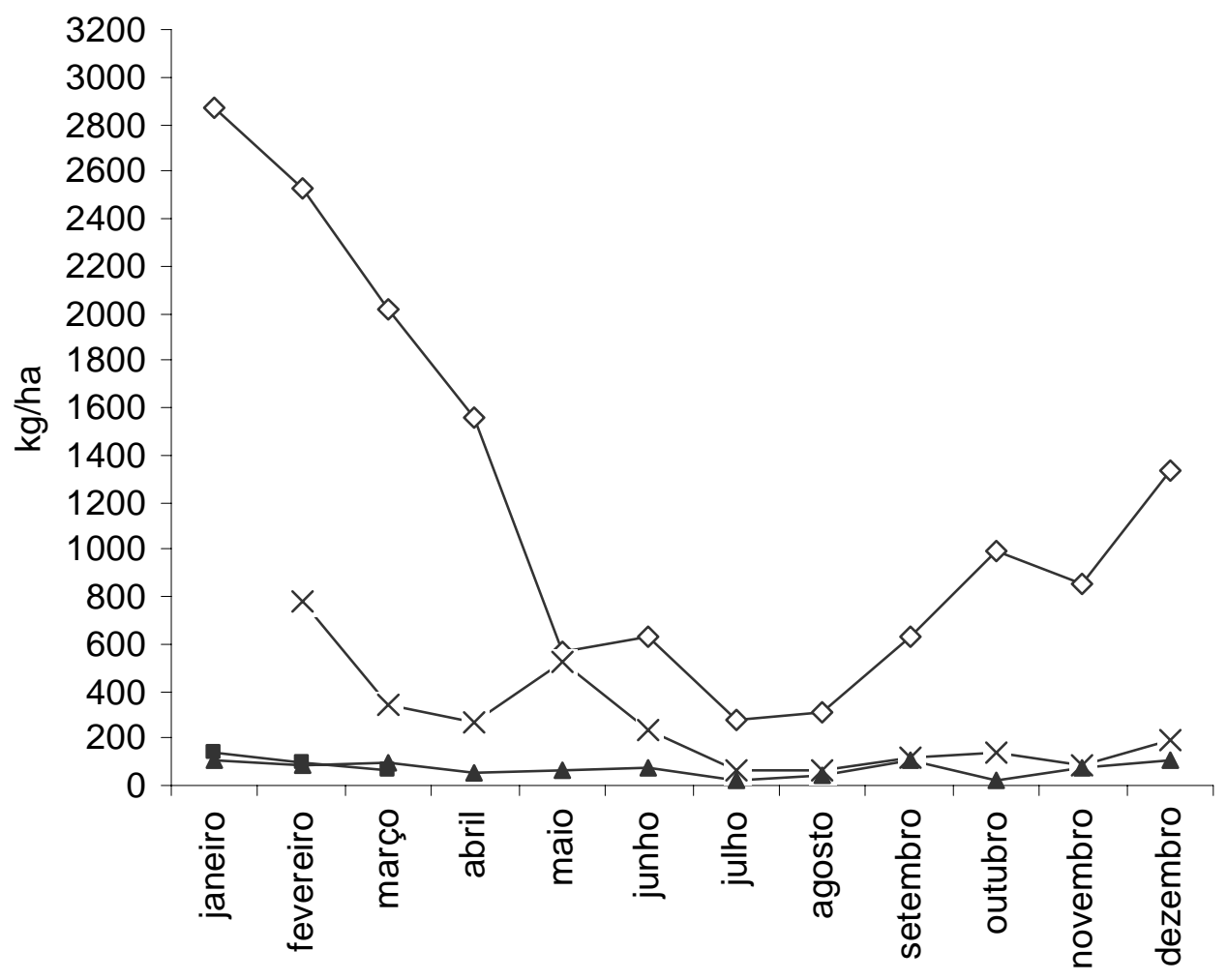

Figura 30 - Variação mensal na biomassa de invertebrados (kg/ha) no PECB, em 2002, 2004, 2005 e 2006. 
A abundância de invertebrados foi significativamente associada à temperatura média ao longo dos anos $(\mathrm{F}=7,87 ; \mathrm{gl}=1 ; \mathrm{p}<0,01)$, explicando aproximadamente $79 \%$ da variação. No ano de 2002 houve uma correlação durante todo o ano, em 2004 e 2005 não se observa uma correlação tão clara (Figura 31).

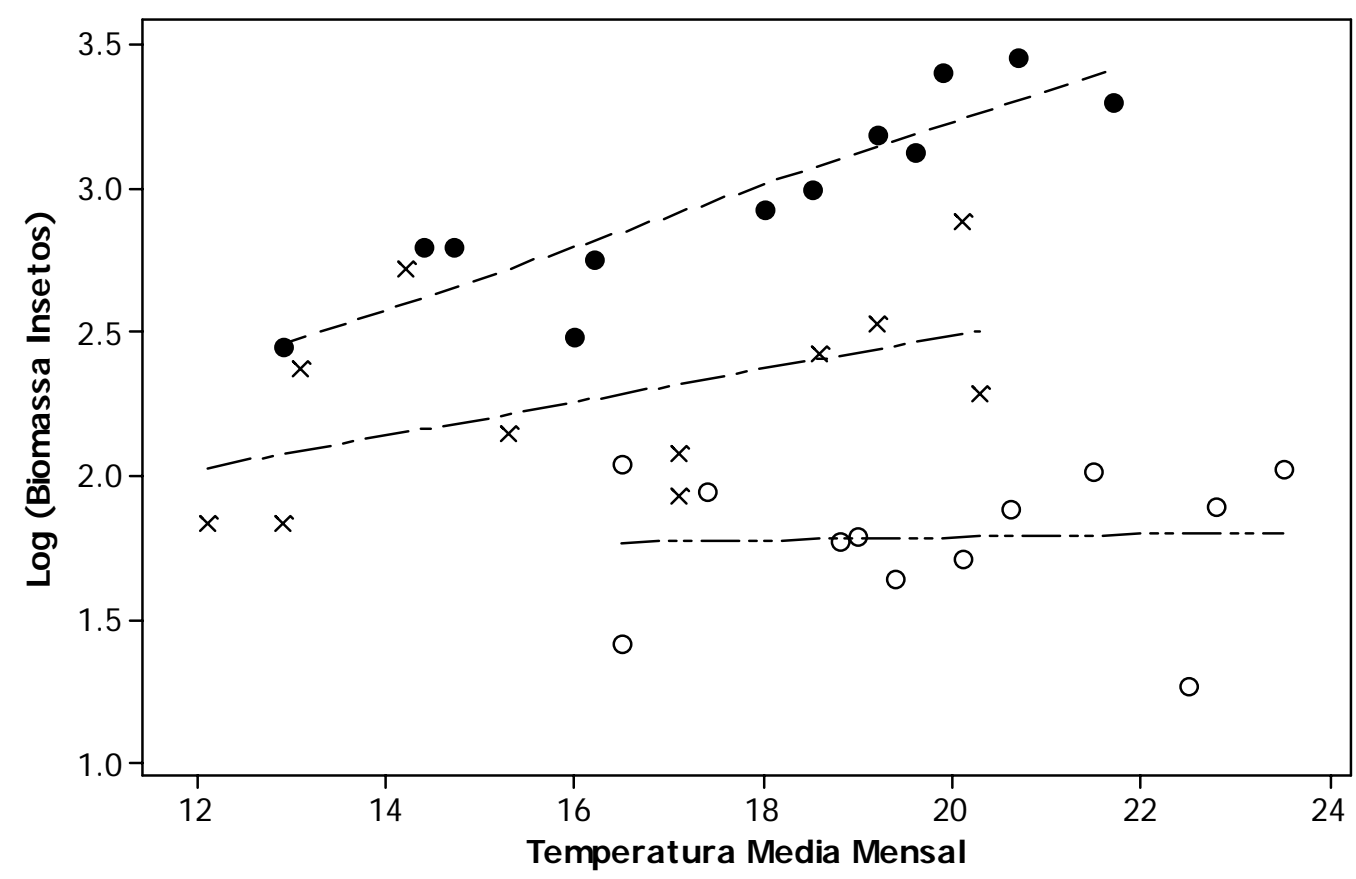

Figura 31 - Correlação entre biomassa de invertebrados e temperatura média mensal $\left({ }^{0} \mathrm{C}\right)$ em 2002 (•), 2004 (x) e 2005 (o).

A variação da abundância média de frutos ao longo dos anos foi significativamente correlacionada com temperatura média $(\mathrm{F}=10,21 ; \mathrm{gl}=1 ; \mathrm{p}<0,005)$, umidade média $(\mathrm{F}=$ $4,48 ; \mathrm{gl}=1 ; \mathrm{p}<0,05)$ e total de chuva $(\mathrm{F}=5,36 ; \mathrm{gl}=1 ; \mathrm{p}<0,05)$, explicando aproximadamente $69 \%$ da variação (Figura 32). 


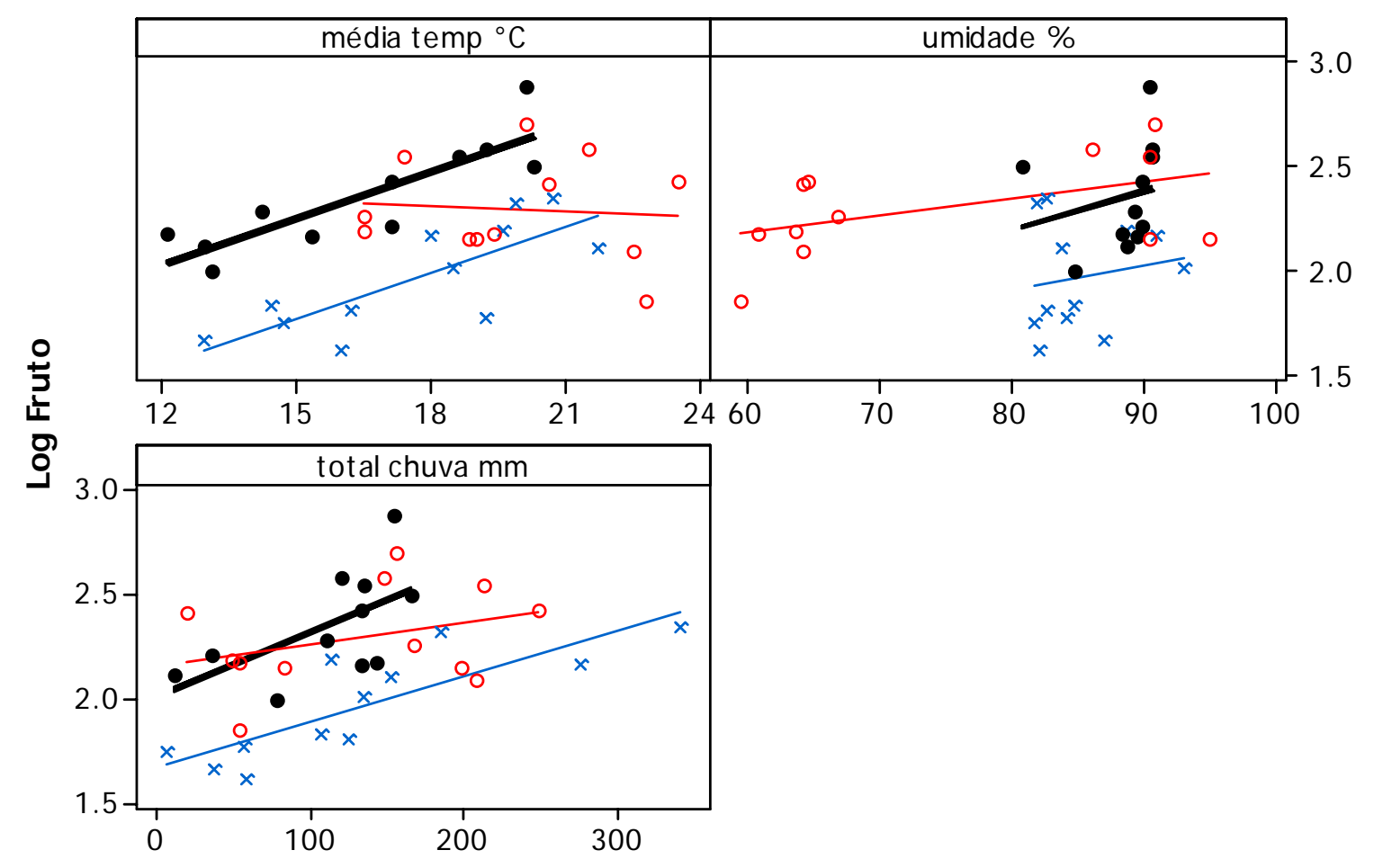

Figura 32 - Correlação entre biomassa de frutos, temperatura média mensal $\left({ }^{0} \mathrm{C}\right)$, porcentagem de chuva e total de chuva (mm) em 2002 (•), 2004 (x) e 2005 (०).

\subsubsection{Distribuição e tipos da fonte de alimento}

De 2003 a 2006, todos os grupos de macacos-prego no PECB apresentaram baixos valores de tempo de depleção de fontes de frutos (de 5 a 10 minutos) e do tamanho das subunidades de alimentação (aproximadamente três indivíduos).

Os valores de IM caíram com o passar dos anos, mas sem diferença significativa entre 2004 e 2005. Ao relacionar com a variação da biomassa de frutos ao longo dos anos, houve correlação significativa com IM ( $\mathrm{F}=9,62 ; \mathrm{gl}=1 ; \mathrm{p}<0,005)$, assim quando a abundância de frutos é menor, o tempo total de alimentação dos indivíduos (IM médio) é menor, enquanto o PCIM não diminui para manter um mínimo de energia per capita para o indivíduo.

Ainda, com o aumento da biomassa de frutos, mas com recursos de pobre qualidade sem sustentar todo o grupo, e com queda da biomassa de invertebrados, os macacos-prego aumentaram o forrageamento por folhas, seguido por frutos, invertebrados e flores (Figura $33)$. 
Ao longo de 2003 a 2006, o grupo Pimenta visitou 285 espécies frutíferas, o Laranja com 331 espécies e todos os outros grupos com 41 espécies (Figura 34). O grupo Pimenta visitou no mínimo 2 espécies (março de 2006) e no máximo 23 espécies (abril de 2004). O grupo Laranja visitou no mínimo 2 espécies (março de 2006) e no máximo 21 espécies (abril de 2003). Todos os outros grupos visitaram no mínimo 1 espécie (fevereiro e setembro de 2003, fevereiro e março de 2004, dezembro de 2005 e janeiro de 2006) e no máximo 6 espécies (setembro de 2005).

As principais árvores e lianas frutíferas utilizadas pelos macacos-prego foram tapiá (Alchornea triplinervia), laranja-de-mico (Posocheria sp.), cuvatã (Matayba elaeagnoides), leiteiro (Sapium sp.), gabirobinha (Campomanesia eugenioides), gabiroba (Campomanesia neriiflora), ingá ferradura (Inga sessilis), ingá (Inga edulis), murici (Byrsonima basiloba), urucurana (Hyeronima alchorneoides), canelinha (Endlicheria paniculata), erva de anta (Psychotria suterella), espora de galo (Strycnhus sp.), tarumã (Vitex sp.), bujueiro (Chrysophyllum viride).

\subsection{Relação entre tamanho de subgrupos e padrões de oferta de alimento}

A análise de regressão para testar se o tamanho médio de subgrupos é afetado pela distribuição, tamanho e abundância de alimento revelou que apenas os modelos incluindo distribuição $(\mathrm{F}=4,46 ; \mathrm{gl}=3 ; \mathrm{p}<0,05)$ e tamanho das fontes de frutos $(\mathrm{F}=3,88 ; \mathrm{gl}=4 ; \mathrm{p}<$ 0,05) foram significativos (Anexo $\mathrm{V}$ ), e a equação contendo ambas as variáveis teve o maior valor de $\mathrm{R}^{2}$ ajustado (Anexo VI), mas a distribuição de alimento contribuiu com a maior parte da correlação $(\mathrm{t}=2,358 ; \mathrm{p}<0,05)($ Anexo VII). 
口\%ins $\square \%$ fruto $\square \%$ flor $\square \%$ indefinido $\square \%$ folha total

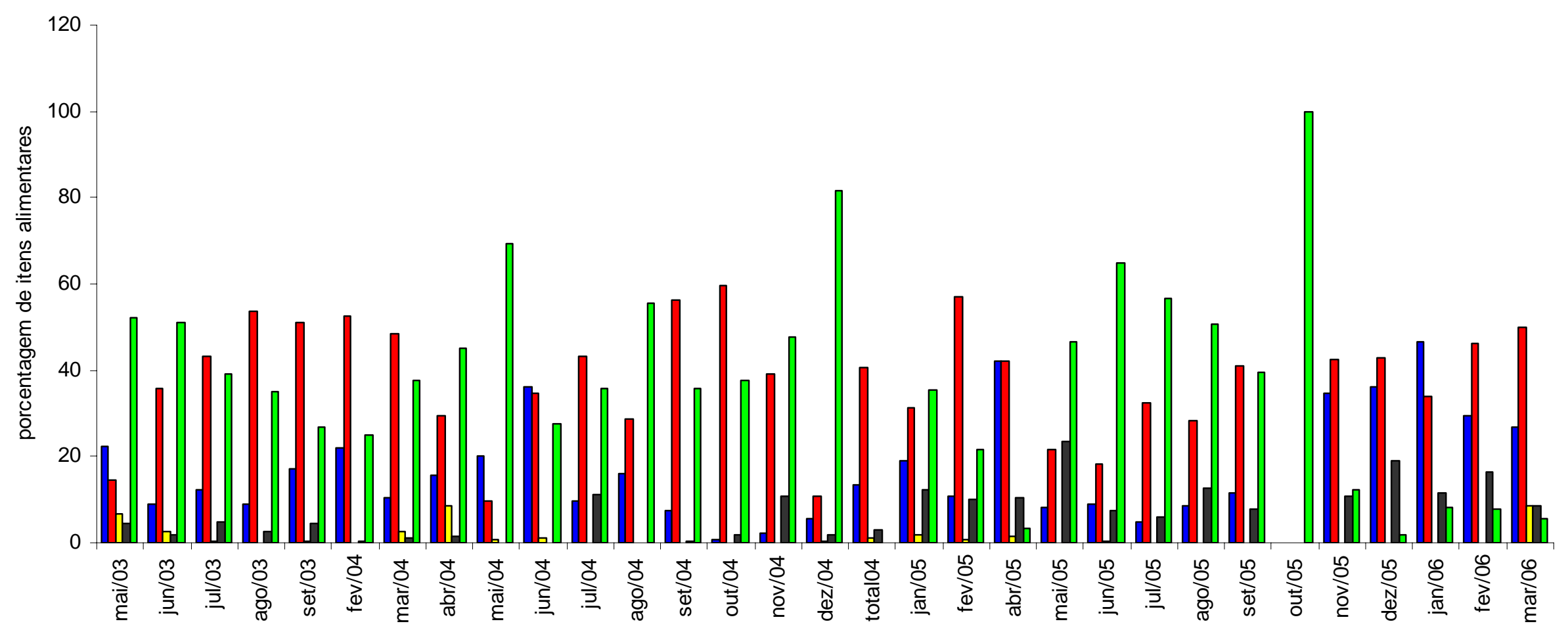

Figura 33 - Porcentagem de tempo de forrageamento dedicado a diferentes itens alimentares do grupo Pimenta ao longo dos meses de 2003 a 2006. 
- Pimenta $\square$ Laranja $\square$ Outros

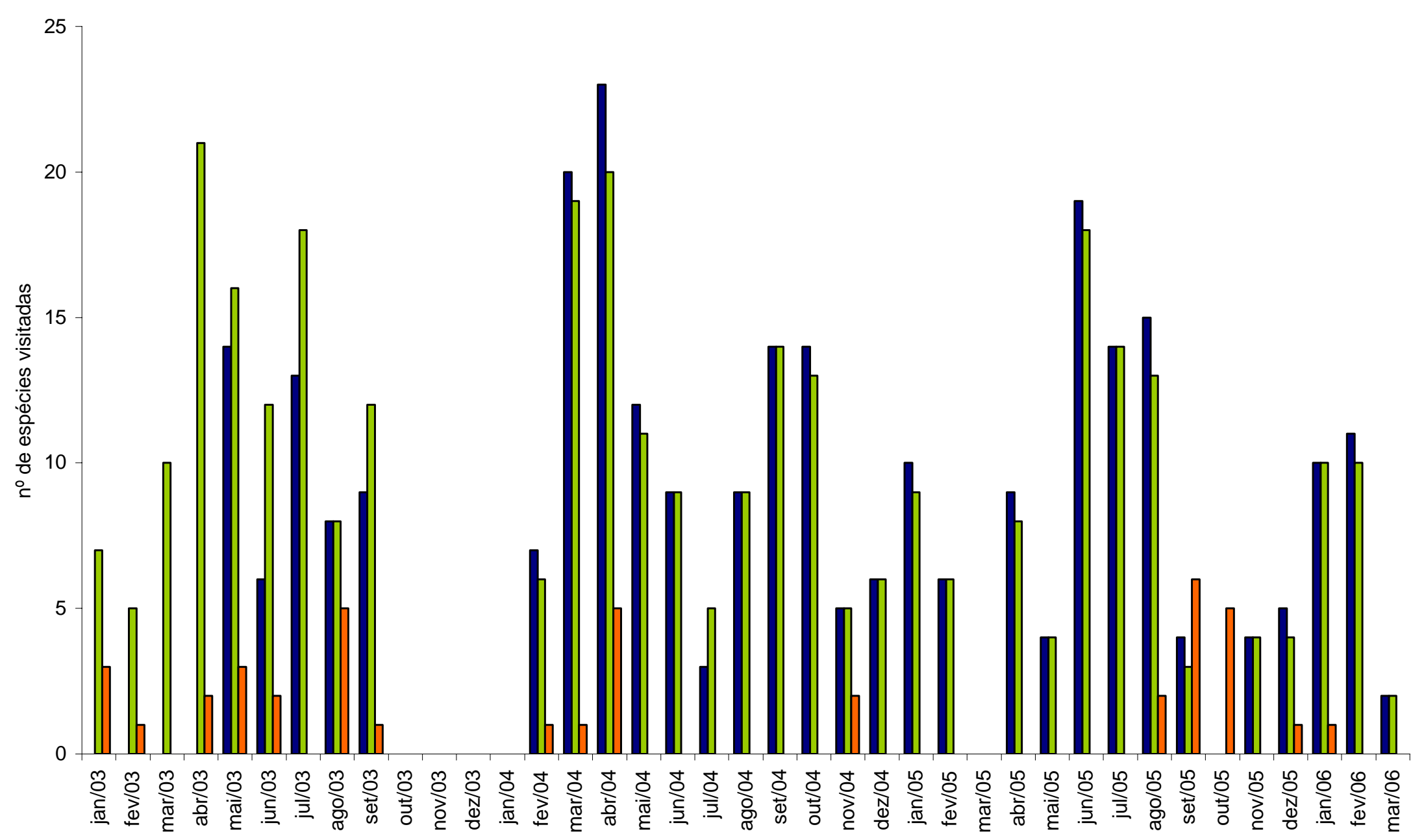

Figura 34 - Número de espécies de frutos utilizados na dieta pelos grupos de macacos-prego no PECB ao longo dos meses no ano de 2003 a 2006. 
A análise de regressão para testar se tamanho máximo de subgrupo é afetado por distribuição $(\mathrm{F}=7,2 ; \mathrm{gl}=1 ; \mathrm{p}<0,05)$, tamanho $(\mathrm{F}=7,7 ; \mathrm{gl}=2, \mathrm{p}<0,05)$ e abundância de alimento $(\mathrm{F}=5,5 ; \mathrm{gl}=3 ; \mathrm{p}<0,05)$ revelou que todos os modelos foram significativos (Anexo VIII), e a equação contendo todas as variáveis teve o maior valor de $\mathrm{R}^{2}$ ajustado (Anexo IX), mas, novamente, a distribuição de alimento contribuiu com a maior parte da correlação $(t=2,783 ; p<0,05)($ Anexo $X)$.

Os dados apresentados acima permitem concluir que há uma relação entre tamanho de subgrupo e padrão da oferta de alimento. Quanto maiores e mais uniformemente distribuídas as fontes de frutos no habitat das quais os animais estão se alimentando, maior o subgrupo.

\subsection{Síntese}

A oferta de frutos revelou um padrão sazonal com maior disponibilidade nos meses mais quentes e menor nos meses mais frios do ano. A oferta de invertebrados não revelou sazonalidade tão clara.

A variação da biomassa de frutos teve correlação significativa com IM e não com PCIM.

O tamanho médio de subgrupo foi afetado pela distribuição e tamanho das fontes de frutos. O tamanho máximo de subgrupo foi afetado pela distribuição, tamanho e abundância de frutos. 


\section{Discussão}

A maior parte dos estudos sobre macacos-prego, realizados com populações de florestas Amazônicas e semi-decíduas da Argentina (Janson, 1985; Robinson \& Janson, 1987; Izawa, 1994; Di Bitetti, 2001), indicam que esses primatas vivem em grupos coesos, sem a formação de subgrupos, e estáveis na composição, com mudança apenas devido a nascimentos, mortes e emigração de machos, sendo as fêmeas filopátricas (Jason, 1984; Robinson \& Jason, 1987; Kinzey, 1997; Di Bitetti, 2001). No entanto, dois estudos conduzidos com populações de Mata Atlântica indicaram a divisão de grupos sociais em subgrupos, mas não concluíram se os processos que foram observados eram de divisão permanente de um grupo grande ou se realmente essas populações assumem a organização social do tipo de fissão-fusão (Lynch, 2001; Izar, 2004).

Os resultados apresentados no presente estudo indicaram que os macacos-prego do PECB organizam-se em sociedades de fissão-fusão, dividindo-se constantemente em subgrupos de tamanho e composição variável, com associações preferenciais entre pares de macho e fêmea, composição multi-macho/multi-fêmea e ausência de dominância entre as fêmeas. Todas essas características são semelhantes às sociedades de fissão-fusão de chimpanzés e primatas neotropicais (Tabela 6). Uma diferença importante entre os primatas que fazem fissão-fusão e os macacos-prego do PECB refere-se à dispersão do grupo natal, que é realizada pelas fêmeas em todas as espécies de fissão-fusão, enquanto que nos macacos-prego do PECB os machos deixam o grupo natal quando atingem a maturidade sexual, e as fêmeas também podem migrar (Izar, 2004; este estudo). 
Tabela 6 - Comparação dos macacos-prego (PECB) com diferentes espécies que realizam fissão-fusão

\begin{tabular}{l|l|l|l|l|l}
\hline Características: & Chimpanzés & Macaco-aranha & Muriqui ${ }^{3}$ & $\begin{array}{l}\text { Macaco- } \\
\text { barrigudo }^{4}\end{array}$ & $\begin{array}{l}\text { Macacos-prego } \\
\text { (PECB) }\end{array}$ \\
\hline Tamanho corporal & grande & grande & grande & grande & pequeno \\
\hline $\begin{array}{l}\text { Associações } \\
\text { preferenciais }\end{array}$ & fêmea-macho & macho-macho & macho-macho & fêmea-macho & fêmea-macho \\
\hline $\begin{array}{l}\text { Composição } \\
\text { individual dos } \\
\text { subgrupos }\end{array}$ & fluidez & fluidez & coeso e fluido ${ }^{\text {a }}$ & coeso & fluidez \\
\hline $\begin{array}{l}\text { Composição sexual } \\
\text { dos subgrupos }\end{array}$ & $\begin{array}{l}\text { multi-macho multi- } \\
\text { fêmea, unimacho e } \\
\text { unifêmea }\end{array}$ & $\begin{array}{l}\text { multi-macho } \\
\text { multi-fêmea }\end{array}$ & $\begin{array}{l}\text { multi-macho } \\
\text { multi-fêmea, } \\
\text { unimacho e }\end{array}$ & $\begin{array}{l}\text { multi-macho } \\
\text { multi-fêmea }\end{array}$ & $\begin{array}{l}\text { multi-macho multi- } \\
\text { fêmea }\end{array}$ \\
\hline $\begin{array}{l}\text { Relação das fêmeas } \\
\text { fraca hierarquia de } \\
\text { dominância }\end{array}$ & $\begin{array}{l}\text { ausência de } \\
\text { hierarquia de } \\
\text { dominância }\end{array}$ & $\begin{array}{l}\text { não há evidência } \\
\text { de hierarquia de } \\
\text { dominância }\end{array}$ & $\begin{array}{l}\text { fraca hierarquia } \\
\text { de dominância }\end{array}$ & $\begin{array}{l}\text { ausência de } \\
\text { hierarquia de } \\
\text { dominância }\end{array}$ \\
\hline \begin{tabular}{l} 
Migração \\
\hline
\end{tabular} & fêmeas & fêmeas & fêmeas & fêmeas & machos e fêmeas \\
\hline
\end{tabular}

${ }^{1}$ Nishida \& Hiraiwa Hasegawa, 1987; Sakura, 1994; Boesch, 1996; Matsumoto Oda et al., 1998; Boesch \& Boesch, 2000.

${ }^{2}$ Symington, 1988; Chapman, 1990a; Shimooka, 2003.

${ }^{3}$ Milton, 1984; Strier, 1990; Lemos de Sá \& Strier, 1992; Strier et al., 1993; Moraes et al., 1998.

${ }^{a}$ Depende do habitat e do tempo de estudo (Strier et al., 1993; Moares et al., 1998).

${ }^{4}$ Stevenson et al., 1994; Di Fiore, 2004; Di Fiore \& Fleischer, 2005. 


\subsection{Organização social de Cebus nigritus: comparação com outras populações}

Parte dos resultados aqui apresentados indica que o sistema social dos macacos-prego no PECB apresenta semelhanças com a população estudada por Lynch (2001), na Estação Biológica de Caratinga (EBC). Em primeiro lugar, embora em ambos os estudos tenham sido observados diferentes tipos de composição de subgrupo, o tipo de composição de subgrupo mais comumente observado obedeceu ao padrão multi-macho/multi-fêmea, com maior proporção de fêmeas, que é uma característica do gênero Cebus (Robinson \& Janson, 1987; Fragaszy et al., 2004b). Além disso, em ambos os estudos observaram-se associações preferenciais entre pares de macho e fêmea adultos.

Entretanto, algumas diferenças fundamentais entre os dois estudos foram encontradas. Lynch (2001) não pode determinar se o fenômeno de formação de subgrupos observado na EBC era uma estratégia sazonal de regulação do tamanho do grupo frente à diminuição da oferta de alimento ou se era um lento processo de divisão de um grupo grande, para formação de dois ou mais grupos menores. A autora observou uma fluidez sazonal no tamanho dos subgrupos e uma distribuição uniforme da freqüência de subgrupos de tamanhos diferentes no início da estação chuvosa, o que caracterizaria uma sociedade de fissão-fusão. No entanto, no final da estação chuvosa e durante a estação seca, a autora observou uma distribuição bimodal da freqüência de subgrupos de tamanhos diferentes, indicando a divisão do grupo em um subgrupo grande e outro pequeno. Tipicamente, as fêmeas dominantes e o macho alfa formavam um grande subgrupo e as fêmeas e machos subordinados formavam subgrupos menores. Dessa forma, Lynch observou associações diádicas fortemente relacionadas à hierarquia de dominância, ou seja, as fêmeas de alto status estavam associadas com o macho alfa e as fêmeas de baixo status passaram mais tempo com os machos subordinados. A fluidez na composição dos subgrupos foi causada apenas pelos indivíduos sub-adultos, principalmente os machos subordinados e fêmeas sub-adultas, durante o processo de 
transferência entre subgrupos (Lynch Alfaro, 2007). A autora observou um padrão típico de sociedades matrilineares em estágio pré-fissão permanente de um grupo grande, como observado, por exemplo, em Saimiri sciureus (Baldwin \& Baldwin, 1981) e nos cercopitecóides, como, por exemplo, Macaca sinica (Dittus, 1988).

Ao contrário do estudo conduzido na $\mathrm{EBC}$, os resultados encontrados no presente estudo permitem afirmar que a organização social dos macacos-prego no PECB é do tipo fissão-fusão. Os grupos sociais dividiam-se em subgrupos que mudavam constantemente de tamanho e composição, ao longo do todo o ano, durante os três anos de estudo, sem influência sazonal. Os grupos dividiram-se mais freqüentemente pela metade do tamanho do grupo e os subgrupos apresentaram alta fluidez de composição. Além disso, embora no presente estudo não tenha sido possível identificar relações de dominância entre as fêmeas do grupo Pimenta, devido à baixíssima freqüência de interações agonísticas observadas, não foram encontradas diferenças individuais quanto ao tamanho do subgrupo em que foram observados. Portanto, no PECB, os macacos-prego são mais parecidos com as sociedades de fissão-fusão do que os macacos-prego na EBC (Tabela 7).

\subsection{Fatores ecológicos que afetam o tamanho dos subgrupos}

Quase todas as espécies de primatas ajustam o tamanho do grupo ou subgrupo às variáveis ecológicas como tamanho, densidade e distribuição das fontes alimentares (Chapman et al., 1995; Strier, 2003). 
Tabela 7 - Comparação de Cebus nigritus entre os estudos de Lynch (2001) na EBC e o presente estudo no PECB

\begin{tabular}{l|l|l}
\hline Características: & \multicolumn{1}{|c}{ EBC } & \multicolumn{1}{|c}{ PECB } \\
\hline $\begin{array}{l}\text { Distribuição do tamanho } \\
\text { dos subgrupos }\end{array}$ & $\begin{array}{l}\text { bimodal: subgrupo } \\
\text { grande com indivíduos } \\
\text { dominantes, subgrupos } \\
\text { pequenos com } \\
\text { indivíduos subordinados }\end{array}$ & $\begin{array}{l}\text { com metade dos mebros } \\
\text { do grupo, sem relação } \\
\text { com hierarquia }\end{array}$ \\
\hline $\begin{array}{l}\text { Freqüência de formação } \\
\text { de subgrupos }\end{array}$ & sazonal & ano inteiro \\
\hline $\begin{array}{l}\text { Composição individual } \\
\text { dos subgrupos }\end{array}$ & $\begin{array}{l}\text { relativamente estável, } \\
\text { fluidez quanto aos } \\
\text { subordinados }\end{array}$ & fluidez \\
\hline $\begin{array}{l}\text { Composição sexual dos } \\
\text { subgrupos }\end{array}$ & $\begin{array}{l}\text { multi-macho } \\
\text { multi-fêmea }\end{array}$ & $\begin{array}{l}\text { multi-macho } \\
\text { multi-fêmea }\end{array}$ \\
\hline
\end{tabular}

\subsubsection{Tamanho e qualidade da fonte de alimento}

O tamanho de uma fonte de alimento agrupada afeta o número de indivíduos de um grupo que podem se alimentar juntos ao mesmo tempo e, conseqüentemente, afeta o tamanho dos subgrupos (Strier, 2003). Em fontes de alimento pequenas, é mais provável ocorrer a divisão do grupo em subgrupos do que nas fontes grandes, que podem acomodar o grupo todo.

O tamanho da fonte, o tempo dedicado à alimentação nessa fonte e o número de indivíduos na fonte alimentar são correlacionados entre si (Chapman, 1988; Stevenson et al., 1994; Mourthé, 2006). Em todos os grupos de macacos-prego no PECB, o tamanho das subunidades de alimentação foi pequeno, com aproximadamente três indivíduos. Além disso, as fontes de frutos utilizadas apresentaram baixos valores de tempo de depleção (de 5 a 10 minutos). Esses resultados indicam que no PECB as fontes de frutos são pequenas, de baixa qualidade e pouco produtivas. Assim, a fissão em subgrupos pode ser uma resposta ao 
tamanho e qualidade das fontes de frutos, como sugerido por Izar (2004). É possível que a coesão dos grupos de macacos-prego observada pela autora no PECB, em 2001 e 2002, tenha sido causada pela oferta excepcional de frutos de espécies com grande produtividade de frutos em grandes copas (Izar \& Nakai, 2006).

A fissão em subgrupos quando os frutos se encontram em fontes pequenas e a fusão quando as fontes podem acomodar o grupo todo também ocorrem em outras espécies como muriquis, macacos-aranha e chimpanzés (Strier, 2003).

Tanto em macacos-aranha quanto chimpanzés, o tamanho de subunidade de alimentação é correlacionado ao tamanho da fonte de frutos (Symington, 1990). Em macacosaranha, o número de indivíduos forrageando dentro da fonte alimentar é ajustado ao tamanho da fonte (Symington, 1988). Em chimpanzés, mais indivíduos se alimentam em grandes fontes alimentares e, conseqüentemente, o tamanho do subgrupo aumenta (White \& Wrangham, 1988; Boesch, 1996; Boesch \& Boesch, 2000; Newton-Fischer et al., 2000). Além disso, a subunidade de alimentação é menor quando o fruto está disponível por um curto período de tempo e aumenta quando o fruto está disponível por um tempo maior (Basabose, 2004).

Em muriquis, tanto o número de indivíduos (total e que se alimentam simultaneamente), quanto o tempo gasto se alimentando em uma determinada fonte de alimento mostraram relação com o tamanho dessa fonte (Mourthé, 2006). Segundo o autor, os muriquis adequam o tamanho da subunidade de alimentação de forma que a fonte não seja totalmente esgotada pelo consumo de um grande número de indivíduos ao mesmo tempo. Strier (1989) obteve resultado similar, observando uma correlação positiva entre a média de FTFS, o tamanho da subunidade de alimentação e o tamanho da fonte de frutos explorada pelos muriquis. 
Entretanto, ao comparar duas espécies de muriquis (Brachyteles arachnoides e $B$. hypoxanthus), em áreas diferentes, o Parque Estadual Carlos Botelho (PECB) e a Estação Biológica de Caratinga (EBC), Moraes et al. (1998) observaram que os muriquis no PECB formavam subgrupos menores e menos coesos do que os muriquis da $\mathrm{EBC}$, apesar das fontes de alimento serem maiores no PECB. Os autores sugeriram que a diferença na densidade populacional de muriquis nas duas áreas (baixa no PECB e alta na $\mathrm{EBC}$ ) e, por conseqüência, no grau de competição entre grupos da espécie, estivesse relacionada à maior coesão dos grupos na EBC.

Diferente dos outros atelíneos, o macaco-barrigudo (Lagothrix lagotricha poeppigii) não apresenta relação do tamanho da fonte com o tamanho de subgrupo (Di Fiore, 2004). Segundo o autor, a presença de recursos alternativos como insetos, outros frutos e folhas novas afetam a decisão de forrageio.

No PECB, a densidade populacional de Cebus é baixa em comparação a outras áreas de ocorrência (Izar, 2004), o que pode ter propiciado subgrupos menores e menos coesos de macacos-prego, à semelhança do padrão encontrado para os muriquis, no PECB. De acordo com essa hipótese, não foram observados encontros entre grupos de macacos-prego ao longo do presente estudo, indicando a ausência de competição entre grupos.

\subsubsection{Competição intra e entre grupos}

A competição intragrupo por frutos é importante para determinar o tamanho da subunidade de alimentação em macacos-prego e macacos-barrigudo. Em ambas as espécies, a competição é mais freqüente quanto maior o número de indivíduos alimentando-se juntos (Stevenson et al., 1998).

Em muriquis, para evitar a competição alimentar com outros membros do grupo, as fêmeas mantêm maior distância interindividual enquanto se alimentam do que enquanto 
descansam. Os machos apresentam um comportamento diferente, ficam mais próximos a outros machos na maior parte do tempo (Strier, 1989). Isso pode explicar o comportamento solitário das fêmeas, que possibilita manter uma alta taxa de tempo de forrageamento e minimizar os efeitos da competição.

Em macacos-aranha e chimpanzés, a regulação do tamanho do subgrupo pode ocorrer através da competição intragrupo nas fontes alimentares (Symington, 1990). Em Ateles, as fêmeas reduzem a competição indireta ao diminuir o tamanho do subgrupo (Chapman, 1990a; Shimooka, 2003). Da mesma forma, a competição de subgrupos de chimpanzés é mais intensa nas pequenas fontes de alimento do que nas grandes fontes, onde uma competição menor resulta em benefícios sociais e defesa coletiva da fonte (White \& Wrangham, 1988).

No PECB, a competição indireta intragrupo foi medida pelo o tempo que cada indivíduo de um grupo social passa se alimentando em uma fonte de alimento agrupado (PCIM). Quanto maior a competição intragrupo, menor o tempo que cada indivíduo passa se alimentando. O estudo de Izar (2004) constatou uma redução significativa no PCIM durante o período de fissão em relação aos meses anteriores à fissão, em função da redução da oferta de frutos. A autora sugeriu que a fissão permitiu a redução da competição intragrupo por alimento.

No presente estudo, os valores de PCIM foram similares ao encontrado para o período de fissão do estudo anterior. A comparação dos valores de PCIM do período de coesão do grupo Laranja em 2002 (exceto junho) com o de fissão de 2003 a 2005 revelou baixos valores para o grupo Pimenta e menor ainda para o grupo Laranja e todos os outros grupos. Esse resultado apóia a hipótese de que os grupos presentes em um ambiente com alta competição intragrupo se dividem para tentar diminuí-la. 
Ainda de acordo com a hipótese, a competição direta intragrupo também diminuiu em relação ao período do estudo anterior (Izar, 2004). Esse resultado indica que em fontes que fornecem pouca energia per capita, não compensa engajar-se em conflitos agonísticos diretos.

Semelhante aos valores de PCIM, o IM do grupo Pimenta também apresentou uma queda com o passar dos anos, os valores de 2002 e 2003 foram significativamente maiores que 2004 e 2005. Entretanto, a relação dos valores de IM com a variação da biomassa de frutos revelou que quando a abundância de frutos é menor, o tempo total de alimentação dos indivíduos (IM médio) é menor, enquanto o PCIM não diminui. Isso indica que o que varia é o número de indivíduos que podem comer juntos para garantir um tempo mínimo de alimentação. Então, provavelmente, o indivíduo precisa ingerir um mínimo de energia per capita, em um determinado tempo.

Além disso, nas sociedades de fissão-fusão, os subgrupos se juntam quando a competição entre grupos aumenta em resposta à ameaça de agressão dos grupos vizinhos (Symington, 1990). Em chimpanzés, os machos adultos patrulham os limites da área de uso e quando há encontro entre comunidades, há risco de agressão severa e morte dos indivíduos das comunidades vizinhas (Nishida \& Hiraiwa Hasegawa, 1987). Interações agonísticas com comunidades vizinhas também ocorrem com macacos-aranha, mas sem violência física (Symington, 1990). Em muriquis, os encontros nem sempre são hostis, envolvem ameaça vocal e perseguições, com machos e fêmeas participando das ameaças dos grupos vizinhos (Strier et al., 1993). A relação entre grupos dos macacos-barrigudo é mais amigável do que em macacos-prego, muriquis e macacos-aranha (Robinson \& Jason, 1987). Os grupos vizinhos de macacos-barrigudo tendem a evitar um ao outro (Stevenson et al., 1994). De fato, no PECB foi observada competição entre grupos quando estavam num período de coesão (2001 e 2002). Nesse período, os encontros de grupos de macacos-prego próximos a fontes de 
alimento resultavam na exibição de comportamento agressivo e expulsão de um dos grupos (Izar, 2004). Já durante o período de fissão-fusão, não foi observada competição entre grupos.

\subsubsection{Abundância de alimentos}

A abundância de alimentos também influencia o tamanho dos subgrupos. Em Ateles, ocorre a formação de grupos pequenos na época de escassez de alimento e grupos grandes quando tem abundância das fontes (Chapman, 1990a; Shimooka, 2003). Por exemplo, quando os recursos alimentares são escassos, os macacos-aranha (Ateles geoffroyi) formam pequenas subunidades de alimentação e depletam mais devagar a fonte de alimento (Symington, 1988).

Em chimpanzés, a abundância das fontes de alimento afeta o tamanho do subgrupo: os subgrupos são maiores na estação chuvosa, quando há maior disponibilidade de alimento e quando há caça, do que na seca, quando há maior disponibilidade de frutos (Boesch, 1996; Boesch \& Boesch, 2000). O tamanho do subgrupo diminui na seca e os chimpanzés gastam mais tempo forrageando recursos de baixa qualidade, como as folhas e frutos fibrosos, do que na estação chuvosa, quando os recursos alimentares são mais abundantes (Doran, 1997).

Neste estudo, a distribuição e o tamanho das fontes de alimento, e não a sua abundância, interferiram no tamanho dos subgrupos. Diversos autores também não associam a abundância de frutos com o tamanho do subgrupo (Sakura, 1994; Hashimoto et al., 2001, 2003; Newton-Fischer et al., 2000; Basabose, 2004). Segundo Basabose (2004), a distribuição e a sazonalidade de frutos ajusta o tamanho do subgrupo, e não a abundância, assim o tamanho do subgrupo aumenta quando os frutos estão agrupados no habitat. Para NewtonFischer et al. (2000), grandes grupos não são formados quando há abundância de alimento, mas quando utilizam uma maior quantidade de fontes alimentares. 


\subsubsection{Risco de predação}

Outro fator ecológico que influencia na organização social é o risco de predação. De acordo com modelos socioecológicos (van Schaik, 1989; Sterck et al., 1997), o risco de predação aumenta as razões para formação de grandes grupos. Esse risco é maior com pequenos grupos, uma vez que diminuem as chances de localizar o predador e aumenta a probabilidade de cada indivíduo ser capturado pelo predador (Chapman \& Chapman, 2000). Segundo os modelos, somente é possível exibir a organização social do tipo fissão-fusão em áreas com baixo risco de predação ou com primatas que possuem grande tamanho corporal como chimpanzé e também nos primatas neotropicais como o muriqui e macaco-aranha (Terborgh \& Jason, 1986). No PECB, há baixo risco de predação como já foi constatado por Izar (2004) e neste estudo não foi registrada nenhuma predação.

Portanto, o baixo risco de predação associado com a alta competição indireta intragrupo e a baixa competição entre grupos permitiram a formação de subgrupos nos macacos-prego no PECB. Além desses fatores, a distribuição espacial e temporal de alimento e o tamanho da fonte de frutos foram importantes variáveis ecológicas na determinação do tamanho de grupo. Quando há grande sazonalidade de frutos e essas fontes são pequenas ou as fontes de alimento são uniformemente distribuídas, é favorável a formação de subgrupos para diminuir a competição intragrupo, sem o risco de predação.

\subsection{Fatores sociais que afetam o tamanho de subgrupo}

Os fatores ecológicos podem ter pouco efeito na formação de subgrupos (Sakura, 1994). Diversos autores consideram fatores sociais como, por exemplo, a presença de fêmeas em estro, importantes para determinar o tamanho de subgrupo (Symington, 1990; MatsumotoOda et al., 1998; Anderson et al., 2002; Boesch \& Boesch, 2000; Newton-Fischer et al., 2000; Hashimoto et al., 2001). A quantidade de fêmeas de chimpanzés em estro influencia 
fortemente o tamanho de subgrupo: na estação chuvosa há mais fêmeas em estro e ocorre a formação de subgrupos maiores do que na estação seca (Boesch, 1996). Semelhante a chimpanzés, o tamanho de subgrupo de macaco-aranha é correlacionado à condição reprodutiva da fêmea (Symington, 1990).

Em muriquis, ajustes sazonais no tamanho de subgrupo refletem a influência da reprodução. Pode haver variação sazonal no tamanho de subgrupo por causa da concentração na cópula e concepção na estação chuvosa e nascimentos na estação seca (Dias \& Strier, 2003).

Em Cebus, Lynch Alfaro (2007) sugeriu que a formação de subgrupos na EBC ocorre em função da distribuição de alimento e pela oportunidade dos machos para acasalar com fêmeas fora do grupo. No PECB, o intervalo entre nascimentos é de três anos, maior do que de outras fêmeas de C. nigritus (Izar et al., no prelo). Durante o estudo, não houve nascimento de filhotes e poucos episódios de fêmea em estro (Izar et al., no prelo). Com a continuação dos estudos em 2006, após o nascimento de infantes, os grupos tornaram-se mais estáveis e coesos, provavelmente devido ao risco de infanticídio por machos. Em geral, o tamanho de subgrupo mais freqüente foi metade do grupo, com um macho adulto em cada subgrupo. Se os subgrupos se juntam, a presença de outro macho adulto do grupo poderia significar risco de infanticídio. Assim, as fêmeas com infantes demonstraram um vínculo maior com macho reprodutor de seu subgrupo (Izar et al., no prelo), dessa forma, o tamanho dos subgrupos permaneceu o mesmo. Embora não tenha ocorrido infanticídio durante o estudo, é possível que esse risco influencie na estabilidade dos subgrupos e conseqüentemente, modifique a dinâmica da organização social de fissão-fusão.

Segundo van Schaik \& Kappeler (1997), o risco de infanticídio, e não o de predação, selecionou as associações de macho e fêmea nos primatas. O sucesso reprodutivo das fêmeas é reduzido com o infanticídio, elas podem desenvolver estratégias, como por exemplo, se 
associar ao macho e compartilhar a proteção do macho com outras fêmeas para reduzir este risco (Sterck et al., 1997). Os ataques de infanticídio ocorrem com a agressão inter-sexual, que inclui ataques contra fêmeas adultas, e intra-sexual, que acontecem durante os encontros agonísticos entre machos (Bartlett et al., 1993).

Recentes estudos atribuem a variação do tamanho de subgrupos a somente um dos fatores, mas a disponibilidade de alimento e a presença de fêmea em estro podem atuar juntas e não em oposição nos modelos de organização social (Mitani et al., 2002), assim como encontrado neste estudo. Portanto, a formação de grandes subgrupos pode ocorrer devido a diversos fatores tais como disponibilidade de alimento, tamanho da fonte alimentar, agressão entre grupos, alta pressão de predação, alta sexualidade das fêmeas, oportunidades de caça (Sakura, 1994; Boesch \& Boesch, 2000). Quando o grau de todos os fatores é baixo, o tamanho de subgrupo torna-se menor e a duração das interações sociais diminui. Se o grau de um ou mais desses fatores for alto, o tamanho do subgrupo aumenta (Boesch \& Boesch, 2000). Então, a fissão-fusão dá a flexibilidade necessária para reagir às variações ecológicas, como em áreas de baixa disponibilidade de frutos para diminuir a competição alimentar, e aos fatores sociais como a presença da fêmea em estro, para evitar o infanticídio.

\subsection{Flexibilidade social}

A organização social do tipo fissão-fusão durante muito tempo não foi descrita para o gênero Cebus. Na maior parte dos estudos, as diferentes espécies de Cebus formam grupos sociais permanentes e coesos (Robinson \& Jason, 1987). O presente estudo comprova a organização de fissão-fusão de C. nigritus no PECB. Segundo Kinzey \& Cunningham (1994), é possível a formação de subgrupos como uma resposta às características ecológicas, fatores demográficos e condições sociais, já que o aumento de indivíduos em um grupo, aumenta o acesso a parceiros sexuais e auxílio para cuidar dos infantes. 
A variabilidade social também é encontrada em outros gêneros, como por exemplo, Alouatta e Pongo. O Alouatta é considerado um grupo estável e coeso, entretanto diversos autores observaram a formação de subgrupos em Aloautta palliata em resposta à variação sazonal das condições ambientais (Leighton \& Leighton, 1982; Chapman, 1990b; Jones, 1995). Em Pongo, vários autores consideravam os orangotangos como solitários, porém estudos recentes afirmam que o gênero realiza fissão-fusão para obter benefícios sociais como oportunidade de acasalamento, socialização dos infantes e proteção (van Schaik, 1999).

Além de compreender a organização e estrutura social de um grupo, é relevante estudar qual o sexo que realiza a dispersão do grupo. Geralmente, a tendência é de um sexo dispersar do grupo, mas em poucas espécies ocorre emigração de ambos os sexos. Nas espécies matrilineares, o macho dispersa e a fêmea apresenta fortes relações afiliativas. Ao contrário das matrilineares, as espécies patrilineares possuem relações afiliativas mais fracas entre fêmeas e ocorre a migração delas. O vínculo da relação macho-macho parece ser mais forte do que entre fêmeas nas espécies patrilineares, com exceção da relação entre mãefilhote, como por exemplo chimpanzés e macacos-aranha (Symington, 1988), que realizam fissão-fusão.

O gênero Cebus é comumente considerado matrilinear (Jason, 1984; Robinson \& Jason, 1987; Fragaszy et al., 2004b). Entretanto, é possível que fêmeas de espécies matrilineares dispersem do grupo por três fatores: (a) quando o saldo energético entre a energia ingerida não supera a energia gasta em comparação com as outras fêmeas do seu grupo, (b) quando não há agressão entre as fêmeas do grupo, ou seja, as relações de dominância indiferenciadas dentro do grupo e (c) quando há sobreposição da área de uso com outros grupos (Isbell \& van Vuren, 1996). Essas variáveis estão de acordo com o observado no PECB, onde não foi possível determinar a hierarquia de dominância das fêmeas e alta competição intragrupo. Izar (2004) observou a migração de fêmeas e, também, nos anos 
subseqüentes foi observada a presença de uma fêmea sub-adulta com o grupo Pimenta em 2005 e a ausência da SOL em 2003 e da SOR em 2005. Após migrarem do grupo natal, as fêmeas apresentaram comportamento proceptivo ao macho dominante para entrar em um novo grupo (Izar 2004; este estudo). Tanto no estudo de Izar (2004) quanto neste estudo, os machos perseguiam os novos machos que tentavam se juntar ao grupo e eram mais tolerantes com as fêmeas. Portanto, em ambos os estudos ocorreu a migração de machos e fêmeas.

Outros autores (Izawa, 1994; Di Bitetti, 2001) também observaram a transferência de fêmeas entre grupos quando houve uma divisão permanente de grupos grandes, que originaram dois ou mais grupos com fêmeas aparentadas.

A migração de fêmeas evidencia mais uma vez a grande plasticidade comportamental deste gênero. Este comportamento flexível em Cebus mostra a importância de estudos duradouros para entender e conservar a espécie.

A maioria das espécies que realizam fissão-fusão possui macho filopátrico, com dispersão das fêmeas. Consequentemente, os machos forrageiam em subgrupos maiores por terem fortes relações afiliativas e as fêmeas costumam forragear de forma solitária. De acordo, os grupos de macacos-prego no PECB apresentaram semelhante organização social com migração de fêmeas e fluidez dos membros do grupo. Porém, continuaram com características típicas da espécie, como organização de multi-macho/multi-fêmea durante o forrageamento.

Ainda é preciso investigar como a cognição atua na estratégia plástica do sistema social, entender como ocorre o processo de formação de subgrupos, se há troca de informações enquanto mudam de subgrupo. Como foi visto, no PECB parece que os macacosprego se adaptam a novos ambientes e se comportam da melhor maneira possível para aumentar sua aptidão. Somente estudos de longo prazo são capazes de fornecer dados que 
possibilitam a compreensão da influência dos fatores ecológicos e sociais no tamanho e na coesão dos grupos de macacos-prego. 


\section{Conclusão}

- A organização social dos macacos-prego no PECB pode ser descrita como uma sociedade de fissão-fusão durante o período de estudo.

- Os subgrupos variam em tamanho e composição, com grande fluidez dos indivíduos, a composição é do tipo multi-macho/multi-fêmea, com associações preferenciais entre os indivíduos e com ausência de dominância entre as fêmeas.

- O subgrupo mais freqüente corresponde à metade do tamanho de todo o grupo para todos os grupos estudados no PECB.

- As fontes de fruto no PECB são pequenas e de pobre qualidade, consequentemente os valores de FTFS e tamanho das subunidades de alimentação foram baixos para todos os grupos de macacos-prego.

- Ao comparar o estudo de Izar (1994) e este estudo, a formação de subgrupos foi mais freqüente neste período de estudo, os valores do tamanho das fontes (medido pelo tempo de depleção), do tamanho das subunidades de alimentação e da energia per capita ingerida foram significativamente menores, quando a competição intra e entre grupos diminuíram.

- Há uma relação entre tamanho de subgrupo e padrão da oferta de alimento.

- Em um ambiente de alta competição intragrupo, os grupos de macacos-prego dividiram-se em subgrupos para tentar diminuí-la.

- A diferença entre os chimpanzés e primatas neotropicais é a dispersão sexual do grupo natal. Nos macacos-prego do PECB, machos e fêmeas migram, enquanto nas sociedades de fissãofusão os machos são filopátricos.

- Quando há nascimento de filhotes, o risco de infanticídio influencia na estabilidade do grupo macacos-prego no PECB.

- Os macacos-prego podem exibir uma flexibilidade na organização social, bem como composição de dieta e técnicas de forrageamento, de acordo com as condições ecológicas. 


\section{Referências bibliográficas}

Aguiar, O. T. (2003). Comparação entre os métodos de quadrantes e parcelas na caracterização da composição florística e fitossociológica de um trecho de Floresta Ombrófila Densa do Parque Estadual “Carlos Botelho” - São Miguel Arcanjo, São Paulo. Dissertação de Mestrado, Escola Superior de Agricultura "Luiz de Queiroz", Universidade de São Paulo, Piracicaba.

Altmann, J. (1974). Observational study of behaviour: sampling methods. Behaviour, 49, 223-265.

Anderson, D. P.; Nordheim, E. V.; Boesch, C.; Moermond, T. C. (2002). Factors influencing fission-fusion in chimpanzees in the Taï National Park, Côte d'Ivoire. In: C. Boesch; G. Hohmann; L. F. Marchant (Eds.), Behavioral diversity in chimpanzees and bonobos. (pp. 90-101). Cambridge: Cambridge University Press.

Aureli, F.; Schaffner, C. M.; Verpooten, J.; Slater, K.; Ramos-Fernandez, G. (2006). Raiding parties of male spider monkeys: insightsin to human warfare? American Journal of Physical Anthropology, 131, 486-497.

Baldwin, J. D.; Baldwin, J. I. (1981). The squirrel monkeys, Genus Saimiri. In: A. F. Coimbra-Filho; R. A. Mittermeier (Eds.), Ecology and Behaviour of Neotropical Primates (pp.277-330). Rio de Janeiro: Academia Brasileira de Ciências.

Bartlett, T. Q.; Sussman, R. W.; Cheverud, J. M. (1993). Infant killing in primates: a review of observed cases with specific reference to the Sexual Selection Hypothesis. American Anthropologist, 95(4), 958-990.

Basabose, A. K. (2004). Fruit availability and chimpanzee party size at Kahuzi montane Forest, Democratic Republic of Congo. Primates, 45, 211-219. 
Beisiegel, B. M. (1999). Contribuição ao estudo da história natural do cachorro do mato, Cerdocyon thous e do cachorro vinagre, Speothos venaticus. Tese de Doutorado, Instituto de Psicologia, Universidade de São Paulo, São Paulo.

Boesch, C. (1996). Social grouping in Taï chimpanzees. In: W. C. McGrew; L. F. Marchant; T. Nishida (Eds), Great Ape Societies (pp. 101-113). Cambridge: Cambridge University Press.

Boesch, C.; Boesch, H. (2000). Social structure of Tai chimpanzees. In: C. Boesch; H. Boesch-Achermann (Eds.), The chimpanzees of Tai forest behavioural ecology and evolution (pp.88-108). Achernam: Oxford University Press.

Carosi, M; Linn, G. S; Visalbergui, E. (2005). The sexual behavior and breeding system of tufted capuchin monkeys (Cebus apella). Advances in the study of behavior, 35, 105 148.

Carvalho Junior, Oswaldo de (1996). Dieta, padrões de atividades e de agrupamento do mono-carvoeiro (Brachyteles arachnoides) no Parque Estadual Carlos Botelho - SP. Dissertação de mestrado, Centro de Ciências Biológicas, Universidade Federal do Pará, Belém.

Chapman, C. A. (1988). Patch use and patch depletion by spider and howling monkeys of Santa Rosa National Park, Costa Rica. Behaviour, 105, 99-116.

Chapman, C. A. (1990a). Association patterns of spider monkeys: the influence of ecology anda sex on social organization. Behavioral Ecology and Sociobiology, 26, 409-414.

Chapman, C. A. (1990b). Ecological constraints on group size in three species of neotropical primates. Folia Primatologica, 55, 1-9.

Chapman, C. A. (2004). Variance in ecological conditions and the nature of fission-fusion social organizations. Folia Primatologica, 75, 385-414. 
Chapman, C. A.; White, F. I.; Wrangham, R. W. (1993). Defining subgroup size in fissionfusion societies. Folia Primatologica, 63, 31-34.

Chapman, C. A.;White, F. I.; Wrangham, R. W. (1994). Party size in chimpanzees and bonobos. In: R. W. Wrangham; W. C. McGrew, F. B. de Wall, P. G. Heltne (Eds.), Chimpanzee cultures (pp.41-57). Harvard University Press.

Chapman, C. A.; Wrangham, R. W.; Chapman, L. J. (1995). Ecological constraints on group size: an analysis of spider monkey and chimpanzee subgroups. Behavioral Ecology and Sociobiology, 36, 59-70.

Chapman, C. A. \& Chapman, L. J. (2000). Determinants of group size in primates: the importance of travel costs. In: S. Boinski; P. A. Garber (Eds.), On the move: how and why animals travel in groups (pp. 24-42). Chicago: University of Chicago Press.

Defler, T. R. (1996). Aspects of the ranging pattern in a group of wild wooly monkeys (Lagothrix lagothricha). American Journal of Primatology, 38, 289-302.

Dew, J. L. (2005). Foraging, food choice, and processing by sympatric ripe-fruit specialists: Lagothrix lagotricha poeppigii and Ateles belzebuth belzebuth. International Journal of Primatology, 26(5), 1107-1135.

Di Bitetti, M. S. (2001). Home-range use by the tufted capuchin monkey (Cebus apella nigritus) in a subtropical rainforest of Argentina. Journal Zoological London, 253, 3345.

Di Fiore, A. (2004). Diet and feeding ecology of wolly monkeys in a Western Amazonian rain forest. International Journal of Primatology, 25(4), 767-801.

Di Fiore, A.; Campbell, C. J. (2005). Contemporary issues in ecology, behavior and evolution of the Atelin primates. International Journal of Primatology, 26(5), 995-997. 
Di Fiore, A.; Fleischer, R. C. (2005). Social behavior, reproductive strategies, and population genetic structure of Lagothrix poeppigii. International Journal of Primatology, 26(5): 1137-1173.

Dias, A. C. (2005). Composição florística, fitossociologia, diversidade de espécies arbóreas e comparação de métodos de amostragem na Floresta Ombrófila Densa do Parque Estadual Carlos Botelho/SP - Brasil. Tese de Doutorado, Escola Superior de Agricultura “Luiz de Queiroz”, Universidade de São Paulo, Piracicaba.

Dias, A. C.; Custodio Filho, A.; Franco, G. A. D. C.; Couto, H. T. Z. (1995). Estrutura do componente arbóreo em um trecho de floresta pluvial atlântica secundária - Parque Estadual Carlos Botelho. Revista do Instituto Florestal, 7(2), 125-155.

Dias, L. G.; Srier, K. B. (2003). Effects of group size on ranging patterns in Brachyteles arachnoides hypoxanthus. International Journal of Primatology, 24(2), 209-221.

Dittus, W. P. J. (1988). Group fission among wild toque macaques as a consequence of female resource competition and environmental stress. Animal Behavior, 36, 1626-1645.

Domingues, E. N.; Silva, D. A. (1988). Geomorfologia do Parque Estadual de Carlos Botelho. Boletim Técnico do Instituto Florestal, 42, 71-105.

Doran, D. (1997). Influence of seasonality on activity patterns feeding behavior, ranging, and grouping patterns in Täi chimpanzees. International Journal of Primatology, 18(2), 183206.

Ferreira, R.; Resende, B. D.; Mannu, M.; Ottoni, E. B.; Izar, P. (2002). Bird predation and preytransfer in brown capuchin monkeys (Cebus apella). Neotropical Primates, 10(2), 84-89.

Fragaszy, D.; Visalberghi, E.; Robinson, J. (1990). Variability and adaptability in the genus Cebus. Folia Primatologica, 54, 114-118. 
Fragaszy, D.; Izar, P.; Visalberghi, E.; Ottoni, E. B.; Oliveira, M. G. (2004a). Wild capuchin monkeys (Cebus libidinosus) use anvils and stone pounding tools. American Journal of Primatology, 64, 359-366.

Fragaszy, D.; Visalberghi, E.; Fedigan, L. M. (2004b). The complete capuchin - the biology of the genus Cebus. Cambridge: Cambridge University Press.

Freese, C. H.; Oppenheimer, J. R. (1981). The Capuchin Monkeys, Genus Cebus. In: A. F. Coimbra-Filho; R. A. Mittermeier (Eds.), Ecology and Behaviour of Neotropical Primates (pp. 331-390). Rio de Janeiro: Academia Brasileira de Ciências.

Galleti, M. (1990). Predation on the squirrel, Sciurus aestuanus by capuchin monkeys, and Cebus apella. Mammalia, 54, 152-154.

Galetti, M.; Pedroni, F. (1994). Seasonal diet of capuchin monkeys (Cebus apella) in a semideciduous forest in south-east Brazil. Journal of Tropical Ecology, 10(1), 27-39.

Groves, C. P. (2001). Primate taxonomy. Washington: Smithsonian Institution Press.

Hashimoto, C.; Furuichi, T.; Tashiro, Y. (2001). What factors affect the size of chimpanzee parties in the Kalinzu forest, Uganda? Examination of fruit abundance and number of estrous females. International Journal of Primatology, 22(6), 947-959.

Hashimoto, C.; Suzuki, S.; Takenoshita, Y.; Yamagiwa, J.; Basabose, A. K.; Furuichi, T. (2003). How fruit abundance affects the chimpanzee party size: a comparison between four study sites. Primates, 44, 77-81.

Isbell, L. A. (1991). Contest and scramble competition: patterns of female aggression and ranging behaviour among primates. Behavioral Ecology, 2(2), 143-155.

Isbell, L. A.; Van Vuren, D. (1996). Differential costs of locational and social dispersal and their consequences for female group-living primates. Behaviour, 133, 1-36. 
Isbell, L. A.; Young, T. P. (2002). Ecological models of female social relationships in primates: similarities, disparities, and some directions for future clarity. Behaviour, 139, 177-202.

Izar, P. (1994). Análise da estrutura social de um grupo de macacos-prego (Cebus apella) em condições de semi-cativeiro. Dissertação de Mestrado, Instituto de Psicologia, Universidade de São Paulo, São Paulo.

Izar, P. (1999). Aspectos de ecologia e comportamento de um grupo de macacos-prego (Cebus apella) em área de Mata Atlântica, SP. Tese de Doutorado, Instituto de Psicologia, Universidade de São Paulo, São Paulo.

Izar, P. (2004). Female social relationship of Cebus apella nigritus in a Southeastern Atlantic forest: na analysis through ecological models of primate social evolution. Behaviour, 141, 71-99.

Izar, P.; Ferreira, R. G.; Sato, T. (no prelo). Describing the organization of dominance relationships by Dominance Directed Tree method. American Journal of Primatology.

Izar, P.; Japyassú, H. F.; Alberts, C. C. (2005). Métodos da teoria dos grafos para análise quantitativa do comportamento. In: A. Garcia; R. S. Tokumaru; E. B. Borloti (Eds.), Etologia: uma perspectiva histórica e tendências contemporâneas (pp. 249-258). Vitória: Multiplicidade.

Izar, P.; Nakai, E. S. (2006). Fission-fusion in tufted capuchin monkeys (Cebus apella nigritus) in Brazilian Atlantic Forest. International Journal of Primatology, 27(1), 226.

Izar, P.; Sato, T. (1997). Influência de abundância alimentar sobre a estrutura de espaçamento interindividual e relações de dominância em um grupo de macacos-prego (Cebus apella). In: S. Ferrari; H. Schneider (Eds.), A Primatologia no Brasil 5, Belém, PA.

Izar, P.; Stone, A.; Carnegie, S.; Nakai, E. S. (no prelo). Sexual selection, female choice and mating systems. 
Izawa, K. (1979). Foods and Feeding behavior of wild black-capped capuchin (Cebus apella). Primates, 20, 57-76.

Izawa, K. (1994). Social changes within a group of wild black-capped capuchins, IV. Field studies of new world monkeys, La Macarena, Colombia, 9, 15-21.

Janson, C. H. (1984). Female choice and mating system of the brown capuchin monkey Cebus apella (Primates: Cebidae). Zeitschrift fur Tierpsychologie, 64, 177-200.

Janson, C. H. (1985). Aggressive competition and individual food consumption in wild brown capuchin monkeys (Cebus apella). Behavioral Ecolology and Sociobiology, 18, 125138.

Janson, C. H. (1988). Intra-specific food competition and primate social structure: a synthesis. Behaviour, 105, 1-17.

Janson, C. H.; Stiles, E. W.; White D. W. (1986). Selection on plant fruiting traits by brown capuchin monkeys: a multivariate approach. In: A. Estrada; T.H. Fleming (Eds.), Frugivores and seed dispersal (pp.83-92). Dordrecht: Dr W. Junk Publishers.

Jones, C. B. (1995). Howler subgroups as homeostatic mechanisms in disturbed habitats. Neotropical Primates, 3(1), 7-9.

Kappeler, P. M.; van Schaik, C. P. (2002). Evolution of primate social systems. International Journal of Primatology, 23(4), 707-728.

Kinzey, W. (1997). New World Primates. New York: Aldine De Gruyter.

Kinzey, W. G.; Cunningham, E. P. (1994). Variability in platyrrhine social organization. American Journal of Primatology, 34, 185-198.

Klein, L.L. (1972). The ecology and social organization of the spider monkey, Ateles belzebuth. Berkley: University of California. 
Korstjens, A. H.; Sterck, E. H. M.; Nöe, R. (2002). How adaptative or phylogenetically inert is primate social behaviour? A test with tow sympatric colobines. Behaviour, 139, 203225.

Lee, P. C. (1994). Social structure and Evolution. In: P. J. B. Slater \& T. R. Halliday (Eds), Behaviour and Evolution. Cambridge: Cambridge University Press.

Leighton, M. \& Leighton, D.R. (1982). The relationship of size of feeding aggregate to size of food patch: howler monkeys (Alouatta palliata) feeding in Trichilia cipo fruit trees on Barro Colorado Island. Biotropica, 14(2), 81-90.

Lemos de Sá, R. M.; Strier, K. B. (1992). A preliminary comparison of forest structure and use by two isolated groups of wolly spider monkeys, Brachyteles arachnoides. Biotropica, 24(3), 455-459.

Lynch, J. W. (2001). Male behaviour and endocrinology in wild tufted capuchin monkeys, Cebus apella nigritus. Tese de Doutorado, University of Wisconsin-Madison.

Lynch Alfaro, J. W. (2007). Subgrouping patterns in a group of wild Cebus apella nigritus. International Journal of Primatology, 28, 271-289.

Matsumoto-Oda, A.; Hosaka, K.; Huffman, M. A.; Kawanaka, K. (1998). Factors affecting party size in chimpanzees of the Mahale mountains. International Journal of Primatology, 19(6), 999-1011.

Macleod, M .C. (1993). Another patrilineal primate? A behavioural study of a captive group of wolly monkeys, Lagothrix lagotricha. Thesis for the master of science, Human evolution \& Behaviour, University College London.

Milton, K. (1984). Habitat, diet, and activity patterns of free-ranging wooly spider monkeys (Brachyteles arachnoides E. Geoffroy 1806). International Journal of Primatology, 5(5), 491-514. 
Milton, K. (1985). Mating patterns of wolly spider monkeys, Brachyeteles arachnoides: implications for female choice. Behavioral Ecology and Sociobiology, 85(17), 53-59.

Mitani, J. C.; Watts, D. P.; Lwanga, J. S. (2002). Ecological and social correlates of chimpanzee party size and composition. In: C. Boesch; G. Hohmann; L. F. Marchant (Eds.), Behavioral diversity in chimpanzees and bonobos (pp. 102-111). Cambridge: Cambridge University Press.

Moraes, P. L. R. de; Carvalho Junior, O. de; Strier, K. B. (1998). Population variation in patch and party size in muriquis (Brachyteles arachnoides). International Journal of Primatology, 19(2), 325-337.

Mourthé, I. M. C. (2006). A ecologia do forrageamento do muriqui-do-norte (Brachyteles hypoxanthus Kuhl, 1820). Dissertação de Mestrado, Instituto de Ciências Biológicas, Universidade Federal de Minas Gerais, Minas Gerais.

Murray, C. M.; Eberly, L. E.; Pusey A. E. (2006). Foraging strategies as a function of season and rank among wild female chimpanzees. Behavioral Ecology, 17(6), 1020-1028.

Negreiros, O. C.; Custódio Filho, A.; Dias, A. C.; Franco, G. A. D. C.; Couto, H. T. Z.; Vieira, M. G.; Moura Netto, B. V. (1995). Análise estrutural de um trecho de floresta pluvial tropical, Parque Estadual de Carlos Botelho, Núcleo Sete Barras (SP - Brasil). Revista do Instituto Florestal, São Paulo, 7, 1-33.

Newton-Fisher, N. E.; Reynolds, V.; Plumptre, A. J. (2000). Food supply and chimpanzee (Pan troglodytes schweinfurthii) party size in the Budongo Forest Reserve, Uganda. International Journal of Primatology, 21(4), 613-628.

Nishida, T.; Hiraiwa-Hasegawa, M. (1987). Chimpanzees and bonobos: cooperative relationships among males. In: B. B. Smuts; D. L. Chenney; R. M. Seyfarth; R. W. Wrangham; T. T. Struhsaker (Eds.), Primates societies (pp. 165-177). Chicago: The University of Chicago Press. 
Ottoni, E. B.; Mannu, M. (2001). Semi-free ranging tufted capuchin monkeys (Cebus apella) spontaneously use tools to crack open nuts. International Journal of Primatology, 22(3), 347-358.

Peres, C. A. (1993). Structure and spatial organization of an Amazonian terra firme forest primate community. Journal of Tropical Ecology, 9, 259-276.

Peres, C. A. (1994). Primate responses to phenological changes in an Amazonian terra firme forest. Biotropica, 26(1), 98-112.

Pfeifer, R. M.; Carvalho, W. A.; Silva, D. A.; Rossi, M.; Mendicino, L. F. (1986). Levantamento semi-detalhado dos solos do Parque Estadual de Carlos Botelho. Boletim Técnico do Instituto Florestal, São Paulo, 40, 75-109.

Resende, B. D.; Greco, V. L. G.; Ottonni, E. B.; Izar, P. (2004). Some observations on the predation of small mammals by tufted capuchin monkeys (Cebus apella). Neotropical primates, 11(2), 103-104.

Robinson, J. G.; Janson, C. H. (1987). Capuchins, squirrel monkeys, and atelines: socioecological convergence with old world primates. In: B. B. Smuts; D. L. Chenney; R. M. Seyfarth; R. W. Wrangham; T. T. Struhsaker (Eds.), Primates societies (pp. 69-82). Chicago: The University of Chicago Press.

Rylands, A. B.; Kierulff, M. C. M.; Mittermeier, R. A. (2005). Notes on the taxonomy and distributions of the tufted capuchin monkeys (Cebus, Cebidae) of South America. Lundiana, 6 (supplement), 97-110.

Sakura, O. (1994). Factors affecting party size and composition of chimpanzees (Pan troglodytes verus) at Bossou, Guinea. International Journal of Primatology, 15(2), 167183.

Shimooka, Y. (2003). Seasonal variation in association patterns of wild spider monkeys (Ateles belzebuth belzebuth) at La Macarena, Colombia. Primates, 44, 83-90. 
Sterck, E. H. M.; Watts, D. P.; van Schaik, C. P. (1997). The evolution of female social relationships in nonhuman primates. Behavioral Ecology and Sociobiology, 41, 291-309.

Stevenson, P. R.; Quiñones, M. J.; Ahumada, J. A. (1994). Ecological strategies of woolly monkeys (Lagothrix lagotricha) at Tinigua National Park, Colombia. American Journal of Primatology, 32, 123-140.

Stevenson, M. F.; Quiñones, M. J.; Ahumada, J. A. (1998). Effects of fruit patch availability on feeding subgroup size and spacing patterns in four primate species at Tinigua National Park, Colombia. International Journal of Primatology, 19(2), 313-324.

Strier, K. B. (1989). Effects of patch size on feeding associations in muriquis (Brachyteles arachnoides). Folia Primatologica, 52, 70-77.

Strier, K. B. (1990). New world primates, new frontiers: insights from the woolly spider monkey, or muriqui (Brachyteles arachnoides). International Journal of Primatology, 11(1), 7-19.

Strier, K. B. (1992). Ateline adaptations: behavioral strategies and ecological constraints. American Journal of Physical Anthropology, 88, 515-524.

Strier, K. B. (2003). Primate behavioral ecology. Boston: Allyn and Bacon.

Strier, K. B.; Mendes, F. D. C.; Rímoli, J.; Rímoli, A. O. (1993). Demography and social structure of one group of muriquis (Brachyteles arachnoides). International Journal of Primatology, 14(4), 513-526.

Symington, M. M. (1988). Food competition and foraging party size in the black spider monkey (Ateles paniscus chamek). Behaviour, 105, 117-134 .

Symington, M. M. (1990). Fission-fusion social organization in Ateles and Pan. International Journal of Primatology, 11(1), 47-61.

Terborgh, J. (1983). Five new world primates: a study in comparative ecology. Princeton: Princeton University Press. 
Terborgh, J.; Jason, C. H. (1986). The socioecology of primate groups. Annual Review of Ecology and Systematics, 14, 111-135.

Trivers, R. L. (1972). Parental investment and sexual selection. In: B. Campbell (Ed.), Sexual selection and the descent of man. Chicago: Aldine Press.

van Hoof, A. R. A. M.; van Schaik, C. P. (1992). Cooperation in competition: the ecology of primates bonds. In: A.H. Harcourt; F.D.M. de Wall (Eds.), Coalitions and alliances in humans and other animals (pp. 357-389). Oxford: Oxford Science Publications.

van Roosmalen, M. G. M. (1985). Habitat preferences, diet, feeding strategy and social organization of the black spider monkey (Ateles paniscus paniscus Linnaeus 1758) in Surinam. Acta Amazonica, 15(3/4), 1-238.

van Schaik, C. P. (1983). Why are diurnal primates living in groups? Behaviour, 87, 120144.

van Schaik, C. P. (1989). The ecology of social relationships amongst female primates. In: V. Standen; R.A. Foley (Eds.), Comparative socioecology: the behavioral ecology of humans and other mammals (pp. 195-218). Oxford: Blackwell.

van Schaik, C. P. (1999). The socioecology of fission-fusion sociality in Orangutans. Primates, 40(1), 69-86.

van Schaik, C. P.; Kappeler, P. M. (1997). Infanticide risk and the evolution of male-female association in primates. Proceedings of the Royal Society London B, 264, 1687-1694.

Wallace, R. B. (2005). Seasonal variations in diet and foranging behavior of Ateles chamek in a Southern Amazon Tropical Forest. International Journal of Primatology, 26(5), 10531075.

White, F. J.; Wrangham, R. W. (1988). Feeding competition and patch size in the chimpanzee species Pan paniscus and Pan troglodytes. Behaviour, 105, 148-164. 
Williams, J. M.; Liu, H. Y.; Pusey, A. E. (2002). Costs and benefits of grouping for female chimpanzees at Gombe. In: C. Boesch; G. Hohmann; L. F. Marchant (Eds.), Behavioral diversity in chimpanzees and bonobos (pp. 192-203). Cambridge: Cambridge University Press.

Wrangham, R. W. (1980). An ecological model of female-bonded primate groups. Behaviour, 75, 262-300.

Zhang, S. (1995). Activity and ranging patterns in relation to fruit utilization by brown capuchin monkeys (Cebus apella) in French Guiana. International Journal of Primatology, 16(3), 489-507. 


\section{Anexos}

Anexo I - Árvore Geradora Mínima para os indivíduos adultos e sub-adultos do grupo Pimenta no PECB durante o ano de 2003. $\square$ - machos; $\bigcirc$ - fêmeas.

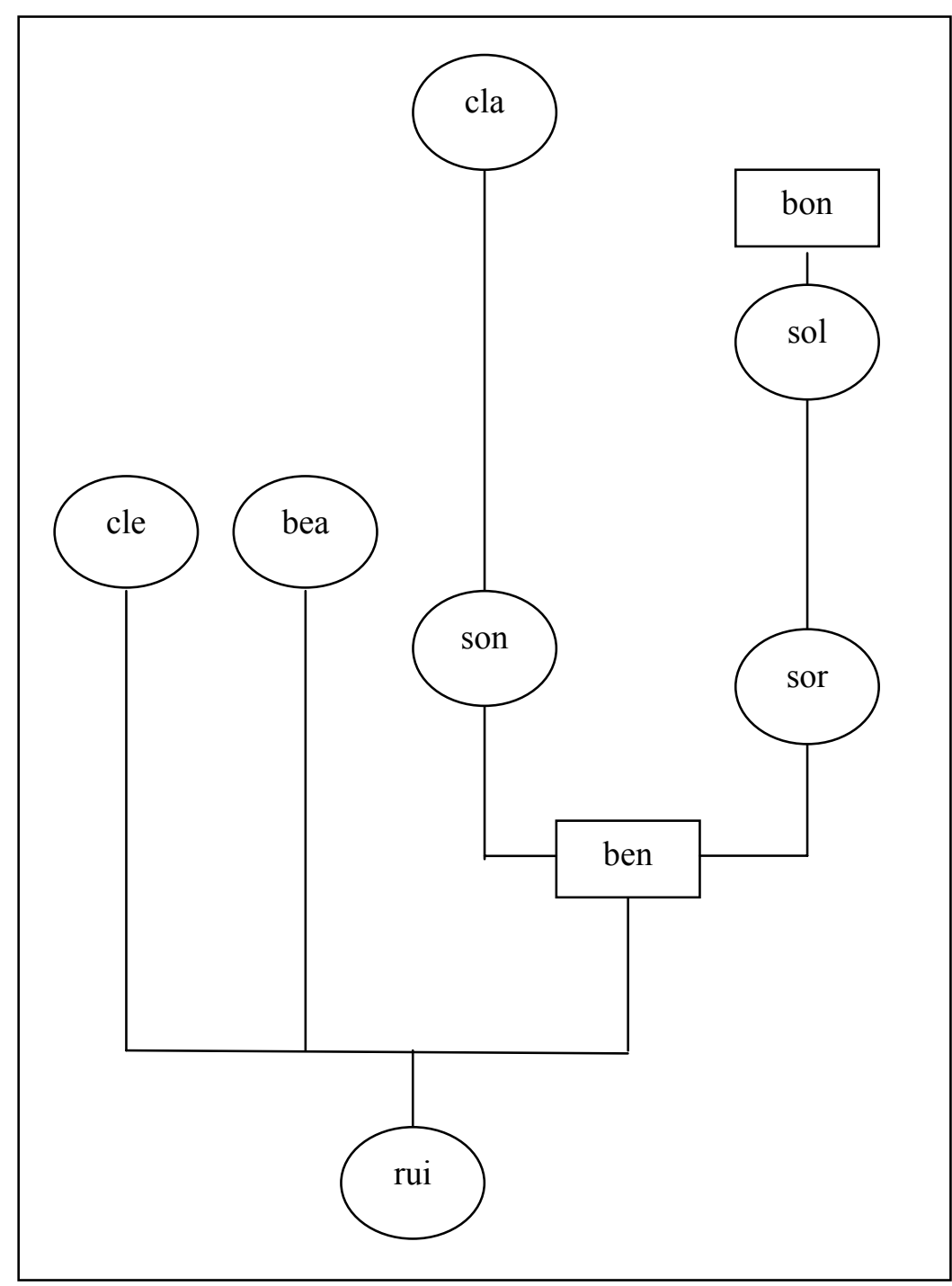


Anexo II - Árvore Geradora Mínima para os indivíduos adultos e sub-adultos do grupo Pimenta no PECB durante $o$ ano de 2004. $\square$ - machos; $\bigcirc$ - fêmeas.

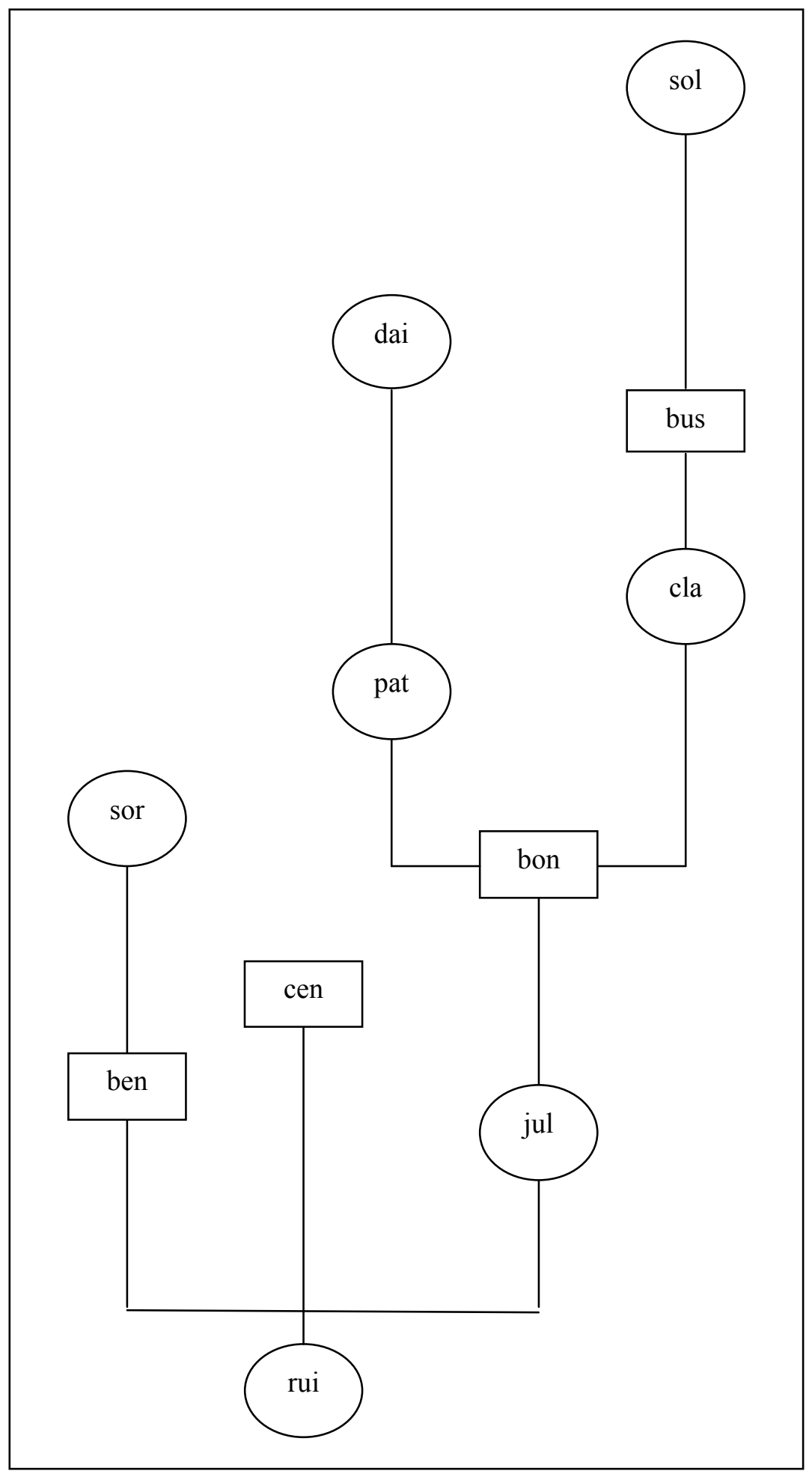


Anexo III - Árvore Geradora Mínima para os indivíduos adultos e sub-adultos do grupo Pimenta no PECB durante $o$ ano de 2005. $\square$ - machos; $\bigcirc$ - fêmeas.

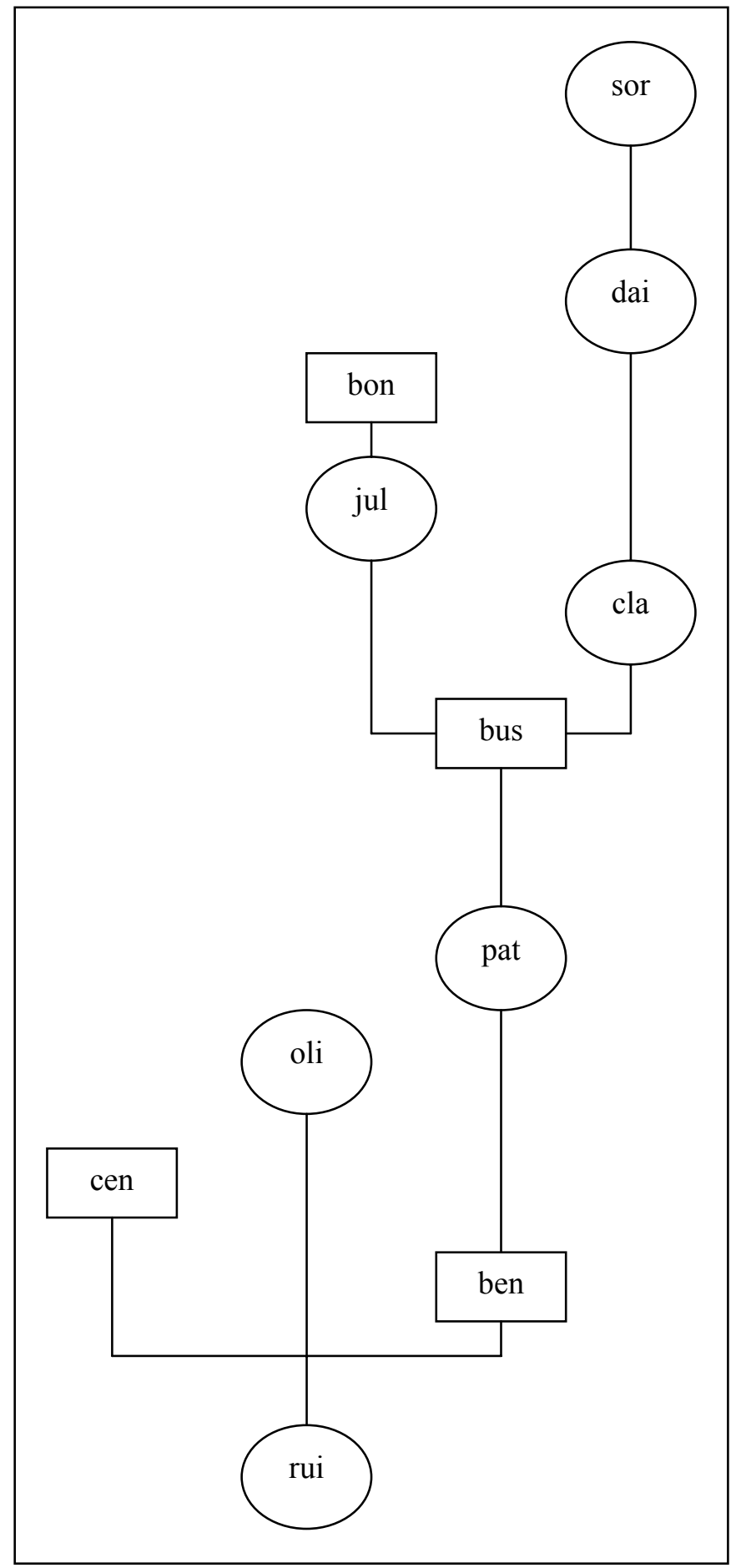


Anexo IV - Árvore Geradora Mínima para os indivíduos adultos e sub-adultos do grupo Pimenta no PECB durante $o$ ano de 2006. $\square$ - machos; $\bigcirc$ - fêmeas.

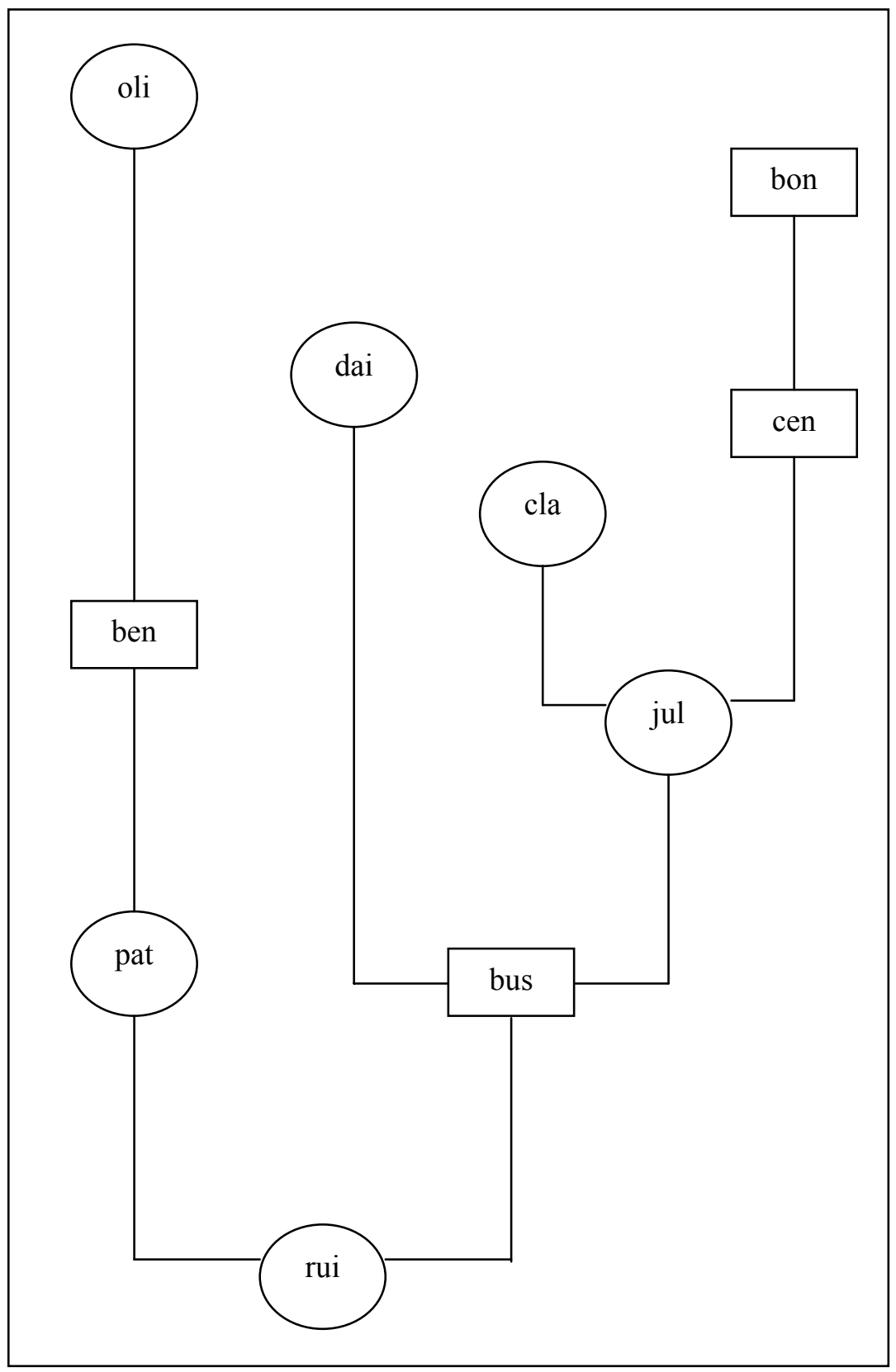


Anexo V - Resultados de ANOVA para regressão múltipla de tamanho médio de subgrupo

ANOVA

\begin{tabular}{|ll|r|r|r|r|r|}
\hline Model & & $\begin{array}{c}\text { Sum of } \\
\text { Squares }\end{array}$ & df & Mean Square & \multicolumn{1}{c|}{$\mathrm{F}$} & \multicolumn{1}{c|}{ Sig. } \\
\hline 1 & Regression & 5.706 & 1 & 5.706 & 1.166 & $.294^{\mathrm{a}}$ \\
& Residual & 88.076 & 18 & 4.893 & & \\
& Total & 93.782 & 19 & & & $.586^{\mathrm{b}}$ \\
\hline 2 & Regression & 5.714 & 2 & 2.857 & .552 & \\
& Residual & 88.068 & 17 & 5.180 & & $.019^{\mathrm{c}}$ \\
& Total & 93.782 & 19 & & & \\
\hline 3 & Regression & 42.691 & 3 & 14.230 & 4.457 & \\
& Residual & 51.091 & 16 & 3.193 & & \\
& Total & 93.782 & 19 & & & \\
\hline 4 & Regression & 47.738 & 4 & 11.935 & 3.888 & \\
& Residual & 46.043 & 15 & 3.070 & & \\
& Total & 93.782 & 19 & & & \\
\end{tabular}

a. Predictors: (Constant), fruha

b. Predictors: (Constant), fruha, inha

c. Predictors: (Constant), fruha, inha, nspmed

d. Predictors: (Constant), fruha, inha, nspmed, medindfon

e. Dependent Variable: nindmed

Anexo VI - Modelos de regressão múltipla para tamanho médio de subgrupo

Model Summary

\begin{tabular}{|l|r|r|r|r|}
\hline Model & \multicolumn{1}{|c|}{ R } & R Square & $\begin{array}{c}\text { Adjusted } \\
\text { R Square }\end{array}$ & $\begin{array}{c}\text { Std. Error of } \\
\text { the Estimate }\end{array}$ \\
\hline 1 & $.247^{\mathrm{a}}$ & .061 & .009 & 2.21204 \\
2 & $.247^{\mathrm{b}}$ & .061 & -.050 & 2.27606 \\
3 & $.675^{\mathrm{c}}$ & .455 & .353 & 1.78694 \\
4 & $.713^{\mathrm{d}}$ & .509 & .378 & 1.75202 \\
\hline
\end{tabular}

a. Predictors: (Constant), fruha

b. Predictors: (Constant), fruha, inha

c. Predictors: (Constant), fruha, inha, nspmed

d. Predictors: (Constant), fruha, inha, nspmed, medindfon 
Anexo VII - Coeficientes de correlação entre variáveis independentes e tamanho médio de subgrupo em cada modelo

Coefficients $^{\mathrm{a}}$

\begin{tabular}{|c|c|c|c|c|c|c|}
\hline \multirow[b]{2}{*}{ Mode } & & \multicolumn{2}{|c|}{$\begin{array}{l}\text { Unstandardized } \\
\text { Coefficients }\end{array}$} & \multirow{2}{*}{$\begin{array}{l}\text { Standardized } \\
\text { Coefficients } \\
\text { Beta }\end{array}$} & \multirow[b]{2}{*}{$\mathrm{t}$} & \multirow[b]{2}{*}{ Sig. } \\
\hline & & B & Std. Error & & & \\
\hline \multirow[t]{2}{*}{1} & (Constant) & 7.367 & .923 & & 7.982 & .000 \\
\hline & fruha & .003 & .003 & .247 & 1.080 & .294 \\
\hline \multirow[t]{3}{*}{2} & (Constant) & 7.362 & .956 & & 7.697 & .000 \\
\hline & fruha & .004 & .005 & .256 & .771 & .451 \\
\hline & inha & .000 & .004 & -.014 & -.041 & .968 \\
\hline \multirow[t]{4}{*}{3} & (Constant) & 3.980 & 1.246 & & 3.195 & .006 \\
\hline & fruha & .002 & .004 & .171 & .653 & .523 \\
\hline & inha & $-4.6 \mathrm{E}-005$ & .003 & -.004 & -.015 & .988 \\
\hline & nspmed & 1.077 & .316 & .633 & 3.403 & .004 \\
\hline \multirow[t]{5}{*}{4} & (Constant) & 2.924 & 1.473 & & 1.986 & .066 \\
\hline & fruha & -.001 & .004 & -.070 & -.220 & .829 \\
\hline & inha & $-2.3 E-005$ & .003 & -.002 & -.008 & .994 \\
\hline & nspmed & .846 & .359 & .497 & 2.358 & .032 \\
\hline & medindfon & 1.079 & .842 & .371 & 1.282 & .219 \\
\hline
\end{tabular}

a. Dependent Variable: nindmed

Anexo VIII - Resultados de ANOVA para regressão múltipla de tamanho máximo de subgrupo

ANOVA

\begin{tabular}{|c|c|c|c|c|c|c|}
\hline \multicolumn{2}{|c|}{ Model } & $\begin{array}{l}\text { Sum of } \\
\text { Squares }\end{array}$ & $\mathrm{df}$ & Mean Square & $\mathrm{F}$ & Sig. \\
\hline \multirow[t]{3}{*}{1} & Regression & 56.246 & 1 & 56.246 & 7.183 & $.015^{\mathrm{a}}$ \\
\hline & Residual & 140.954 & 18 & 7.831 & & \\
\hline & Total & 197.200 & 19 & & & \\
\hline \multirow[t]{3}{*}{2} & Regression & 93.629 & 2 & 46.815 & 7.684 & $.004^{b}$ \\
\hline & Residual & 103.571 & 17 & 6.092 & & \\
\hline & Total & 197.200 & 19 & & & \\
\hline \multirow[t]{3}{*}{3} & Regression & 100.541 & 3 & 33.514 & 5.548 & $.008^{\mathrm{C}}$ \\
\hline & Residual & 96.659 & 16 & 6.041 & & \\
\hline & Total & 197.200 & 19 & & & \\
\hline \multirow[t]{3}{*}{4} & Regression & 105.389 & 4 & 26.347 & 4.305 & $.016^{\mathrm{d}}$ \\
\hline & Residual & 91.811 & 15 & 6.121 & & \\
\hline & Total & 197.200 & 19 & & & \\
\hline
\end{tabular}
a. Predictors: (Constant), medindfon
b. Predictors: (Constant), medindfon, nspmes
c. Predictors: (Constant), medindfon, nspmes, fruha
d. Predictors: (Constant), medindfon, nspmes, fruha, inha
e. Dependent Variable: nindmax 
Anexo IX - Modelos de regressão múltipla para tamanho máximo de subgrupo

Model Summary

\begin{tabular}{|l|r|r|r|r|}
\hline Model & \multicolumn{1}{|c|}{ R } & R Square & $\begin{array}{c}\text { Adjusted } \\
\text { R Square }\end{array}$ & $\begin{array}{r}\text { Std. Error of } \\
\text { the Estimate }\end{array}$ \\
\hline 1 & $.534^{\mathrm{a}}$ & .285 & .246 & 2.79836 \\
2 & $.689^{\mathrm{b}}$ & .475 & .413 & 2.46828 \\
3 & $.714^{\mathrm{C}}$ & .510 & .418 & 2.45788 \\
4 & $.731^{\mathrm{d}}$ & .534 & .410 & 2.47401 \\
\hline
\end{tabular}

a. Predictors: (Constant), medindfon

b. Predictors: (Constant), medindfon, nspmes

c. Predictors: (Constant), medindfon, nspmes, fruha

d. Predictors: (Constant), medindfon, nspmes, fruha, inha

Anexo X - Coeficientes de correlação entre variáveis independentes e tamanho máximo de subgrupo em cada modelo

Coefficients ${ }^{\mathrm{a}}$

\begin{tabular}{|c|c|c|c|c|c|c|}
\hline \multirow{2}{*}{\multicolumn{2}{|c|}{ Model }} & \multicolumn{2}{|c|}{$\begin{array}{c}\text { Unstandardized } \\
\text { Coefficients }\end{array}$} & \multirow{2}{*}{$\begin{array}{c}\begin{array}{c}\text { Standardized } \\
\text { Coefficients }\end{array} \\
\text { Beta }\end{array}$} & \multirow[b]{2}{*}{$\mathrm{t}$} & \multirow[b]{2}{*}{ Sig. } \\
\hline & & $\mathrm{B}$ & Std. Error & & & \\
\hline \multirow[t]{2}{*}{1} & (Constant) & 6.655 & 2.162 & & 3.079 & .006 \\
\hline & medindfon & 2.253 & .841 & .534 & 2.680 & .015 \\
\hline \multirow[t]{3}{*}{2} & (Constant) & 6.149 & 1.918 & & 3.207 & .005 \\
\hline & medindfon & 1.466 & .807 & .347 & 1.817 & .087 \\
\hline & nspmes & .276 & .111 & .474 & 2.477 & .024 \\
\hline \multirow[t]{4}{*}{3} & (Constant) & 6.692 & 1.976 & & 3.387 & .004 \\
\hline & medindfon & .619 & 1.128 & .147 & .548 & .591 \\
\hline & nspmes & .302 & .114 & .519 & 2.659 & .017 \\
\hline & fruha & .005 & .005 & .265 & 1.070 & .301 \\
\hline \multirow[t]{5}{*}{4} & (Constant) & 6.761 & 1.990 & & 3.397 & .004 \\
\hline & medindfon & .457 & 1.150 & .108 & .397 & .697 \\
\hline & nspmes & .343 & .123 & .589 & 2.783 & .014 \\
\hline & fruha & .002 & .006 & .114 & .377 & .711 \\
\hline & inha & .004 & .005 & .239 & .890 & .388 \\
\hline
\end{tabular}

a. Dependent Variable: nindmax 